NASA/TP-2005-213606 (Vol. 1)

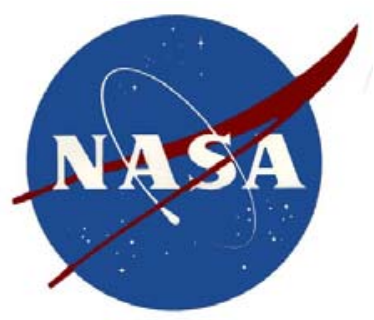

\title{
UWB EMI To Aircraft Radios: \\ Field Evaluation on Operational Commercial Transport Airplanes
}

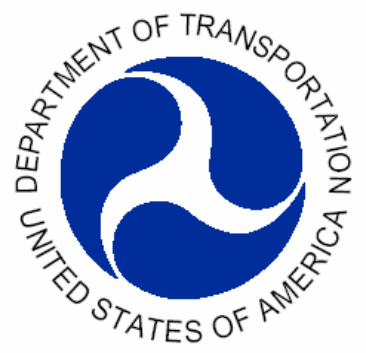

Jay J. Ely

NASA Langley Research Center, Hampton, Virginia

Warren L. Martin

NASA Jet Propulsion Laboratory, Pasadena, California

Timothy W. Shaver

Federal Aviation Administration, Washington, DC

Gerald L. Fuller

Eagles Wings Incorporated, Mariposa, California

John Zimmerman, Robert L. Fuschino

United Airlines, Denver, Colorado

William E. Larsen

Federal Aviation Administration, Moffett Federal Airfield, California 


\section{The NASA STI Program Office ... in Profile}

Since its founding, NASA has been dedicated to the advancement of aeronautics and space science. The NASA Scientific and Technical Information (STI) Program Office plays a key part in helping NASA maintain this important role.

The NASA STI Program Office is operated by Langley Research Center, the lead center for NASA's scientific and technical information. The NASA STI Program Office provides access to the NASA STI Database, the largest collection of aeronautical and space science STI in the world. The Program Office is also NASA's institutional mechanism for disseminating the results of its research and development activities. These results are published by NASA in the NASA STI Report Series, which includes the following report types:

- TECHNICAL PUBLICATION. Reports of completed research or a major significant phase of research that present the results of NASA programs and include extensive data or theoretical analysis. Includes compilations of significant scientific and technical data and information deemed to be of continuing reference value. NASA counterpart of peerreviewed formal professional papers, but having less stringent limitations on manuscript length and extent of graphic presentations.

- TECHNICAL MEMORANDUM. Scientific and technical findings that are preliminary or of specialized interest, e.g., quick release reports, working papers, and bibliographies that contain minimal annotation. Does not contain extensive analysis.

- CONTRACTOR REPORT. Scientific and technical findings by NASAsponsored contractors and grantees.
- CONFERENCE PUBLICATION. Collected papers from scientific and technical conferences, symposia, seminars, or other meetings sponsored or co-sponsored by NASA.

- SPECIAL PUBLICATION. Scientific, technical, or historical information from NASA programs, projects, and missions, often concerned with subjects having substantial public interest.

- TECHNICAL TRANSLATION. English-language translations of foreign scientific and technical material pertinent to NASA's mission.

Specialized services that complement the STI Program Office's diverse offerings include creating custom thesauri, building customized databases, organizing and publishing research results ... even providing videos.

For more information about the NASA STI Program Office, see the following:

- Access the NASA STI Program Home Page at http://www.sti.nasa.gov

- E-mail your question via the Internet to help@sti.nasa.gov

- Fax your question to the NASA STI Help Desk at (301) 621-0134

- Phone the NASA STI Help Desk at (301) 621-0390

- Write to:

NASA STI Help Desk NASA Center for AeroSpace Information 7121 Standard Drive Hanover, MD 21076-1320 
NASA/TP-2005-213606 (Vol. 1)

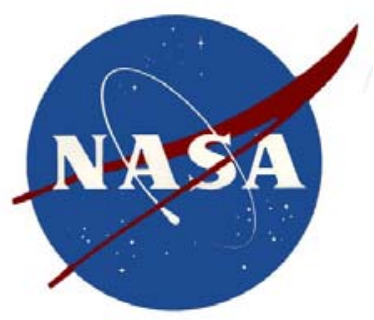

\section{UWB EMI To Aircraft Radios: \\ Field Evaluation on Operational Commercial Transport Airplanes}

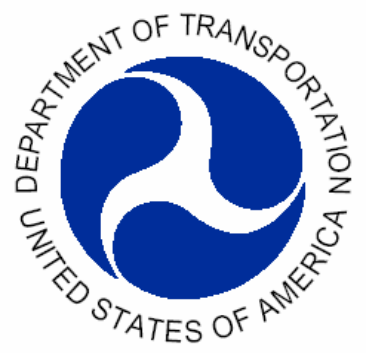

Jay J. Ely

NASA Langley Research Center, Hampton, Virginia

Warren L. Martin

NASA Jet Propulsion Laboratory, Pasadena, California

Timothy W. Shaver

Federal Aviation Administration, Washington, DC

Gerald L. Fuller

Eagles Wings Incorporated, Mariposa, California

John Zimmerman, Robert L. Fuschino

United Airlines, Denver, Colorado

William E. Larsen

Federal Aviation Administration, Moffett Federal Airfield, California 


\section{Acknowledgements}

Sky West Airlines: The test team coordinated with the SkyWest Airlines avionics shop, located in Fresno, California, to gain access to airplanes for this series of field-tests. The avionics supervisor, Allen Ray, provided equipment and personnel support for configuring and monitoring the aircraft VHF Communications, VOR, ILS, ATCRBS, TCAS, DME and GPS systems. Members of the SkyWest team were eager to learn about the research, anticipated logistical needs, and contributed valuable insight ensuring these tests were successful. Paul Vasquez and other avionics shop personnel helped the test team with details about ramp test equipment and avionics functionality that would not have been understood otherwise. The test team was thoroughly impressed with the professionalism, integrity, and proficiency of the SkyWest staff and the cleanliness and organization the Fresno facility.

United Airlines: The authors are especially appreciative of the United Airlines San Francisco Maintenance Depot and Avionics Shop for providing generous access to airplanes required this series of field-tests. The test team worked with avionics shop personnel to obtain maintenance manuals and detailed real-world test information for aeronautical radio systems installed in United Airlines airplanes. Brian Haynes, Manager for United Flight Operations Technology was instrumental in enabling United Airlines support for this work, which would not have occurred without his support and enthusiasm.

NASA Office of Space Communications: Scott Pace (NASA's Chief Technologist for Space Communications in the Office of Space Flight), with the assistance of Jim Hollansworth (Manager of Spectrum Advocacy, NASA Glenn Research Center Office of Space Communications) provided management oversight, funding and guidance for this effort.

NASA Aviation Safety and Security Program: NASA Langley program support for this work was provided by the Single Aircraft Accident Prevention Project, managed by John White at NASA Langley Research Center. The authors are highly appreciative that NASAs Aviation Safety Program allowed scarce manpower resources and travel budget to be allocated to this test and documentation opportunity.

NASA Langley Airborne Systems Competency: Field test support, calibrations, shipping, fabrication, planning and data analysis were provided by Willie Munden, Max Williams and Theresa Salud of Lockheed Martin, under contract with NASA Langley's Electromagnetic Research and Sensors Research Branches. The authors are appreciative of guidance and support from R. Wes Lawrence (Electromagnetic Research Branch Chief), Rudy Williams (High Intensity Radiate Fields Laboratory Mangager), and the entire High Intensity Radiate Fields Laboratory team for providing technical insight valuable to this test effort.

NASA Langley Systems Engineering Competency: The authors are appreciative of semi-anechoic chamber facility support provided by Courtney Rollins of the Test and Development Branch in the Systems Engineering Competency at NASA Langley Research Center. Without access to specialized instrumentation and the semi-anechoic chamber, it would not have been possible to obtain valid UWB source calibration information.

NASA Langley Office of Public Affairs: Professional video documentation of this work was provided by Kathryn Morales, of Crewestone Technologies Inc. The authors are greatly appreciative of the detail and quality of this coverage as it was highly valuable in performing subsequent data analysis, and is expected to be even more valuable in communicating the details of this testing over the months following publication of this report.

Final reviewing and editing of this report was done by A. J. Oria of Overlook Systems Technologies, Inc.

The use of trademarks or names of manufacturers in this report is for accurate reporting and does not constitute an official endorsement, either expressed or implied, of such products or manufacturers by NASA. 


\section{Executive Summary}

Ultrawideband (UWB) transmitters may soon be integrated into a wide variety of portable electronic devices (PEDs) that passengers routinely carry on board commercial airplanes. Airlines and the Federal Aviation Authority (FAA) will have difficulty controlling passenger use of UWB transmitters during flights with current airline policies and existing wireless product standards. The aeronautical community is concerned as to whether evolving FCC UWB rules are adequate to protect legacy and emerging aeronautical radio systems from electromagnetic interference (EMI) from emerging UWB products. To address these concerns, the NASA Office of Space Communications and Chief Spectrum Managers assembled a multidisciplinary team from NASA Langley Research Center (LaRC), NASA Jet Propulsion Laboratory (JPL), NASA Ames Research Center (ARC), FAA, United Airlines, Sky West Airlines, and Eagles Wings Inc. (EWI) to carry out a comprehensive series of tests aimed at determining the nature and extent of any EMI to aeronautical communication and navigation systems from UWB devices meeting FCC-approved and proposed levels for unlicensed handheld transmitters. These tests build upon limited functional testing previously reported in a NASA Technical Memorandum (October 2002).

The approach of this study was to introduce specific UWB EMI threats to radio systems installed on airplanes, and to observe effects in the same context that they would appear to flight crews, in a realistic operational signal environment. Because all UWB threat signals were calibrated referenced to FCC limits for unlicensed devices, this report documents the most extensive PED EMI direct effects susceptibility testing ever performed on commercial airplanes. Test results show that aeronautical radio systems operating below $960 \mathrm{MHz}$ are at-risk to UWB EMI from handheld consumer products meeting existing FCC rules. Aeronautical radio systems operating above $960 \mathrm{MHz}$ are found unlikely to be affected by UWB Emissions at levels meeting the FCC 15.519 limit mask for handheld UWB systems, but interference margins for these aeronautical systems will be adversely affected if FCC UWB emission limits are increased. The presence of modulation (i.e. ON/OFF keying, dithering) on spurious UWB emissions cannot be assumed to reduce the likelihood of harmful interference, and in fact may only guarantee channel overlap within aeronautical radio frequency bands. Numerous UWB PRF selections are shown to be effective at interfering with aircraft radios. This study did not address the effects of UWB signals to onboard wireless systems (door key pad, cargo smoke detection, cabin communication and surveillance systems).

Aside from UWB-specific test results, this study finds that existing aircraft certification and operation processes do not adequately address aeronautical radio vulnerability to EMI from PEDs. For some systems, performance degradation and failure effects were found to occur without activating the system's failure detection circuitry. As such, no flags, annunciations, or system status displays indicating system failure or loss of capability were provided to the flight crew. Several issues related to these failures became apparent during this testing.

- Avionics system interdependencies may allow system performance to be degraded as a result of interference effects propagating from other systems.

- Some UWB signal formats can be constructed which may cause interference to several different aeronautical radio systems, operating on different channels, simultaneously.

- Airline pilots are not adequately equipped to address system EMI events that may be due to spurious or out-of-band radiation from PEDs. Crew procedures for identifying, reporting, and resolving such events do not exist.

- Current aircraft system designs do not incorporate devices to detect the presence of EMI or alert the crew that degradation that may be occurring. 
- Non-standardized displays of navigation and flight information make it impossible to describe the airline-wide effects of EMI expected on particular COM/NAV systems from one aircraft type to another.

The report provides recommendations to the RTCA SC-202 committee on PEDS, government regulators, airlines, industry committees and research organizations to better address the impact of EMI from UWB and other PED technologies upon aeronautical radio systems.

\section{Roadmap for Readers}

The main body of this report provides a comprehensive overview of the background, objective and approach of the study, as well as a summary of results, detailed conclusions, findings and additional issues identified during the course of the work. Several appendices ( $C$ through $G)$ are categorized as NASA Administratively Controlled Information (ACI), for release only to U.S Government Agencies and U.S. Government Agency Contractors, and provide significant additional detail to allow verification of test results and validation of conclusions. Appendices $C$ through $G$ are not necessary for most readers and are available on a limited basis as Volume 2 to this technical publication ${ }^{1}$. The table below provides a description of each appendix, its audience focus and classification status.

Audience Focus and Classification Status for Report Sections

\begin{tabular}{|l|l|l|}
\hline Report Section & Audience Focus & Classification Status \\
\hline Executive Summary & Executive Overview- all readers & Public Release \\
\hline Main Report Body & $\underline{\text { Technical Overview- most readers }}$ & Public Release \\
\hline Appx. A: Team Biographies & General Background- interested readers & Public Release \\
\hline Appx. B: Glossary & $\underline{\text { Technical Background: terms and acronyms }}$ & Public Release \\
\hline Appx. C: Test Plan & Technical Detail for establishing validity of results & Restricted (ACI) \\
\hline Appx. D: Description of Systems & Technical Review for understanding system effects & Restricted (ACI) \\
\hline Appx. E: Detailed Test Results & Technical Detail for validating conclusions & Restricted (ACI) \\
\hline Appx. F: Data Inventory & Reference Data for results \& additional research & Restricted (ACI) \\
\hline Appx. G: Video Documentation & Reference Data for technical communication & Restricted (ACI) \\
\hline
\end{tabular}

Appendix C (Test Plan) is a stand-alone document, and was completed prior to the writing of this report. A comprehensive technical understanding of the measurement setups, calibrations, interpretation of data, and comparison of results may be obtained by studying Appendix $\mathrm{C}$ and Appendix E. Appendix D provides important functional information about aeronautical radio systems. Appendix $\mathrm{F}$ provides a critical link between Appendices $\mathrm{C}$ and $\mathrm{E}$ for the reader who wishes to validate the aircraft test data and its interpretation in Appendix E. In fact, Appendix F is intended to be useful for further analysis beyond the scope of this report, but is not meaningful without first understanding Appendices $\mathrm{C}$ and $\mathrm{E}$. Appendix $\mathrm{G}$ provides unique video documentation of interference effects. The figure below outlines a roadmap for fully evaluating the entire report.

\section{Roadmap for Reading This Report}

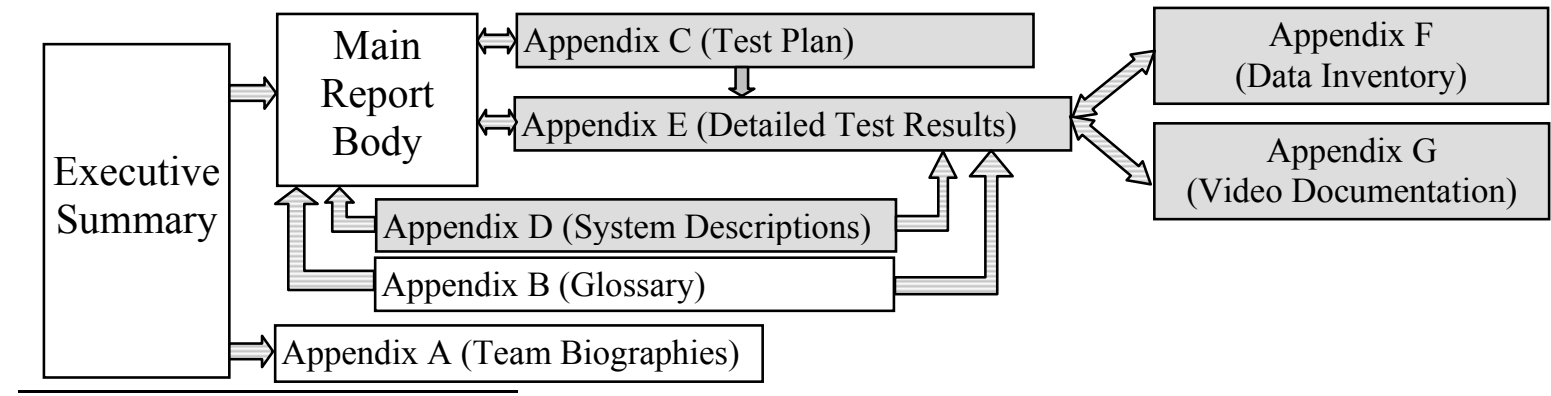

${ }^{1}$ NASA/TP-2005-213606 Vol. 2 


\section{Table of Contents}

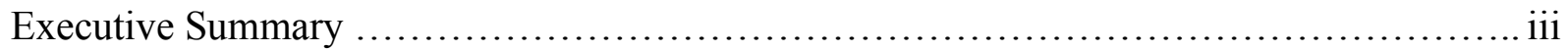

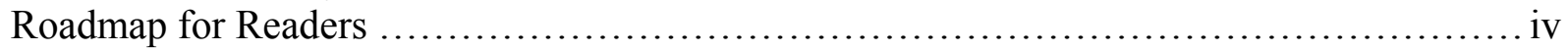

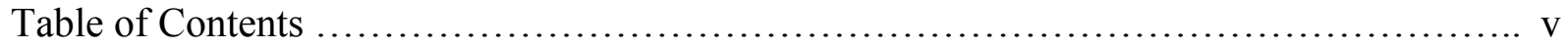

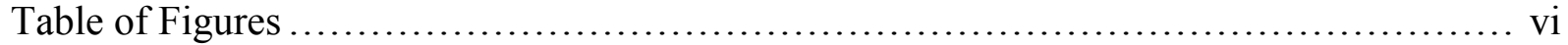

Table of Tables ........................................................................... vi

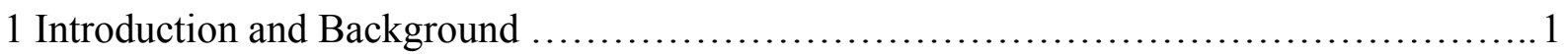

1.1 Radiated Emission Limits for UWB PEDs ............................... 1

1.2 Airplane EMI Coupling from UWB PEDs ................................

1.3 Statement of the Problem ...................................................... 6

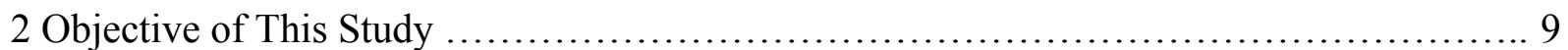

2.1 Analytical Studies, Laboratory Testing and Field Testing ......................... 9

2.2 UWB EMI to Aircraft Systems: Reference Summary …...................... 9

3 Approach: Field Test on Operational Airplanes ....................................... 15

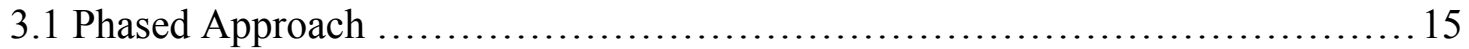

3.2 UWB Source Characterization ............................................ 16

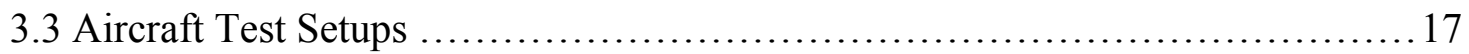

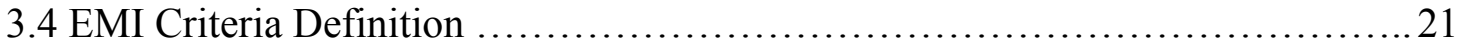

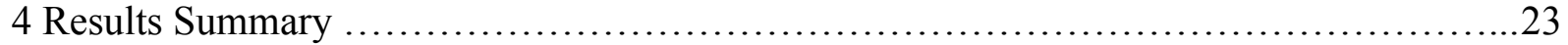

4.1 VHF Com (Very High Frequency Communication) .............................23

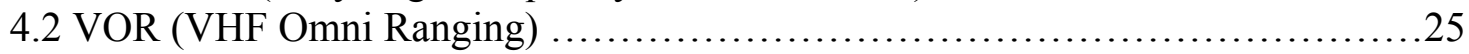

4.3 LOC (Instrument Landing System Localizer) ................................26

4.4 GS (Instrument Landing System Glideslope) .................................. 27

4.5 DME (Distance Measuring Equipment) ......................................29

4.6 ATC (Air Traffic Control Radio Beacon System) ............................. 30

4.7 TCAS (Traffic Alert and Collision Avoidance System) ..........................32

4.8 GPS (Global Positioning System) ....................................... 33

4.9 SATCOM (Satellite Com.- INMARSAT Aeronautical Mobile Sat. Sys.) ........ 35

4.10 Aircraft System Interdependencies ........................................ 36

4.11 Summary For Aircraft Systems Operating Below $960 \mathrm{MHz}$................... 37

4.12 Summary For Aircraft Systems Operating Above $960 \mathrm{MHz}$.................... 39

5 Conclusions and Additional Issues ................................................. 43

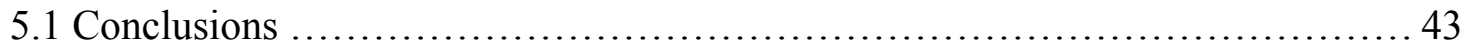

5.2 Important EMI Issues Beyond UWB Focus of This Study ................... 43

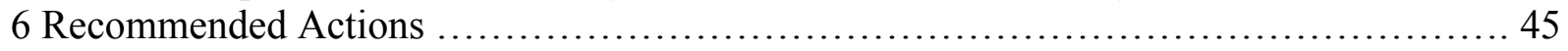

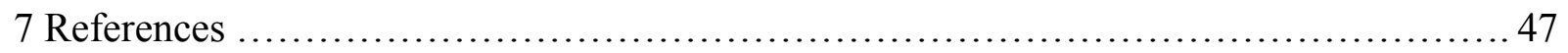

Appendix A: $\quad$ Team Biographies . . . . . . . . . . . . . . . . . . . . . 51

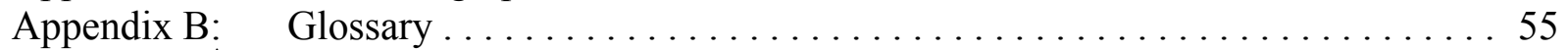

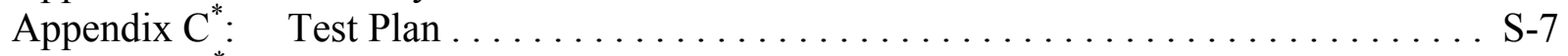

Appendix D*: Detailed Description of Systems . . . . . . . . . . . . . . . . . . S-111

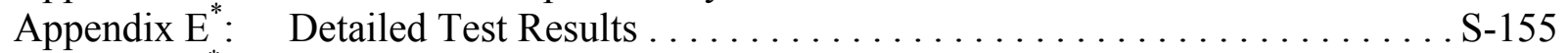

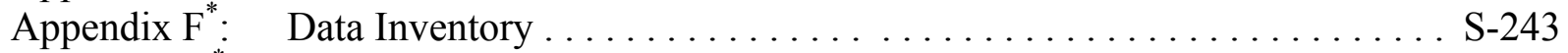

Appendix $\mathrm{G}^{*}$ : $\quad$ Video Documentation .............................. 287

(*) Available in NASA/TP-2005-213606 (Vol. 2) - Administratively Controlled Information 


\section{Table of Figures}

Figure 1: UWB radiated emission limits from $100 \mathrm{MHz}$ to $10.6 \mathrm{GHz}$. ........................2

Figure 2: Slope emission limit mask for UWB out-of-band emissions. ......................... 4

Figure 3: A typical PED EMI coupling path for a top mounted aircraft antenna.............5

Figure 4:ANSI C63.4 compliant measurement setup for determining the amplitude of radiated emissions from a UWB transmitting source. ....................................... 17

Figure 5: Typical setup for UWB EMI effects testing. ............................................ 18

Figure 6: UWB interfering signal generating equipment used on board aircraft ............20

Figure 7: Simplified Diagram of UWB source equipment .................................... 21

Figure 8: UWB-induced Operational Failure of Aeronautical radio systems operating Below $960 \mathrm{MHz}$. Minimum UWB levels to cause operational failure for each airplane-type are compared to FCC15.209 pass levels

Figure 9: UWB-induced Operational Failure of Aeronautical radio systems operating Above $960 \mathrm{MHz}$. Minimum UWB levels to cause operational failure for each airplane-type are compared to FCC15.519 pass levels

Figure 10: UWB-induced Operational Failure of Aeronautical radio systems operating Above $960 \mathrm{MHz}$. Minimum UWB levels to cause operational failure for each airplane-type are compared to FCC15.209 pass levels

\section{Table of Tables}

Table 1: Reference List: Studies Evaluating UWB EMI to Aircraft Systems ............... 10

Table 2: Aeronautical radio systems evaluated during field testing............................ 15

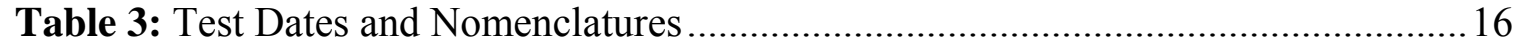

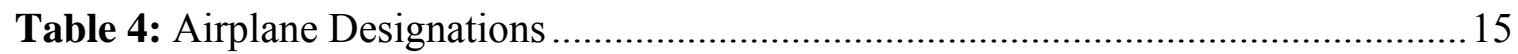

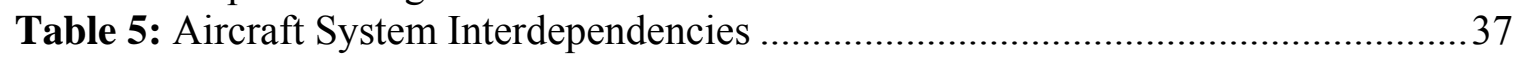




\section{Introduction and Background}

In the spring of 2002, NASA, United Airlines and Eagles Wings Incorporated (EWI), conducted a preliminary test, using an ultra-wideband (UWB) pulse radio source to explore \& evaluate electromagnetic interference (EMI) effects on various aircraft radio systems' performance. Upsets were documented and reported on the Traffic Alert and Collision Avoidance System (TCAS) and Instrument Landing Systems (ILS). ${ }^{1}$ While the National Telecommunication and Information Administration (NTIA) had completed some analytical studies exploring potential EMI to aeronautical radio systems from UWB, no one had performed testing on airplanes to screen for unforeseen effects or to verify analytical studies. ${ }^{2,3,4,5}$ NASA's Office of Space Communications and Spectrum Management organizations had already been evaluating UWB applications and participating in the U. S. rulemaking activities for UWB, and became interested in supporting further UWB EMI tests on airplanes after becoming aware of the airplane EMI testing. As a shared resource project with United Airlines, Sky West Airlines and NASA's Aviation Safety and Security Program, this report documents the results of field test activity to quantify the aviation safety impact of potential EMI from handheld portable electronic devices (PEDs) incorporating UWB radio technology, that passengers may likely bring onto airplanes in the near future.

\subsection{Radiated Emission Limits for UWB PEDs}

On May 16, 2002, the Federal Communications Commission (FCC) published in the Federal Register a Final Rule, permitting marketing and operation of new products incorporating UWB technology. ${ }^{6}$ The FCC rulemaking process for introducing UWB technology has been contentious, particularly where UWB systems have been designated to coexist in spectrum that is already allocated to safety-critical, military, or licensed radio frequency bands. Numerous U.S. government organizations, companies and universities have invested considerable resources in assisting the FCC to develop emission limits and guidelines for the introduction of UWB technology into consumer wireless products. The FCC Final Rule defines new technical requirements for various UWB radio device applications, including "low, medium and high-frequency imaging" systems, "vehicular radar" systems, "indoor" UWB systems, and "handheld" UWB systems. Each UWB application type must meet different requirements for radiated emission limits. The requirements for "handheld" UWB systems, as addressed in FCC Final Rule Part 15.519, are of primary concern when considering UWB technology applications that may be incorporated into PEDs. This is because handheld UWB systems are specified by FCC rules to include laptop computers and portable digital assistants (PDAs), and belong to the class of communications and measurement systems that are not restricted to law enforcement, fire and emergency rescue, or specific industrial applications, and do not require coordination with the FCC to operate them. Thus, it is most likely that handheld-type UWB products will be carried on board commercial airplanes by passengers. The Institute of Electrical and Electronic Engineers (IEEE) is actively working on a new standard for high data rate personal area networks, IEEE 802.15.37. The IEEE standard will be the basis of the "Wimedia" and "Wireless USB" industry standards for inter-compatible, UWB-based products that will be regulated under FCC Part 15.519 rules. $^{8}$

Below $960 \mathrm{MHz}$, handheld UWB device emission limit levels are covered by the standard FCC Part 15.209 limits that apply to unlicensed transmitters not covered elsewhere in the FCC Rules ${ }^{9}$. In considering EMI from handheld UWB devices to aeronautical radio systems, radiated emissions below $100 \mathrm{MHz}$ are not a primary concern because PEDs are too electrically small to radiate efficiently, and aircraft fuselage shielding tends to limit coupling from inside the passenger cabin to aircraft antennas at these frequencies. From $100 \mathrm{MHz}$ to $960 \mathrm{MHz}$, the FCC Part 15.209 limits are specified as electric 
field intensity, measured with a CISPR quasi-peak detector. If an isotropic radiation pattern is assumed, the FCC 15.209 limits can be converted to effective isotropic radiated power (EIRP). The $100 \mathrm{MHz}$ to $960 \mathrm{MHz}$ portion of Figure 1 shows the FCC Part 15.209 limits, converted to EIRP, in graphical form.

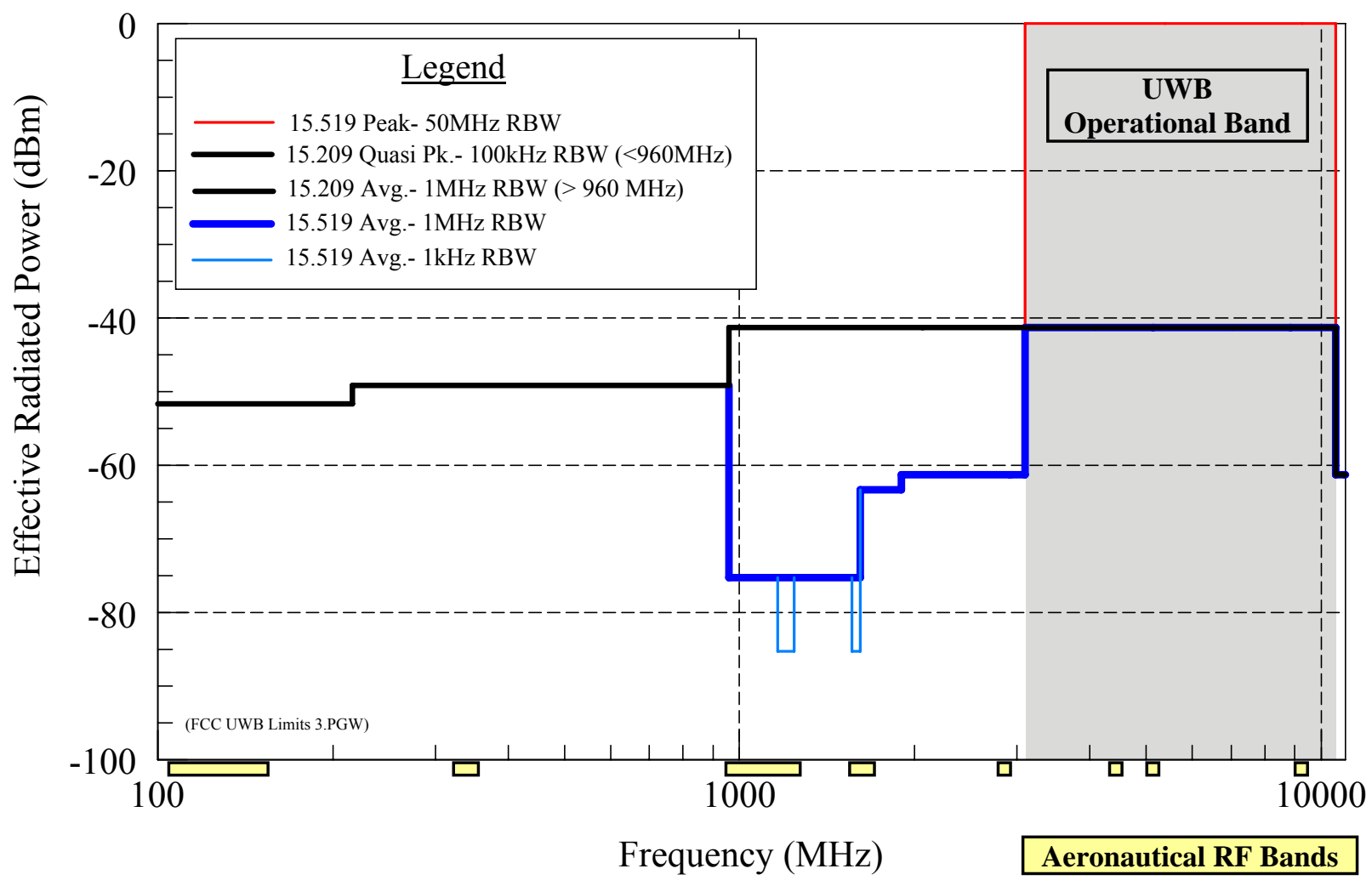

Figure 1: UWB radiated emission limits from $100 \mathrm{MHz}$ to $10.6 \mathrm{GHz}$. Below $960 \mathrm{MHz}$ the FCC 15.209 QuasiPeak Limits apply to handheld UWB system spurious radiated emissions, specified as electric field intensity $3 \mathrm{~m}$ from the device. Electric field intensity is converted to peak effective isotropic radiated power for data below $960 \mathrm{MHz}$ in this figure. Above $960 \mathrm{MHz}$ FCC 15.519 provides distinct radiated emission limits when using average (AVG) detection, peak detection, and different resolution bandwidths. For 15.519 limits, effective radiated power measured at the antenna port. The FCC does not specify gain requirements for UWB system antennas. For comparison, aeronautical RF bands are shown by yellow lines below the frequency axis.

From $960 \mathrm{MHz}$ to above $10.6 \mathrm{GHz}$, FCC Part 15.519 specifies handheld UWB device emission limit levels as effective isotropic radiated power (EIRP), measured with a RMS detector, having a 1 millisecond or less averaging time ${ }^{10}$. For intended peak emissions contained within a $50 \mathrm{MHz}$ bandwidth centered on the frequency at which the highest radiated emission occurs, FCC Part 15.519 allows a 0dBm peak EIRP. FCC Part 15.521 specifies how this peak limit must be reduced when using smaller resolution bandwidths ${ }^{11}$. (i.e. For a $1 \mathrm{MHz}$ resolution bandwidth, the peak limit becomes $-34 \mathrm{dBm}$.) It is useful to note that the UWB bandwidth, as defined by FCC 15.503, is bounded by points that are $10 \mathrm{~dB}$ below the highest radiated emission. While this provides some degree of expectation that spurious emissions (outside the UWB bandwidth) of practical devices will be even lower than $10 \mathrm{~dB}$ below the maximum UWB emission, there is no requirement for this to be true.

The aircraft UWB EMI tests reported herein are specifically designed to address the threat of unintended UWB emissions into aircraft communications, navigation and surveillance radio frequency 
bands. Since Part 15.519 compliant handheld UWB systems are required to operate between 3100 and $10,600 \mathrm{MHz}$, the $0 \mathrm{dBm}$ peak-in-a-50dB-bandwidth rule (and associated 15.521 rule for smaller resolution bandwidths) should not apply to the aircraft radio frequency bands addressed by the tests described herein. (However, if applied, the $0 \mathrm{dBm}$ peak-in-a-50dB-bandwidth rule would allow peak emissions nearly equal to FCC 15.209 limits in aeronautical RF bands below $960 \mathrm{MHz}$ anyway. This rule would allow peak UWB emissions up to $-34+75.3=41.3$ higher than RMS UWB limits from 960 to $1610 \mathrm{MHz}$.) Figure 1 shows the FCC UWB emission limits in graphical form.

The FCC has expressed a concern that their adopted standards may be too conservative and some future relaxation of constraint may be in order. The FCC's First Report and $\operatorname{Order}^{12}$ (1ST R\&O) states in relevant part:

We are concerned, however, that the standards we are adopting may be overprotective and could unnecessarily constrain the development of UWB technology. Accordingly, within the next six to twelve months, we intend to review the standards for UWB devices and issue a further rule making to explore more flexible technical standards and to address the operation of additional types of UWB operations and technology.

Numerous Petitions for Reconsideration were submitted by UWB developers, representatives of authorized radio services, and others seeking changes to FCC UWB rules. In keeping with their concerns about the adopted standards being too conservative, the Commission released a Memorandum Opinion and Order and Further Notice of Proposed Rulemaking ${ }^{13}$ (MO\&O) amending its Part 15 Rules pertaining to UWB. While the MO\&O did not make significant changes to exiting UWB technical parameters, it did dispose of some 14 Petitions for Reconsideration seeking to change restrictions on UWB devices. Disposition of these petitions is summarized herein.

1. Petitions for Reconsideration from UWB Developers

a) Public Safety Imaging Systems ${ }^{14}$

b) Ground Penetrating Radar Systems ${ }^{15,16}$

c) Wideband Radar and Other Low PRF Systems in the 3.1-10.6 GHz Band ${ }^{17}$

d) Vehicular Radar Systems ${ }^{18}$

e) Indoor UWB Operation ${ }^{19}$

FCC disposition of these petitions mostly waived existing restrictions on UWB applications and dismissed concerns by incumbent spectrum users regarding requests from UWB developers to waive existing restrictions.

2. Petitions for Reconsideration from Representatives of Authorized Radio Services

a) UWB Emissions in the Cellular and PCS Frequency Bands ${ }^{20}$

b) UWB Emissions in the SDARS Frequency Bands ${ }^{21}$

c) UWB Emissions in the FSS Frequency Band ${ }^{22}$

d) UWB Emissions in the Aviation Frequency Bands ${ }^{23}$

e) UWB Emissions in the MDS and ITFS Frequency Bands ${ }^{24}$

FCC disposition of these petitions generally dismissed concerns by incumbent spectrum users that UWB rules are not adequate to protect their radio services.

3. Petitions for Reconsideration Regarding Non-UWB Standards ${ }^{25}$

Following the recommendations of the FCC's Spectrum Policy Task Force ${ }^{26}$, The Commission released a Notice of Inquiry ${ }^{27}$ announcing: 
By this action, the Commission proposes to introduce a new "interference temperature" model for quantifying and managing interference.

Under the new technical rules that are ultimately adopted, we anticipate that unlicensed devices would be allowed to operate at higher power levels than currently allowed by the rules....

To meet these needs, we have adopted new licensing schemes under which bands of spectrum are assigned to licensees on a geographical basis and those licensees are provided flexibility to determine the types of services and the technologies and the technical implementation designs used to provide those services.

Finally, the FCC issued an Order ${ }^{28}$ dismissing a request "for Declaratory Ruling . . f filed on behalf of twenty three companies" that "all emissions associated with digital circuitry used to generate ultrawideband emissions are required to meet the radiated emission limits provided in Subpart F of Part 15 of the Commission's rules for UWB transmitters" [Subpart F of the Part 15 Rules apply exclusively to UWB devices]

In summary, FCC rulemaking activities indicate a trend toward loosening or waiving restrictions on UWB products and shifting the responsibility for demonstrating non-interference from new unlicensed spectrum users to incumbent spectrum users

A different and more conservative approach is being followed in Europe where spectrum regulators have proposed adoption of a "slope mask" for UWB out-of-band emissions, particularly outside bands where UWB is permitted to operate. Figure 2 shows the European slope mask. Such a mask would significantly reduce the concern of incumbent spectrum users, particularly those operating below 960 $\mathrm{MHz}$, that UWB systems can truly operate on a non-interference basis.

The FCC emission limits and the slope emission masks

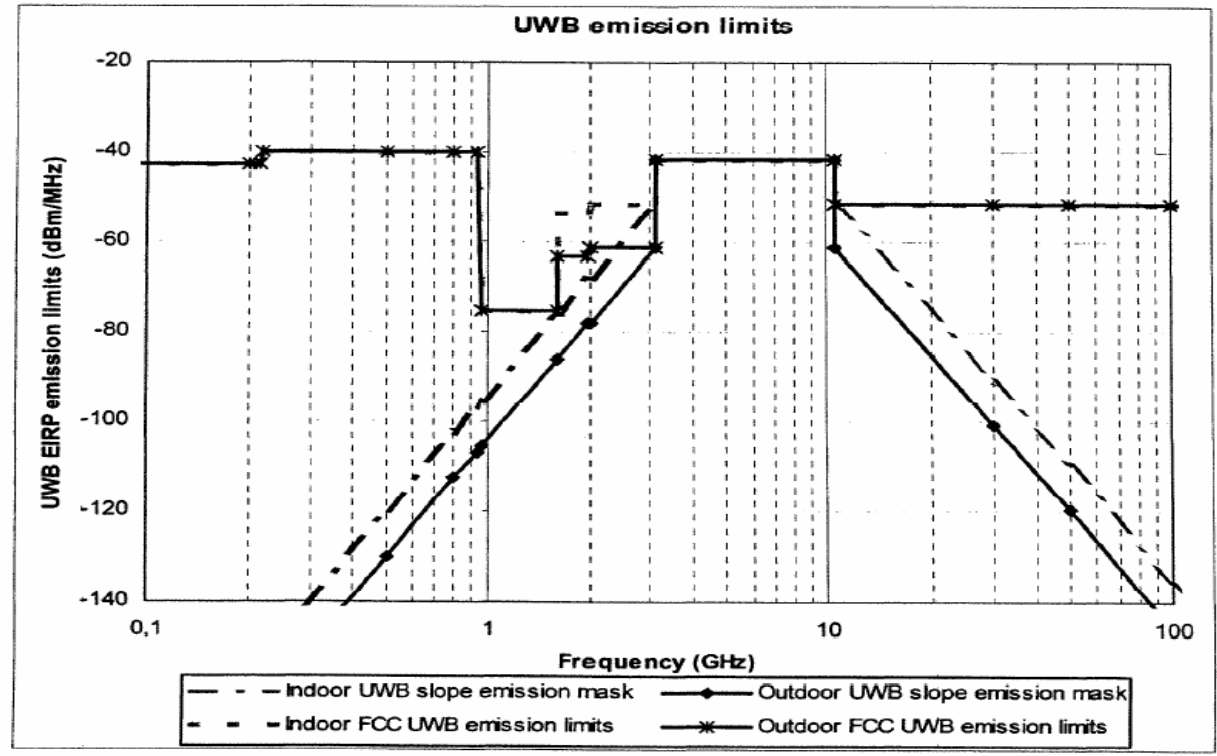

Figure 2: Slope emission limit mask for UWB out-of-band emissions proposed by the European Conference of Postal and Telecommunications Administrations Spectrum Engineering Committee 24 and the European Technical Standards Institute. ${ }^{29}$ 


\subsection{Airplane EMI Coupling from UWB PEDs}

Any EMI situation includes a threat source, a path, and a victim. This report focuses upon the handheld UWB device threat to aeronautical radio systems via radiated signal coupling into aircraft antennas, causing EMI within aeronautical radio frequency bands and on the currently used channel ("in-band, on-channel" EMI). In-band, on-channel EMI has been identified by past RTCA studies as the most likely way PEDs may impact aircraft flight operations. ${ }^{30,31}$ The RTCA studies clearly establish the fact that coupling between airplane passenger cabin and airplane radio antennas is highly dependent upon the aircraft type, and location of the transmitter within the airplane.

This report does not address EMI outside aeronautical radio frequency (RF) passbands, and does not include radiated field (or conducted) coupling to wiring and equipment apertures. The work builds upon a significant body of interference path loss (IPL) measurement data, IPL being defined as the radiated field coupling between passenger cabin locations and aircraft communication and navigation receivers, via their antennas. $32,33,34,35,36,32,33$ IPL data is required for assessing the threat of PEDs to aircraft radios, and is very dependent upon airplane size, the interfering transmitter position within the airplane, and the location of the particular antenna for the aircraft system of concern. Figure 3 provides a graphical overview of PED IPL for top-mounted aircraft antennas. A thorough measurement description for IPL data is provided in NASA/TP-2003-212438. ${ }^{36}$

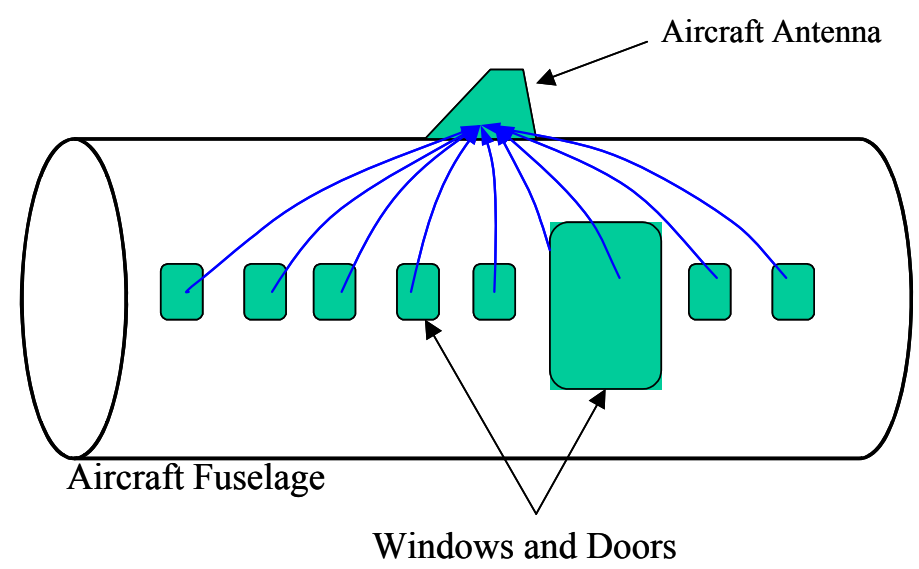

Figure 3: A typical PED EMI coupling path for a top mounted aircraft antenna.

There is currently an RTCA Special Committee tasked to address EMI from intentionally transmitting PEDs (including UWB), when used on board airplanes. ${ }^{37}$ By October 2005, it is expected that SC-202 will provide specific guidance to regulatory agencies, airlines, avionics manufacturers PED manufacturers and industry standards groups regarding the design, use and control of intentionally transmitting PEDs on board airplanes. NASA, the FAA, European regulatory officials, aircraft manufacturers, avionics manufacturers, PED manufacturers and airlines are actively contributing to RTCA SC-202 activities. This report is partially intended to benefit the RTCA SC-202 effort. To date, no other EMI measurement program, focused on UWB, has considered the airframe as part of the coupling path. This report provides a critical link between past (ongoing and future) analytical and laboratory UWB EMI studies involving aircraft systems. 


\subsection{Statement of the Problem}

UWB devices may pose a new type of problem to aeronautical radio systems that could present a major hazard and significantly decrease safety margins. Existing aeronautical radio systems are not designed to coexist with on-channel EMI. Any level of increased on-channel EMI will impair the performance of existing aeronautical radio systems, potentially degrading their availability and accuracy. While handheld UWB products are currently designated to operate in the 3.1 to $10.6 \mathrm{GHz}$ radio frequency band, it is considered likely that some product implementations will also have UWBlike radiated emissions at frequencies below $3.1 \mathrm{GHz}$, at or near applicable FCC limits.

Because repeatable and verifiable occurrences of PED EMI to aircraft COM/NAV systems have been very rare, the aviation RF spectrum community is particularly concerned that the FCC and UWB product manufacturers may view FCC 15.209 limits as a valid constraint to UWB spurious emission levels. However, NASA tests that have shown that spurious emissions from typical PEDs are far below FCC 15.209 limits, and maximum PED emissions are unlikely to coincide with the particular aviation radio channels being used at a given time. ${ }^{38,39}$ The introduction of PEDs that radiate signals at levels near FCC 15.209 limits, over broad bandwidths, would be detrimental to aeronautical radio systems. Any FCC action to increase existing UWB spurious radiated emission limits would exacerbate EMI concerns for aeronautical radio systems.

As reported on subsequent pages, radiated emissions at FCC 15.209 limits can cause interference to critical aircraft communication and navigation systems under certain conditions. If UWB emissions are of sufficient amplitude and appropriate pulse repetition frequency (PRF), multiple COM/NAV receiving systems on one aircraft could be affected simultaneously. Normal operational redundancy and backup required by the FAA for certification may not protect against such situations. With current regulations, handheld UWB device applications are likely to go beyond the ability of the FAA and airlines to control. For example, federal law currently prohibits airborne operation of cellular phones. $^{40}$ The US Code of Federal Regulations (CFR) prohibits the use of any PED, unless the aircraft operator has determined that the device will not cause interference with navigation or communication systems on that particular airplane model. ${ }^{41}$ The FAA provides further advisory guidance to aircraft operators assisting them in compliance with federal regulations, but specifically prohibits cellular telephones (among other intentional transmitters) while the airplane is in flight. ${ }^{42}$ Flight attendants routinely announce the prohibition of passenger mobile phone use before every commercial flight on all airlines. In spite of these clear guidelines restricting passengers from operating mobile phones on board airplanes during flight, passengers frequently operate them anyway, often inadvertently, but sometimes intentionally. This unauthorized activity is documented in numerous media reports and has also been quantified with measurement equipment as part of an ongoing RTCA study of airplane PED EMI issues. ${ }^{43}$ Given the precedent of unauthorized mobile phone use, it is inevitable that passengers will also operate handheld UWB transmitters on airplanes. UWB manufacturers promote an exciting vision of incorporating UWB radios into low-cost consumer products including digital cameras, handheld computers and audio/video entertainment equipment. The expanded integration of wireless technology into multifunction PEDs ensures that some passengers and flight crews will not be able to identify whether a device incorporates UWB transmitter technology. It is thus recommended that U.S. government rulemaking discourage the proliferation of technologies with the potential to compromise public safety unless there are effective means in place for their control

Some UWB developers have embraced the concept of a common signaling mode (CSM) or common signaling protocol (CSP) that enables interoperability between various handheld UWB 
product standards, and includes the provision for disabling the UWB transmitter via the radio link. ${ }^{44,45}$ The transmit-disable provision will allow simple and automatic control of UWB transmitters in hospitals, secure locations and on board airplanes. For commercial air travelers, this provision may allow greater level of control of UWB transmitters than exists with any other T-PED technology, particularly during the safety-critical takeoff and landing phases of flight, and could be a significant factor in promoting the acceptance of UWB radio technologies. We recommend that a transmitdisable provision be widely adopted by UWB product manufacturers, and preferably be mandated by the FCC. 
(This page was left intentionally blank) 


\section{Objective of This Study}

A comprehensive series of tests was aimed at determining the nature and extent of any interference to operational aircraft communication and navigation systems from UWB devices meeting FCCapproved and proposed levels for unlicensed handheld transmitters.

\subsection{Analytical Studies, Laboratory Testing and Field Testing}

Determination of the susceptibility of aeronautical radio systems to UWB EMI may be approached in three complimentary ways:

- Analytical studies: By obtaining aeronautical radio sensitivity thresholds, noise immunity requirements and desired signal characteristics from standards documents (RTCA, EUROCAE, ARINC) and manufacturers specifications, and calculating the expected path loss from a threat source, an allowable level of interference can be determined. Analytical studies do not require specialized equipment and can be performed with openly available reference material. However, standards documents and manufacturers specifications often do not accurately characterize the full operational capability of in-service aircraft equipment, and do not address immunity to in-band, on-channel rejection of various types of threat signals that may be encountered in EMI situations.

- Laboratory Bench Tests: The capability of in-service avionics equipment can be directly evaluated by measuring operational degradation under controlled EMI threat conditions in a laboratory. Laboratory testing allows very accurate control of individual test variables that are repeatable and easy to verify, but correlation to the operational EMI signal environment is not always obvious, and it may be difficult to assess the operational impact of EMI effects observed.

- Field Tests on Operational Airplanes: By introducing specific EMI threats to aeronautical radio systems installed on airplanes, it is possible to observe effects in the same context that they would appear to flight crews, in a realistic operational signal environment. The entire FAA aircraft EMI certification process is built around this approach as applied to specific airplane type configurations and installed equipment. Field-testing is valuable for demonstrating functionality and limitations of radio systems in a context representative of their operational EMI environment, but offers limited control of individual test variables, and is often expensive.

Any of these three approaches alone should not be used as a basis for recommending radiated emission limits for consumer UWB devices. The study described in this report considers field-tests on operational airplanes. An operational safety assessment of UWB PED EMI to aircraft systems should be performed. For this assessment, a functional hazard analysis must include analytical studies, laboratory tests and field tests to establish safe radiated emission boundaries for UWB devices used, intentionally or inadvertently, in an aviation environment. It is important to note that radiated emission limits for handheld UWB PEDs have been established as rule of law, on the basis of mathematical analyses and limited testing that did not even consider EMI with many aviation radio systems. We assert that the protection of safety-critical aviation radio frequency bands is relevant to setting maximum allowable limits for consumer devices.

\subsection{UWB EMI to Aircraft Systems: Reference Summary}

To date, there have been several analytical studies, laboratory tests and field tests addressing UWB EMI to aeronautical radio systems. A summary and comparison of these studies are provided in 
Table 1. While significant work has been accomplished, previous studies are seriously deficient for determining the potential for emerging UWB-enabled PEDs to cause harmful interference to aeronautical radio services. The study described in this report represents the most comprehensive field tests ever performed for determining the nature and extent of any interference to operational aircraft communication and navigation systems from UWB devices meeting FCC-approved and proposed levels for unlicensed handheld transmitters.

Table 1: Reference List: Studies Evaluating UWB EMI to Aircraft Systems

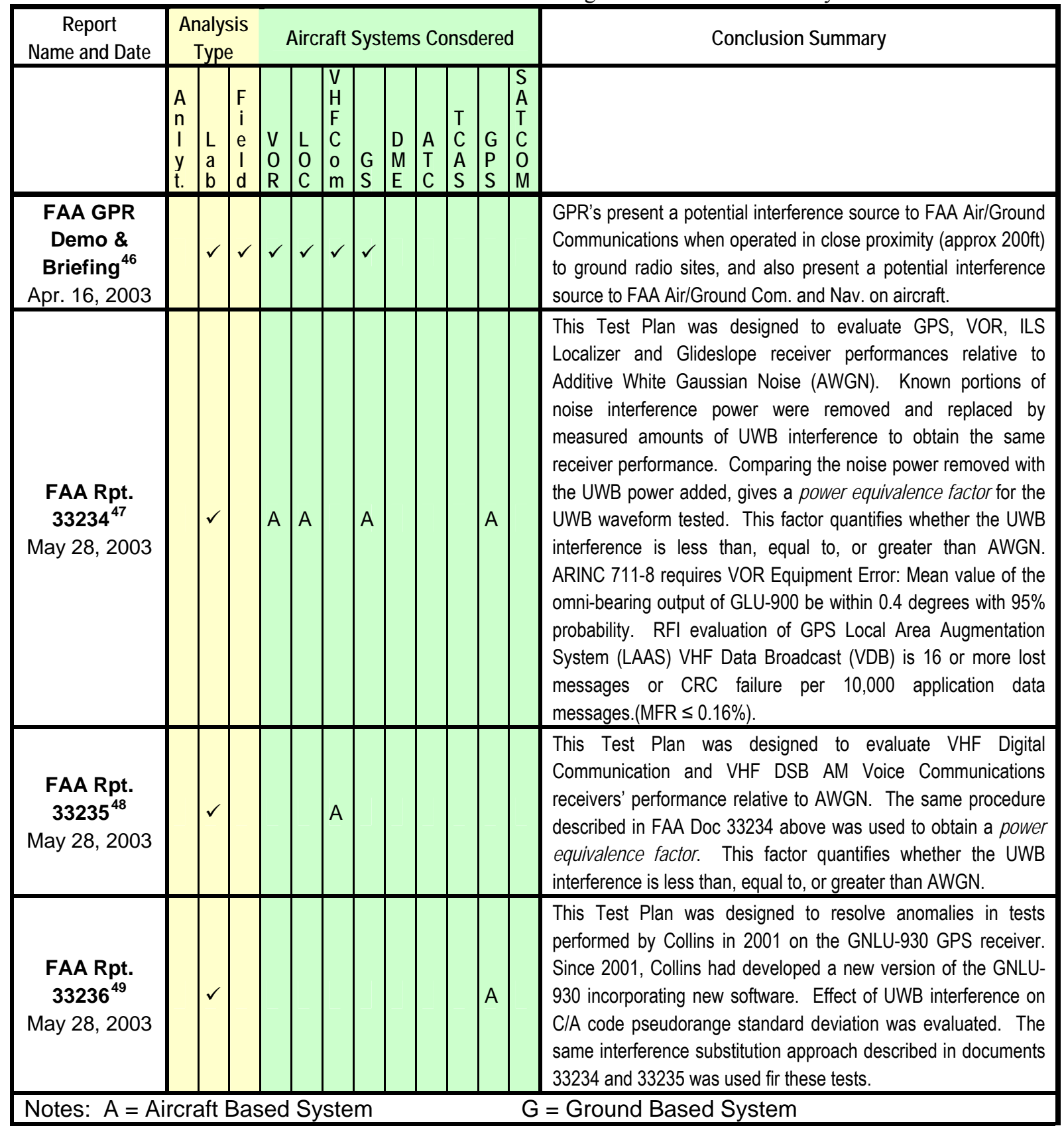


Table 1: Reference List: Studies Evaluating UWB EMI to Aircraft Systems (Cont.)

\begin{tabular}{|c|c|c|c|c|c|c|c|c|c|c|}
\hline \multirow[t]{2}{*}{$\begin{array}{c}\text { Report } \\
\text { Name and Date }\end{array}$} & \multicolumn{3}{|c|}{$\begin{array}{c}\text { Analysis } \\
\text { Type }\end{array}$} & \multicolumn{6}{|c|}{ Aircraft Systems Consdered } & \multirow[t]{2}{*}{ Conclusion Summary } \\
\hline & $\begin{array}{l}\text { A } \\
n \\
I \\
y \\
t \\
t .\end{array}$ & $\begin{array}{l}\text { L } \\
\text { a } \\
b\end{array}$ & $\begin{array}{l}F \\
i \\
e \\
\text { I } \\
d\end{array}$ & & \begin{tabular}{l|l}
$\mathrm{V}$ \\
$\mathrm{H}$ \\
$\mathrm{F}$ \\
$\mathrm{C}$ \\
$\mathrm{O}$ \\
$\mathrm{C}$ \\
$\mathrm{m}$
\end{tabular} & \begin{tabular}{|l|l} 
& \\
& \\
& \\
$S$ & $E$ \\
\end{tabular} & \begin{tabular}{l|l}
$\mathrm{D}$ & 1 \\
$\mathrm{M}$ & \\
$\mathrm{E}$ &
\end{tabular} & \begin{tabular}{l|l}
$A$ & T \\
A & C \\
C & $A$ \\
$C$ & $S$ \\
\end{tabular} & \begin{tabular}{|l|l} 
& $\mathrm{S}$ \\
& $\mathrm{A}$ \\
$\mathrm{G}$ & $\mathrm{T}$ \\
$\mathrm{C}$ \\
$\mathrm{P}$ & $\mathrm{O}$ \\
$\mathrm{S}$ & $\mathrm{M}$ \\
\end{tabular} & \\
\hline $\begin{array}{c}\text { NTIA Rpt. 01- } \\
\text { 383 }^{\text {50 }} \\
\text { Jan. } 2001\end{array}$ & $\checkmark$ & $\checkmark$ & & & & & & & & $\begin{array}{l}\text { Primary objective of these laboratory tests were to observe and } \\
\text { record the temporal and spectral characteristics of several UWB } \\
\text { signals. Measurements were made in both conducted and } \\
\text { radiated (at } 1 \text {-meter) modes and were supported by analytical } \\
\text { and simulation studies. From a group of twenty UWB devices, } \\
\text { five were measured to obtain relevant characteristics. Device A } \\
\text { had a } 10 \mathrm{kHz} \text { PRF with most energy in the } 5.1-6.1 \mathrm{GHz} \text { band. } \\
\text { Device B, intended for voice communications, provided four data } \\
\text { rates in the } 16-128 \mathrm{kbps,} \mathrm{and} \mathrm{had} \mathrm{most} \mathrm{energy} \mathrm{in} \mathrm{the} 1.2-1.8 \\
\mathrm{GHz} \text { band. Device C employed "relative" dithering and covered } \\
\text { the } 1.5-2.1 \mathrm{GHz} \text { band. Device D operated with PRFs of } 1,5 \text {, and } \\
10 \mathrm{MHz} \text {; with gating duty cycles of } 25 \% \text { and } 100 \% \text {; and a fixed } \\
\text { dithering of } 25 \% \text { in all modes. Device E was apparently a GPR } \\
\text { with operational frequencies of } 300,900 \text {, and } 1500 \mathrm{MHz} \text { and was } \\
\text { capable of operating at multiple PRFs. Finally, an electric drill } \\
\text { was measured and found to emit signals in the } 0.6-5.0 \mathrm{GHz} \\
\text { range with a noticeable "bulge" in the } 3.1-4.2 \mathrm{GHz} \text { band. The } \\
\text { sole purpose of this study was to measure the spectra and other } \\
\text { characteristics of these devices. }\end{array}$ \\
\hline $\begin{array}{c}\text { NTIA SP 01- } \\
\mathbf{4 3}^{\mathbf{5 1}} \\
\text { Jan. } 2001\end{array}$ & $\checkmark$ & $\checkmark$ & $\checkmark$ & & & & $\begin{array}{l}A \\
\& \\
G\end{array}$ & $\begin{array}{l}A \\
\& \\
G\end{array}$ & & $\begin{array}{l}\text { NTIA undertook a program to measure, simulate, and analyze } \\
\text { interference effects of UWB devices on several systems critical to } \\
\text { safety-of-life. Aircraft systems included: DME (air \& ground } \\
\text { receivers), Air Traffic Control Radio Beacon System (ATCRBS, } \\
\text { air \& ground receivers), and air Route and Airport Surveillance } \\
\text { Radars. Minimum separation required between a UWB device at } \\
2 \mathrm{~m} \text { height and the DME's antenna was determined by analysis, } \\
\text { while that for radars was based on field measurements. } \\
\text { Separation distances varied between } 20 \mathrm{~m} \text { and } 6 \mathrm{~km} \text {, depending } \\
\text { upon the system. }\end{array}$ \\
\hline $\begin{array}{l}\text { NTIA SP 01- } \\
\quad \mathbf{4 5}^{\mathbf{5 2}} \\
\text { Feb. } 2001\end{array}$ & $\checkmark$ & $\checkmark$ & & & & & & & $\begin{array}{l}A \\
\& \\
G\end{array}$ & $\begin{array}{l}\text { Primary objective was to determine maximum UWB E.IR.P that } \\
\text { can be tolerated by GPS receivers in various applications. } 32 \\
\text { UWB signal types were examined by NTIA for potential } \\
\text { interference to GPS. Conducted and radiated laboratory tests } \\
\text { measured the break lock and reacquisition signal levels resulting } \\
\text { in the presence of a UWB signal. Conclusion: C/A-code GPS } \\
\text { receivers relatively tolerant to UWB sources with a PRF below } \\
100 \mathrm{kHz} \text {; however, at PRFs of } 1,5 \text {, and } 20 \mathrm{MHz} \text {, the receiver's } \\
\text { performance criteria is impacted at the permitted FCC Part } 15 \\
\text { level. }\end{array}$ \\
\hline $\begin{array}{l}\text { Notes:: } \\
\text { A = Aircraft } \\
\text { G = Ground }\end{array}$ & & & & & & & & & & \\
\hline
\end{tabular}


Table 1: Reference List: Studies Evaluating UWB EMI to Aircraft Systems (Cont.)

\begin{tabular}{|c|c|c|c|c|c|c|c|c|c|c|c|}
\hline \multirow[t]{2}{*}{$\begin{array}{c}\text { Report } \\
\text { Name and Date }\end{array}$} & \multicolumn{3}{|c|}{$\begin{array}{l}\text { Analysis } \\
\text { Type }\end{array}$} & \multicolumn{7}{|c|}{ Aircraft Systems Consdered } & \multirow[t]{2}{*}{ Conclusion Summary } \\
\hline & $\begin{array}{l}\text { A } \\
n \\
I \\
y \\
\text { t. } \\
\end{array}$ & $\begin{array}{l}\mathrm{L} \\
\mathrm{a} \\
\mathrm{b}\end{array}$ & $\begin{array}{l}\mathrm{F} \\
\mathrm{i} \\
\mathrm{e} \\
\mathrm{I} \\
\mathrm{d} \\
\end{array}$ & \begin{tabular}{l|l}
$\mathrm{V}$ & $\mathrm{L}$ \\
$\mathrm{O}$ & $\mathrm{C}$ \\
$\mathrm{R}$ & $\mathrm{C}$ \\
\end{tabular} & $\begin{array}{l}\mathrm{L} \\
0 \\
\mathrm{C} \\
\end{array}$ & $\begin{array}{l}\mathrm{V} \\
\mathrm{H} \\
\mathrm{F} \\
\mathrm{C} \\
\mathrm{o} \\
\mathrm{m} \\
\end{array}$ & \begin{tabular}{l|l}
$\mathrm{G}$ & 0 \\
$\mathrm{G}$ & $\mathrm{N}$ \\
\end{tabular} & $\begin{array}{l}\mathrm{D} \\
\mathrm{M} \\
\mathrm{E}\end{array}$ & \begin{tabular}{|l|l} 
& $T$ \\
$A$ & $C$ \\
$T$ & $A$ \\
$C$ & $S$ \\
\end{tabular} & \begin{tabular}{|l|l} 
& S \\
& $A$ \\
& $T$ \\
$G$ & $C$ \\
$P$ & $O$ \\
$S$ & $M$ \\
\end{tabular} & \\
\hline $\begin{array}{l}\text { NTIA Rpt. 01- } \\
\mathbf{3 8 4}^{\text {53 }} \\
\text { Feb. } 2001\end{array}$ & & $\checkmark$ & & & & & & & & A & $\begin{array}{l}\text { Laboratory measurements were made on two GPS receivers with } \\
\text { differing architectures using up to six aggregated UWB devices. } \\
\text { Three elements were present: a GPS simulator source, a UWB } \\
\text { source, and a GPS receiver. Two types of tests were conducted: } \\
\text { Radiated UWB signal and GPS antenna located in an anechoic } \\
\text { chamber. Conducted tests using a coaxial cable between UWB } \\
\text { source and the receiver. Precision attenuators were used to } \\
\text { control signal levels }\end{array}$ \\
\hline $\begin{array}{l}\text { NTIA IRAC } \\
\text { Study } \\
\text { Feb. } 2003\end{array}$ & $\checkmark$ & & & $A \mid A$ & A & A & A $\mid A$ & A & A & & $\begin{array}{l}\text { This NTIA analytical study investigated effects of UWB on } \\
\text { aeronautical communications and navigation systems operating } \\
\text { below } 1 \mathrm{GHz} \text { including: VOR, ILS, VHF communications, VDL, } \\
\text { LAAS, VDB, ILS Marker Beacon, Loran-C, NDB, and UAT. It } \\
\text { sought to determine whether emission limits contained in FCC's } \\
\text { !ST R\&O were adequate. UWB signals with "noise like" and } \\
\text { "spectral line" characteristics were analyzed at minimum } \\
\text { separation distances of } 100 \text { and } 128 \text { feet for precision and non- } \\
\text { precision approaches respectively. The study concluded that } \\
\text { levels permitted by the } 1 \text { ST R\&O produced negative performance } \\
\text { margins for: VHF Data Link and Data Broadcast systems for } \\
\text { UWB "noise-like" sources and for Non-Directional Beacon, ILS } \\
\text { Marker Beacon, VOR, VHF Data Link, and Data Broadcast } \\
\text { systems with UWB sources spectral line emissions. }\end{array}$ \\
\hline $\begin{array}{c}\text { NETEX } \\
\text { AN/ARN-147 } \\
\text { Study }^{55} \\
\text { Feb. } 18,2003\end{array}$ & & $\checkmark$ & & $A \mid A$ & A & A & & A & & & $\begin{array}{l}\text { This DARPA laboratory study examined UWB interference to an } \\
\text { AN/ARN-147 commercial instrument landing receiver's VOR, } \\
\text { Localizer, Glideslope, and Marker Beacon functions by systems } \\
\text { being developed under DoD's Networking in Extreme } \\
\text { Environments (NETEX) program. A custom UWB simulator, } \\
\text { producing a } 250 \text { ps pulses and a multiplicity of waveforms, } \\
\text { modulations, PRFs, etc. was provided by Multispectral Solutions } \\
\text { Inc. Two types of tests were performed: First, a desired signal } 6 \\
\text { dB above the acquisition threshold plus the UWB EMI signal at } \\
\text { increasing levels was injected directly into an AN/ARN-147 } \\
\text { receiver producing failure. Second a UWB signal } 20 \mathrm{~dB} \text { above } \\
\text { the receiver's interference upset level was injected and the } \\
\text { desired signal's level was increased until acquisition occurred. } \\
\text { The study concluded that UWB"s impact was dependant upon its } \\
\text { waveform's characteristics and the amount of interfering signal } \\
\text { falling into the receiver's passband. }\end{array}$ \\
\hline $\begin{array}{l}N \\
A\end{array}$ & & & & & & & & & & & \\
\hline
\end{tabular}


Table 1: Reference List: Studies Evaluating UWB EMI to Aircraft Systems (Cont.)

\begin{tabular}{|c|c|c|c|c|c|c|c|c|c|c|c|c|}
\hline \multirow[t]{2}{*}{$\begin{array}{c}\text { Report } \\
\text { Name and Date }\end{array}$} & \multicolumn{3}{|c|}{$\begin{array}{l}\text { Analysis } \\
\text { Type }\end{array}$} & \multicolumn{8}{|c|}{ Aircraft Systems Consdered } & \multirow[t]{2}{*}{ Conclusion Summary } \\
\hline & $\begin{array}{l}\text { A } \\
\text { n } \\
\text { I } \\
y \\
\text { t. }\end{array}$ & $\begin{array}{l}\mathrm{L} \\
\mathrm{a} \\
\mathrm{b}\end{array}$ & $\begin{array}{l}F \\
i \\
e \\
l \\
d\end{array}$ & \begin{tabular}{l|}
$\mathrm{V}$ \\
$\mathrm{O}$ \\
$\mathrm{R}$ \\
\end{tabular} & $\begin{array}{l}\mathrm{L} \\
\mathrm{O} \\
\mathrm{C}\end{array}$ & $\begin{array}{l}\mathrm{H} \\
\mathrm{F} \\
\mathrm{C} \\
\mathrm{o} \\
\mathrm{m} \\
\end{array}$ & $\begin{array}{l}\text { G } \\
\mathbf{S}\end{array}$ & $\begin{array}{l}\mathrm{D} \\
\mathrm{M} \\
\mathrm{E} \\
\end{array}$ & $\begin{array}{ll}\text { A } \\
\text { T } \\
\text { C }\end{array}$ & & $\begin{array}{ll} & \\
\mathbf{G} & \\
\mathbf{P} & \\
\mathbf{S} & \end{array}$ & \\
\hline $\begin{array}{c}\text { NETEX } \\
\text { AN/ARC-210 } \\
\text { Study }^{56} \\
\text { Feb. 19, } 2003\end{array}$ & & $\checkmark$ & & & & A & & & & & & $\begin{array}{l}\text { This DARPA laboratory study examined UWB interference to an } \\
\text { AN/ARC-210 VHF/UHF communications system. The custom } \\
\text { NETEX UWB source described above for the SN/ARN-147 } \\
\text { receiver was employed. Again, two types of tests were } \\
\text { performed: First, a desired signal } 6 \mathrm{~dB} \text { above the acquisition } \\
\text { threshold plus the UWB EMI signal at increasing levels was } \\
\text { injected directly into an AN/ARN-147 receiver producing failure. } \\
\text { Second a UWB signal } 20 \mathrm{~dB} \text { above the receiver's interference } \\
\text { upset level was injected and the desired signal's level was } \\
\text { increased until acquisition occurred. . The study concluded that } \\
\text { UWB's impact was dependant upon its waveform's } \\
\text { characteristics and the amount of interfering signal falling into the } \\
\text { receiver's passband. }\end{array}$ \\
\hline $\begin{array}{l}\text { NETEX Final } \\
\text { Report }^{57} \\
\text { June } 31 \\
2003\end{array}$ & & $\checkmark$ & & & & & & & & & & $\begin{array}{l}\text { This report documents test results to measure susceptibility of } \\
\text { selected military communication, navigation, and radar systems } \\
\text { to UWB EMI. A total of } 17 \text { different receivers, operating in } 39 \\
\text { modes, operating at } 65 \text { frequencies and } 5 \text { frequency-hop sets } \\
\text { from } 30 \text { to } 16 \mathrm{GHz} \text { were tested. The Report concludes: "' ... } \\
\text { that most of the test waveforms caused caused interference in } \\
\text { the Equipment Under Test (EUT) at full power levels" }\end{array}$ \\
\hline $\begin{array}{l}\text { NASA TM- } \\
2002- \\
211949^{58} \\
\text { Oct. } 2002\end{array}$ & & & $\checkmark$ & & $A$ & $A$ & A & & A & A & $\mathrm{A} \mid$ & $\begin{array}{l}\text { These UWB field interference tests involved personnel and } \\
\text { equipment furnished by NASA, Eagles Wings Inc. (EWI), and } \\
\text { United Airlines Inc (UAL). Interference to VOR, Localizer, } \\
\text { Glideslope, VHF-1 Com, TCAS and GPS systems were } \\
\text { measured on 6-B737 and 4-B747 aircraft. Additionally, the UWB } \\
\text { interference to the SATCOM system, through its low gain } \\
\text { antenna, was tested on B747s. Four "identical" UWB } \\
\text { interference sources, having a pulse width of } 240 \text { ps, were } \\
\text { purchased for these tests. UWB sources were placed at all } \\
\text { closed and locked doors and at selected windows. NASA, EWI, } \\
\text { and UAL demonstrated that a handheld UWB emitter, operating } \\
\text { at -41dBm, can interfere with the ILS Localizer system on a } \\
\text { B737. It was found that modulation affected a B737 Localizer } \\
\text { receiver's threshold Interference to TCAS, ATC, and ILS } \\
\text { Localizer and Glideslope radios was also found. }\end{array}$ \\
\hline This Report & & & $\checkmark$ & A & A & A & A & A & A & A & A 1 & A \\
\hline $\begin{array}{l}\text { Notes:: } \\
A=\text { Aircraft } \\
G=\text { Ground }\end{array}$ & & & & & & & & & & & & \\
\hline
\end{tabular}


(This page was left intentionally blank) 


\section{Approach: Field Test on Operational Airplanes}

\subsection{Phased Approach}

Multiple communication and navigation radios on four different airplane types were evaluated, including transport airplanes and regional airplanes. These airplanes were selected on the basis of their representation of various airplane sizes, availability to the test team, and likelihood of having minimum coupling loss between particular passenger cabin locations and aircraft radio antennas. The airplane designations for data in this report are provided in Table 2. Table 3 identifies the aeronautical radio systems that were evaluated.

Table 2: Airplane Designations

\begin{tabular}{|c|l|}
\hline Airplane Designation & Airplane Category \\
\hline$\# 1$ & Large Transport: Wide Body \\
\hline$\# 2$ & Large Transport: Narrow Body \\
\hline$\# 3$ & Regional Jet \\
\hline$\# 4$ & Regional Propeller \\
\hline
\end{tabular}

Table 3: Aeronautical radio systems evaluated during field testing.

\begin{tabular}{|l|l|l|}
\hline Abbreviation & Name & $\begin{array}{l}\text { Operational Frequency } \\
\text { Range (MHz) }\end{array}$ \\
\hline LOC & Instrument Landing System Localizer & 108 to 113 \\
\hline VOR & VHF Omniranging & 108 to 118 \\
\hline VHF Com & VHF Communications & 118 to 138 \\
\hline GS & Instrument Landing System Glideslope & 328 to 336 \\
\hline DME & Distance Measuring Equipment & 960 to 1215 \\
\hline ATC & Air Traffic Control Radio Beacon System & 1030 (receive freq.) \\
\hline TCAS & Traffic Alert and Collision Avoidance System & 1090 (receive freq.) \\
\hline GPS & Global Positioning System & 1565 to 1585 \\
\hline SATCOM & $\begin{array}{l}\text { INMARSAT Aeronautical Mobile Communication } \\
\text { Satellite System }\end{array}$ & 1545 to 1560 \\
\hline
\end{tabular}

In order to refine the test process and obtain the most comprehensive and accurate data possible, it was preferable to approach the airplane testing iteratively. However, cost limitations and logistical considerations made it desirable to minimize the number of field tests. To balance these needs, the field testing was approached in two phases, each consisting of two field tests.

- Phase 1 Objectives:

- Compile and evaluate existing interference path loss data to estimate the most susceptible RF systems installed in particular types of airplanes.

- Characterize UWB source output levels in terms of FCC regulatory limits for spurious radiated emissions. Develop capability to apply different clock rates and modulations to UWB signal sources.

- Explore the susceptibility of aircraft radios to various UWB signal levels and modulations by observing cockpit displays.

- Evaluate methods of providing aircraft reference signals during field-testing.

- Evaluate methods of assessing aircraft receiver failures, using cockpit displays, audible cues and ground support equipment interfaces.

- Assess the vulnerability of security surveillance and communication systems to UWB signal, if possible. 
- Phase 2 Objectives:

- Document the susceptibility of aircraft radios to pre-defined UWB signal levels and modulations

- Establish and demonstrate a methodology for providing repeatable aircraft reference signals during EMI field-testing.

- Obtain photo/video documentation of specific EMI scenarios.

To minimize setup variations, each of four field tests were planned to focus on either VHF/UHF band aircraft receivers or L-Band aircraft radio receiver systems. All testing was accomplished during four field test visits, lasting from 5 to 10 days. The test dates, and abbreviated nomenclatures are shown in Table 4. The full test plan is provided in Appendix C.

Table 4: Test Dates and Nomenclatures

\begin{tabular}{|l|c|l|}
\hline Test Designation & Abbreviated Nomenclature & Test Dates \\
\hline Phase 1 Test $\# 1$ & P1T1 or Visit 1 & $2 / 17 / 03$ to $2 / 21 / 03$ \\
\hline Phase 1 Test $\# 2$ & P1T2 or Visit 2 & $3 / 18 / 03$ to $3 / 24 / 03$ \\
\hline Phase 2 Test \#1 & P2T1 or Visit 3 & $5 / 28 / 03$ to $6 / 3 / 03$ \\
\hline Phase 2 Test \#2 & P2T2 or Visit 4 & $8 / 5 / 03$ to $8 / 14 / 03$ \\
\hline
\end{tabular}

\subsection{UWB Source Characterization}

UWB threat signals were calibrated relative to FCC-allowable levels for UWB spurious radiated emissions in accordance with FCC 15.519 and FCC 15.209 rules. Details regarding the particular UWB source used, PRFs and modulations may be found in Appendices C and E.

\subsubsection{FCC 15.209 Limit Calibration}

For testing in all aeronautical radio frequency bands (below and above $960 \mathrm{MHz}$ ), the UWB source was calibrated to provide a spectral line on the aeronautical radio channel, at an output level equivalent to the FCC 15.209 limit. Below $960 \mathrm{MHz}$, the UWB source was calibrated in terms of field intensity, 3 meters away from the device under test. The UWB source was initially calibrated using a peak detector, but later recalibrated using a CISPR quasi-peak detector. Above $960 \mathrm{MHz}$, the UWB source was also calibrated with a peak detector, but with the peak measurements scaled according to the peak/RMS detector ratio determined as part of the FCC 15.519 bench calibration. (See "FCC 15.519 Limit Calibration: UWB Systems", below.) Measurements were conducted at NASA Langley Research Center (see Figure 4, data is provided in the Test Plan- Appendix C). For these measurements, the UWB transmit antenna (that was used during aircraft EMI testing) was placed 0.8 meters from the ground plane of a semi-anechoic test chamber, and 3 meters away from the calibrated reference antenna. The height of the reference antenna was adjusted from 1 to 4 meters to obtain the maximum amplitude in each aircraft radio frequency band, as a CW signal was swept across the frequency band. The attenuator/cable loss to be applied to the output of the UWB Signal Emulator was determined in order to provide a UWB threat signal equivalent to the FCC 15.209 limits.

\subsubsection{FCC 15.519 Limit Calibration}

For aeronautical radio systems operating above $960 \mathrm{MHz}$, the UWB source was also calibrated to provide an output level equivalent to the FCC 15.519 limit for handheld UWB systems, and adjusted for peak allowable output (up to $20 \mathrm{~dB}$, depending upon PRF (thin blue line on Figure 1, "15.519 
Peak- 1MHz RBW".) FCC 15.519 limits are provided in terms of RMS EIRP, and apply to UWB spurious emissions radiated from the antenna. The UWB output power was measured directly at the output port of the UWB source. The UWB source was calibrated using both Peak and RMS detectors for 19 different UWB PRFs in each aeronautical radio frequency band. Peak/RMS comparison data is provided in Section C.7 (Appendix C). All calibration measurements were conducted at NASA Langley Research Center (data is provided in the Test Plan- Appendix C). Transmit antenna gain ( $\mathrm{dBi}$, relative to isotropic) was added to the measured output for the antenna that was used during aircraft EMI testing. The attenuator/cable loss to be applied to the output of the UWB Signal Emulator was determined in order to provide a UWB threat signal compliant with the FCC 15.519 limits.

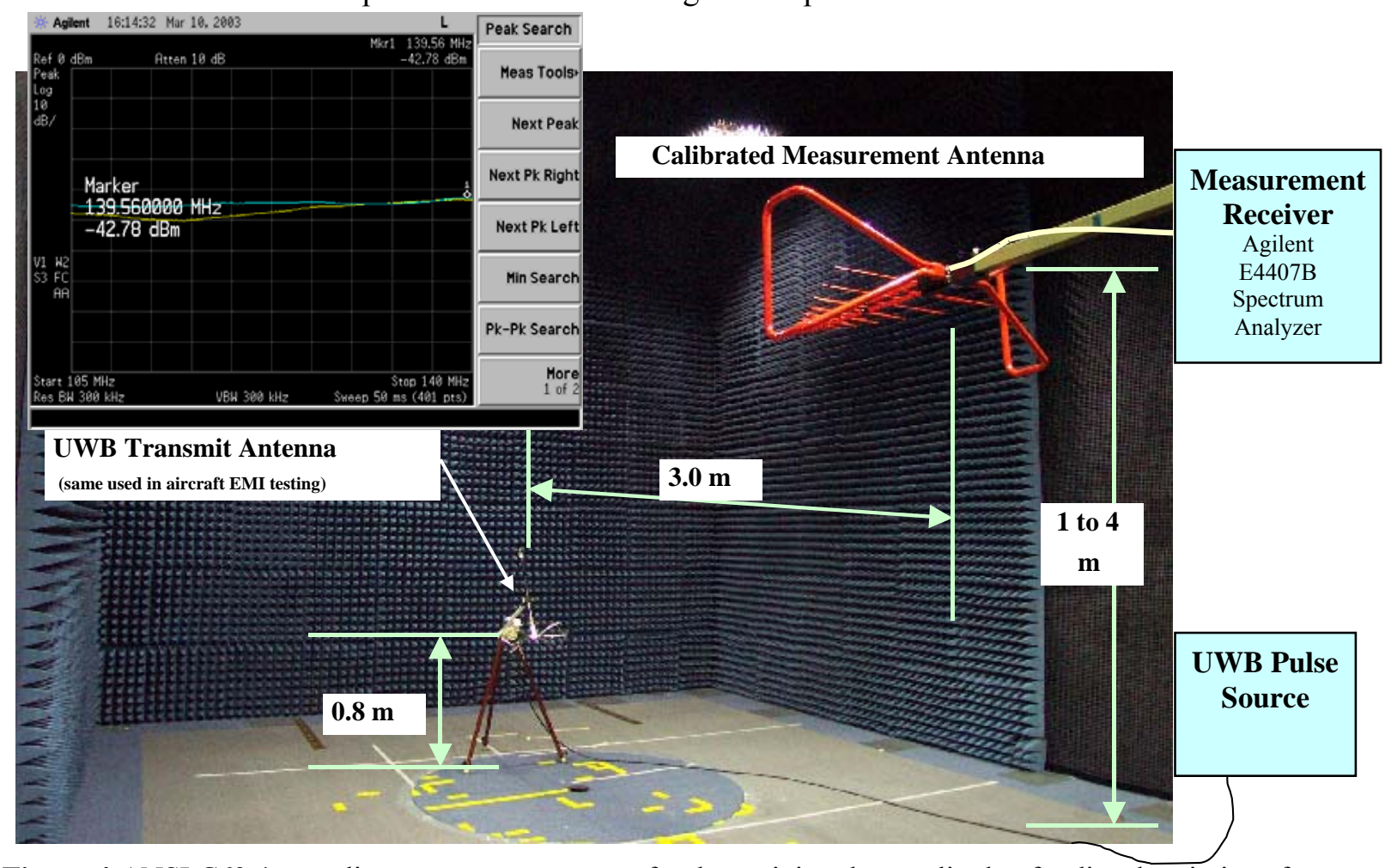

Figure 4:ANSI C63.4 compliant measurement setup for determining the amplitude of radiated emissions from a UWB transmitting source. Left Inset: Spectrum analyzer display of power received from the reference antenna (Dual Ridge Horn), when $-10 \mathrm{dBm}$ is applied from a tracking source to the UWB transmit antenna (Dual Ridge Horn). The yellow line is with the reference antenna positioned at $1 \mathrm{~m}$ height, and the purple line is with the reference antenna positioned at 1.46 meter height (resulting in maximum coupling across the frequency band).

\subsection{Aircraft Test Setups}

Test setups for operating the airplane, generating calibrated aeronautical receiver reference signals and generating calibrated UWB interfering signals (referenced to FCC radiated emission limits) were developed for this work and are summarized in this section. Additional details, equipment lists and procedures may be found in Appendix C.

Figure 5 shows a diagram of a typical setup for UWB direct effects EMI testing on an airplane. To conserve fuel and minimize noise and other personnel safety hazards, it was preferable to provide airplane electrical system power from ground servicing equipment rather than onboard auxiliary power units (APUs). APUs were most often used on the smaller, regional airplanes. It was also necessary to provide 120VAC $60 \mathrm{~Hz}$ power to the UWB source, spectrum analyzer, instrument control computer and other instrumentation. This 120 VAC electronic equipment was usually located inside the aircraft 
to provide weather protection and to facilitate communication between the UWB source operator, pilot and other test team members. To prevent electrostatic discharge and voltage fluctuations from interfering with test equipment and causing personnel safety hazards, it was very important to connect the aircraft structure to both earth ground and to the onboard test equipment ground terminals. To best approximate the electromagnetic boundary conditions of the aircraft in flight, extension cords and RF cabling were routed from the passenger cabin through an aircraft door or window as far as possible from the particular aircraft system antenna being tested. When reference signals were generated by ramp test sets, the signals were usually radiated from an antenna placed a few meters from the subject aircraft antenna. Five personnel were typically required to conduct testing. Their responsibilities were identified as:

- UWB Source Operator

- Aircraft Systems Engineer

- Aircraft Mechanic

- Pilot

- Test Director/Logbook Keeper

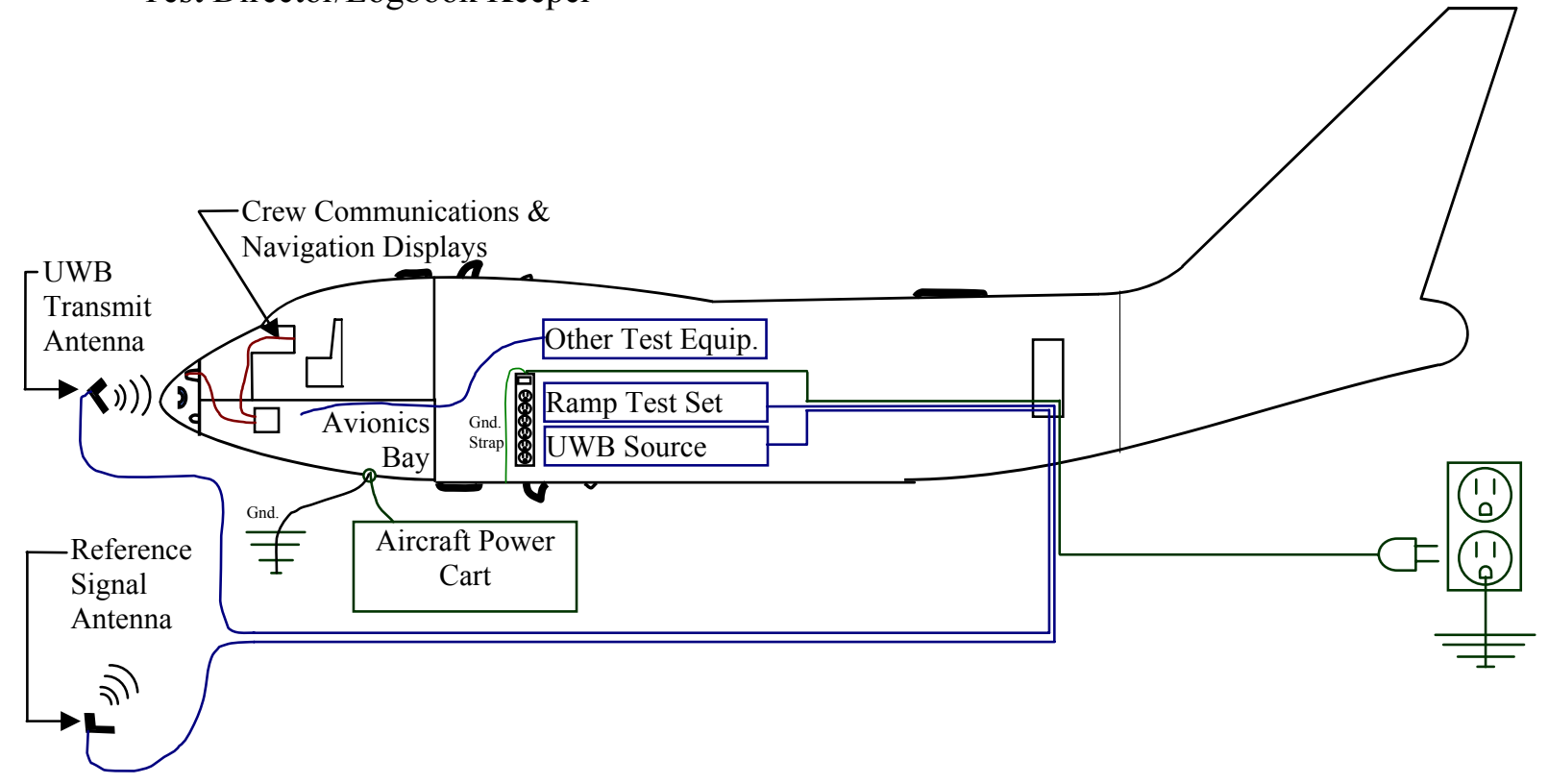

Figure 5: Typical setup for UWB EMI effects testing on aircraft radio receiver systems.

\subsubsection{Aeronautical Reference Signals}

Because United and Sky West Airlines maintenance depot operations are in close proximity to VOR/DME and ILS beacons, ATC and TCAS transponders, and the air traffic control tower, most "live sky" aeronautical radio signals greatly exceeded the minimum necessary for acceptable aircraft receiver performance. This could have been a problem for EMI direct effect testing, because a strong ambient reference signal may mask the effect of a weaker interfering signal that would have otherwise caused problems if the airplane were farther from the airport. A variety of "Ramp Test Sets" were employed to provide calibrated reference signals to each aircraft radio system, in order to verify their performance when installed on an airplane.

For UWB EMI testing, the ramp test sets were operated at a fixed location inside or outside the aircraft, as attenuation was added until the received signal at the aircraft was at the minimum level 
required for reliable lock-on to the reference signal, then $3 \mathrm{~dB}$ of attenuation was removed in order to achieve a solid signal lock. UWB EMI testing was performed while the radio link relationship between the airplane and portable Ramp Test Set was undisturbed. Most testing was performed at night, with aircraft located outdoors and away from other work activity so as to minimize affecting the RF link between the aircraft radios and ramp test sets. Specific radio channels and test settings may be found in Appendix C.

There are a number of difficulties in attempting to provide reference test signals to the GPS and SATCOM aeronautical receiver systems. GPS and SATCOM systems are designed to operate in a manner that constantly adapts to the existing satellite coverage situation. GPS integrates data from a continuously variable combination of satellites, whereas SATCOM follows an interactive protocol in establishing a radio link on one of many available radio channels. Test equipment for realistically simulating GPS and SATCOM radio links with an aircraft was considered prohibitively difficult. Fortunately, GPS and SATCOM provide relatively consistent signal strength to any U.S. location, particularly when compared to beacons, transponders or VHF Com aeronautical radio systems. For these reasons, GPS and SATCOM were tested using the ambient signals available from the satellite constellation at the time of test. The date, time and weather conditions during each test were recorded to aid in subsequent analysis.

\subsubsection{UWB Interfering Signals}

As described in Section 3.2, the UWB source output was characterized in NASA LaRC laboratories according to FCC 15.209 and 15.519 measurement processes. Tables were developed to readily provide the UWB source attenuation required so that UWB signals from the test antenna were exactly compliant with the maximum FCC-allowable limits. These tables are provided in Appendix C. The UWB source output was routed through a precision dial attenuator, allowing $1 \mathrm{~dB}$ resolution and up to $99 \mathrm{~dB}$ of attenuation before being transmitted through the antenna. A photograph of the UWB source equipment on board an airplane is shown in Figure 6a, and a simplified diagram of the equipment is shown in Figure 7. The UWB transmit antenna was placed 1 meter from the aircraft antenna for UTM comparison measurements (example shown on Fig. 6b), and then moved inside the aircraft to simulate the passenger use of a UWB transmitter (example shown on Fig. 6c). Because most aircraft radio systems incorporate identically redundant receiver and antenna systems, 1-meter EMI effects testing was usually performed on the most easily accessible antenna system, whereas the passenger cabin EMI effects testing was usually performed from locations of optimal coupling (minimum path loss).

\section{UWB Transmit Antenna 1-meter From Aircraft Antenna}

Each UWB EMI test was first performed with the UWB threat antenna placed 1 meter away from an accessible antenna of the aircraft radio system. When reference signals were generated by ramp test sets, the reference signals were usually radiated from an antenna placed a few meters from the subject aircraft antenna. Performing UWB susceptibility measurements with a 1-meter UWB threat antenna spacing provides stable electromagnetic boundary conditions, so that aircraft system EMI thresholds can be evaluated using each ultra wideband test modulation (UTM) option. Each test was initiated at a UWB signal power equal to the FCC15.209 limit, which usually resulted in EMI effects. The UWB signal power was then attenuated in 10 to $20 \mathrm{~dB}$ increments until EMI effects no longer occurred. Then, the UWB signal power was increased in 1 to $2 \mathrm{~dB}$ increments to determine EMI effects thresholds. The susceptibility thresholds for four different PRFs were compared, and the worst-case PRF (the UWB PRF causing EMI effects to the aircraft receiver system at the lowest UWB transmit power level) was selected for subsequent tests with the UWB source transmitting from inside the airplane. 

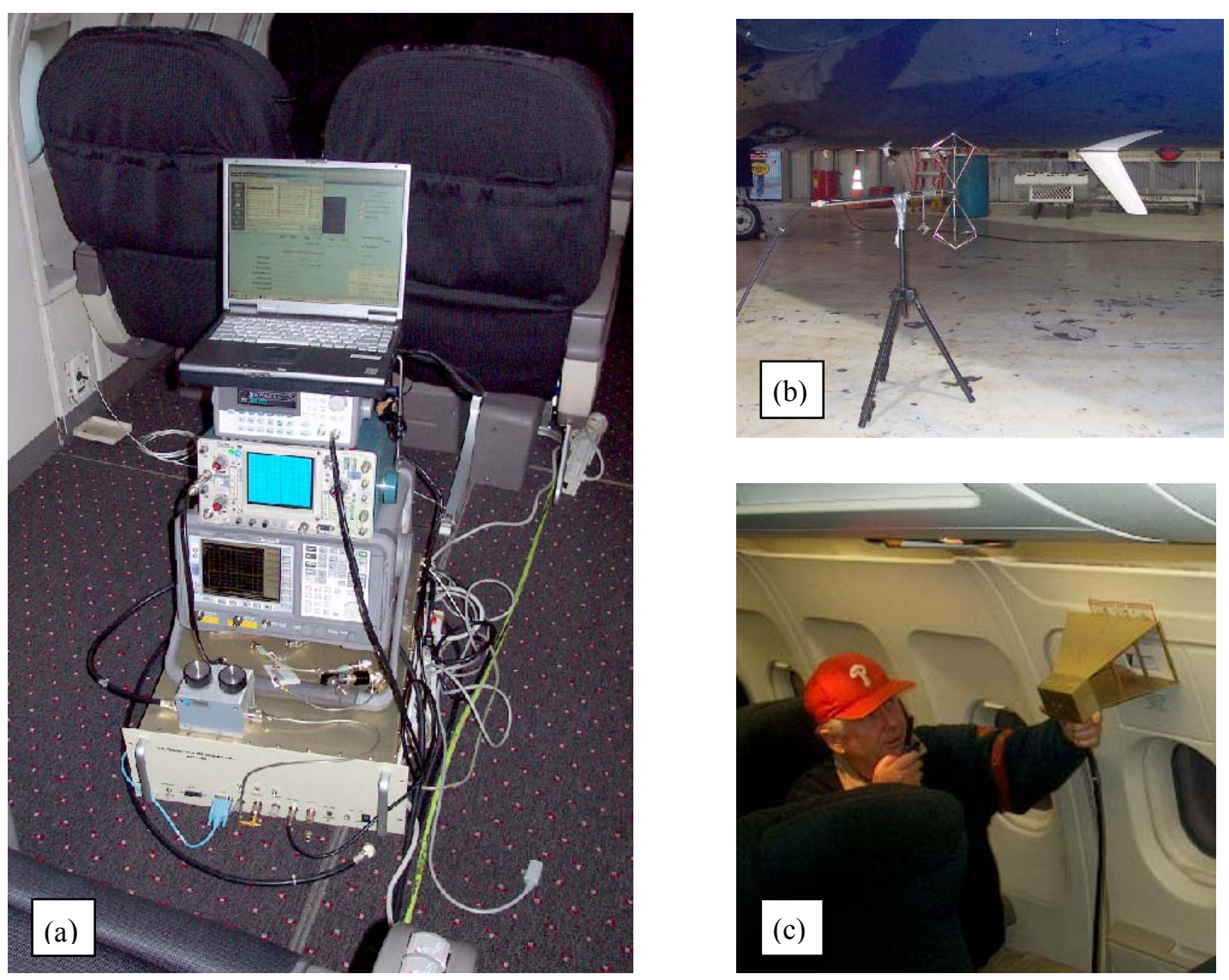

Figure 6: UWB interfering signal generating equipment used on board aircraft. (a) From bottom to top: UWB source, precision $99 \mathrm{~dB}$ attenuator, spectrum analyzer, oscilloscope, function generator, notebook computer. (b) UWB transmit antenna placed 1 meter away from aircraft VHF antenna. (c) UWB transmit antenna positioned at optimal coupling point above an over-wing exit.

\section{UWB Transmit Antenna Inside the Airplane}

After the worst-case PRF for a particular aircraft system was determined from 1-meter testing, the UWB threat antenna was brought inside the airplane. All windows and doors on the airplane were closed. (On one large aircraft, power/signal cables were routed through the avionics bay to outside the airplane. On other aircraft power/signal cables were routed through a window or door as far as possible from the measurement locations.) When victim reference signals were generated by ramp test sets, the associated antenna remained in the same location as for the 1-meter testing (a few meters from the subject aircraft antenna), and the ramp test set attenuation setting was left unchanged. If, by chance, the test setup was disturbed, a recalibration of the ramp test set was accomplished to ensure consistent reference signals. In general, the UWB signal was first adjusted to be equivalent with FCC 15.209 limits, and the UWB threat antenna placed in expected optimal coupling locations (based upon a preliminary analysis by EWI- see Appendix C.3, Attachment 5 "EWI Pre Test Path Loss Report"). If a UWB EMI effect was observed, the UWB signal power was then attenuated in 10 to $20 \mathrm{~dB}$ increments until EMI effects no longer occurred. Then, the UWB signal power was increased in 1 to 2 $\mathrm{dB}$ increments to determine EMI effects thresholds at that location. The process was repeated in multiple passenger cabin locations. 


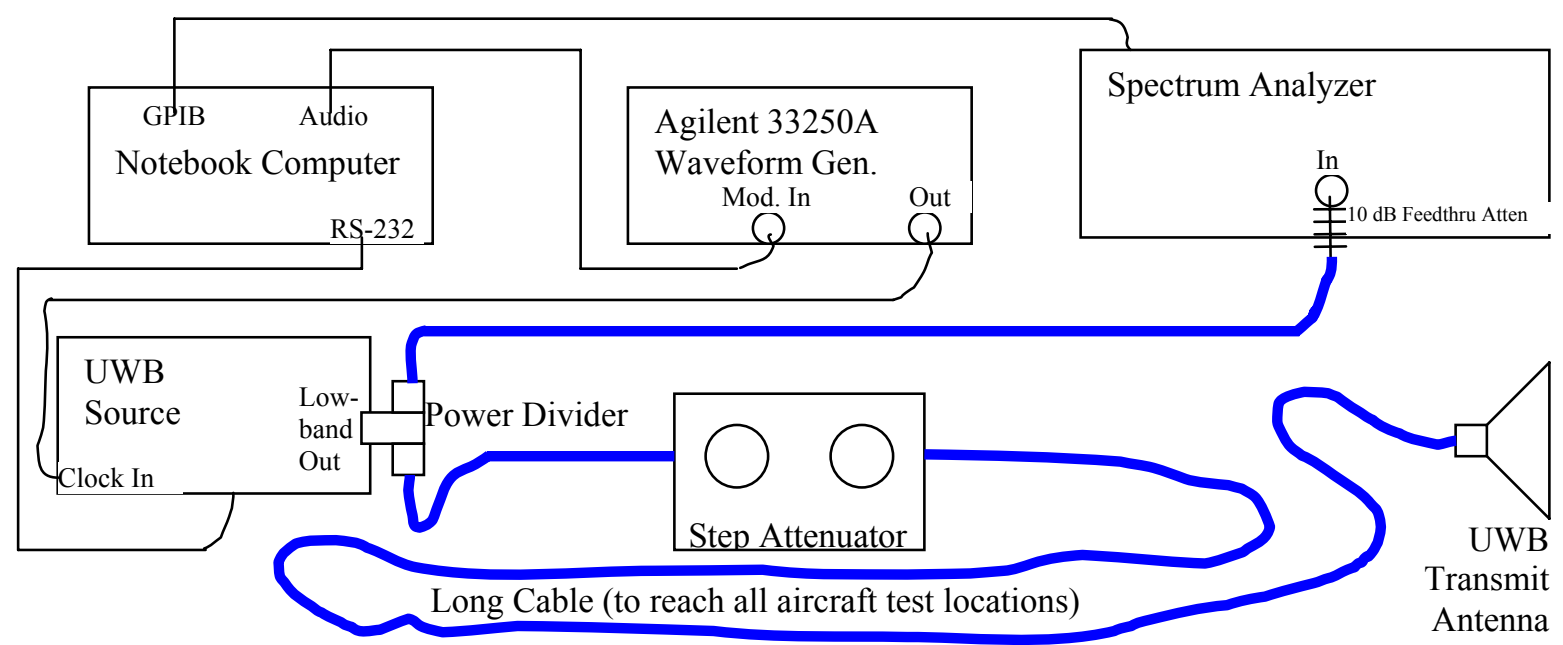

Figure 7: Simplified Diagram of UWB source equipment used for EMI testing of aeronautical radios.

\subsection{EMI Criteria Definition}

The following general criteria were used to assess EMI effects to aeronautical receiver systems. These criteria are more specifically defined for each system in the next section.

- Observable EMI effects are defined as detectable evidence that EMI is affecting aircraft system behavior. These effects may or may not be evident to the flight crew (and in some cases may only be observable using ground test equipment). Observable effects do not necessarily constitute an operational or system failure.

- Operational EMI failures are defined as EMI-induced failures that prevent the system from performing its intended function in the presence of a known good source signal. The function of the system is defined by the standards criteria for which the system was developed. These standards include ICAO, ARINC, RTCA, EUROCAE, Mil-Spec and/or manufacturers specifications.

- System EMI failures are defined as EMI-induced failures that trigger the system's failure indication(s). These failure indications are defined by the system standard or characteristic, and include failure flags, indications or audible/visual warnings. 
(This page was left intentionally blank) 


\section{$4 \quad$ Results Summary}

This section summarizes the system operation, EMI Criteria Derivation and Key Observations for each aircraft system. Detailed test results are provided in Appendix E. Details about system operation are provided in Appendix D. The full test plan is provided in Appendix C, with adequate detail to allow verification of test results.

\subsection{VHF Com (Very High Frequency Communication)}

The VHF communications system includes ground-based and airborne receiving and transmitting equipment, which provides air-to-ground, ground-to-air, air-to-air, and ground-to-ground voice and data communications. The equipment uses amplitude modulation and operates on assigned channels spaced $25 \mathrm{and} /$ or $8.33 \mathrm{kHz}$ apart in the radio-frequency range $118.000 \mathrm{MHz}$ to $136.975 \mathrm{MHz}$. The channel labeling used is based a frequency-channel pairing plan, which allows unique identification of the $8.33 \mathrm{kHz}$ channels. To ensure good communications between the aircraft and control tower, one VHF Com radio antenna is usually mounted on the forward portion of the top centerline of the fuselage. On most airplanes, this particular system is designated as the VHF-1 system. The VHF-1 antenna is nearly always close to the L1 doorway and sometimes it is also very close to the cockpit window. A second VHF Com antenna is usually located underneath the forward fuselage, aft of the nose wheel. It is generally used for the VHF-2 system. The third antenna is either on the top aft or bottom aft position and is generally used for ACARS.

\subsubsection{EMI Criteria Derivation}

Previous studies quantified VHF Com EMI effects in terms of the threat level at which squelchbreaks occur. After some experimentation with audio tones, it was decided to use pre-recorded air traffic control voice audio as the reference signal, and quantify EMI effects by measuring the UWB signal level required to degrade or deny audibility of the reference signal. While EMI-induced squelch-breaks may be annoying to pilots, degradation or denial of air traffic control communications are likely to be far more serious.

Observable EMI effects: Audible tones received upon the tuned radio channel. These audible tones would be superimposed upon over the reference audio signal, if present. The frequency of the audio tone was related to the UWB PRF. For some UWB PRFs, no tone was observed to be present.

Operational EMI Failure: Depending upon the UWB PRF and the particular subject aircraft, operational EMI failure manifested itself in two ways. When UWB EMI caused audible tone interference, operational failure was judged by the pilot to be the point at which the UWB interference caused the reference signal to become unintelligible. When UWB EMI did not cause audible tone interference, operational failure was defined as the point at which the interfering signal blocked the reference signal (thus causing silence) on the tuned radio channel. (Also described as "capturing" the channel.)

System EMI Failure: No specific failure flags, indications or audible/visual warnings occurred during UWB EMI testing for VHF Com, other than audible interference or capturing as defined under Operational Failure Criteria. 


\subsubsection{Key Observations- VHF Com:}

- Interference from inside the airplane: VHF Com could be disrupted on every airplane type when transmitting UWB signals at FCC 15.209 levels from certain locations inside the passenger cabin. In most cases, interference could be observed when transmitting UWB signals at FCC 15.209 levels from anywhere inside the passenger cabin.

- Failure onset times and first-effects levels: Depending upon the UWB PRF used and the particular aircraft, failure was characterized by either by a sudden loss of desired signal or by audible interference effects (such as whistles, whines, and tones) that increased in intensity with increasing UWB power level, such that the failure level had to be a subjective decision by the pilot. When audible interference effects occurred, they first appeared at extremely low UWB power levels. There were no time delays in the onset of effects or failures.

- Effect of different UWB PRFs and Modulations: Operational failure effects and levels were highly dependent upon UWB PRF. In all cases, one particular UWB PRF caused a sudden loss of desired signal with no audible interference effect. Another particular UWB PRF caused the most severe audible interference effect. UWB modulations either improved the EMI situation by as much as $8 \mathrm{~dB}$, or exacerbated the EMI situation by as much as $13 \mathrm{~dB}$. Test results clearly show that UWB modulation cannot be assumed to reduce the likelihood of harmful interference. Additional laboratory testing should be performed to better understand the effect of UWB modulation on VHF Com, and such tests should include aeronautical equipment from different manufacturers.

- $\quad$ Reference Signal Levels: For all VHF Com tests described herein, reference signal levels were set 11 to $12 \mathrm{~dB}$ below ICAO guaranteed minimum signal levels. Typical VHF Com receivers are about $12 \mathrm{~dB}$ more sensitive than required by ICAO in order to provide adequate performance margin. Pilot workload is increased when EMI signals below ICAO specified threshold break squelch or overlay noise on an active channel. This is particularly true when the performance of one VHF Com system is noticeably different from another VHF Com system, or if noticeably different from past experience on the same flight path. These tests indicate that reduced VHF Com receiver sensitivity (to ICAO guaranteed minimum signal levels) would not be sufficient to prevent VHF Com operational failure due to UWB EMI levels equivalent to FCC 15.209 limits, because VHF Com operational failure occurred when transmitting UWB signals 24dB below FCC 15.209 limits from within the passenger cabin.

- Path Loss data compared to UWB test results: When compared to Path Loss data, the UWB signal levels for operational failure at 1-meter versus inside the airplane matched within about $2 \mathrm{~dB}$ for Airplanes \#1 and \#3. Comparison data was not obtained for Airplane \#4. For Airplane \#3, a loud "whine" occurred at UWB levels far below those required to cut off communication, but did not cut off communications when transmitted from inside the airplane, making comparison with path loss data difficult.

- $\quad$ 8.33 KHz Channel Spacing: In one test, it was found that changing the VHF Com radio from a $25 \mathrm{kHz}$ to $8.33 \mathrm{kHz}$ (European standard) bandwidth, while using the same VHF channel and UWB PRF, eliminated the UWB EMI effect.

- Aircraft System Interdependencies: VHF Com is the primary means of communication for the entire national airspace system, and is safety critical for all flight and ground modes of aircraft operation. VHF Com is increasingly being used for emerging digital data exchange with aircraft via VHF Data Link (VDL), and the aircraft communications and reporting system (ACARS). 


\subsection{VOR (VHF Omni Ranging)}

The VOR system is a navigational aid that determines relative bearing with respect to a ground station. The system receives RF signal data from the ground station and converts it into bearing and position data. This data is routed to the flight deck instrument for display of the bearing data. VOR deviation and TO/FROM data is computed for display. VOR operates in the band of $108 \mathrm{MHz}$ to 118 $\mathrm{MHz}$.

\subsubsection{EMI Criteria Derivation}

Observable EMI effects: Side-to-side oscillation of the course deviation indicator (CDI) needle. The oscillation typically consisted of a $+/-1$ to 2-dot swing on the VOR scale at a rate of approximately 3 Hertz. Such an oscillation is an indication that the instrument is unreliable for flight. If the VOR Morse code identifier audio was monitored during testing, UWB EMI caused audible tones on the channel with varying levels of annoyance.

Operational EMI Failure: Blanking (or stowing) of the CDI on the VOR displays. Operational EMI failure of the VOR CDI may or may not have been indicated by a failure flag, and may have appeared as though the reference signal was too weak to be received (i.e. out of range). From the users perspective, the instrument would be unusable and unreliable far before a 2-dot swing of the indicator occurred, but blanking of the VOR CDI was considered the most consistent operational EMI failure criteria between different types of airplanes.

System EMI Failure: Indicated by a VOR failure flag appearing on the navigation display.

\subsubsection{Key Observations- VOR:}

- Interference from inside the airplane: VOR could be disrupted from inside the Airplane \#4 passenger cabin when transmitting UWB signals equivalent to FCC 15.209 levels from the L1 doorway. On Airplanes \#2 and \#3, interference could be observed only when transmitting UWB signals at levels several dB above FCC 15.209 limits. Increased VOR susceptibility to UWB modulations may make interference possible below FCC 15.209 limits on Airplanes \#2 and \#3.

- Failure onset times and first-effects levels: Regardless of the UWB PRF used and the particular aircraft, operational failure was always characterized by blanking of the CDI needle. On Airplane \#2, CDI fluctuations of up to $8^{\circ}$ in direction occurred at UWB levels 1 to $2 \mathrm{~dB}$ below that required for operational failure. On Airplane \#4, the audible Morse code identifier tone was monitored, and found to be affected by the UWB signals, but still intelligible at UWB levels causing operational failure. Emphasis was placed on failure onset levels in the $\Delta \mathrm{F} / \mathrm{NF}$ and $\Delta_{\mathrm{F} / \mathrm{FE}} 1$ Meter data, but not on failure recovery levels. CDI fluctuations and audible interference could be observed at levels far below those required to cause operational failure, thus causing large variability in $\Delta \mathrm{F} / \mathrm{FE}$ data. There were no time delays in the onset of effects or failures.

- Effect of different UWB PRFs and Modulations: Operational failure effects and levels were not particularly dependent upon UWB PRF, except in the case of Airplane \#4, where the aircraft was far less susceptible to the $1 \mathrm{MHz}$ UWB PRF than with higher PRFs. (ie. the 1 MHz UWB PRF caused system failure at higher UWB signal amplitudes than other UWB PRFs.) Each airplane was tested at a different VOR frequency, and subsequently, different 
PRFs. This may explain the variability observed in the 1-meter UWB EMI levels. UWB modulations either improved the EMI situation by as much as $13 \mathrm{~dB}$, or exacerbated the EMI situation by as much as $17 \mathrm{~dB}$. No particular UTM parameter consistently increased or decreased interference effects. (Each UTM level was calibrated to FCC 15.209 limits according to the FCC-defined measurement process for spurious radiated emissions, which negates the reduction of on-channel power caused by modulation. See Appendix C.7.) On airplanes \#2 and \#3, swept dithering UWB modulation caused quick failure/recovery as a UWB spectral line crossed the receiver-tuned frequency. Test results clearly show that UWB modulation cannot be assumed to reduce the likelihood of harmful interference. Additional laboratory testing should be performed to better understand the effect of UWB modulation on VOR, and such tests should include aeronautical equipment from different manufacturers.

- Reference Signal Levels: For all VOR tests described herein, reference signal levels were set 8 to $13 \mathrm{~dB}$ below ICAO guaranteed minimum signal levels. Typical VOR receivers are about $15 \mathrm{~dB}$ more sensitive than required by ICAO in order to provide adequate performance margin. Pilots accustomed to this extra performance margin may notice VOR EMI problems observed outside the ICAO guaranteed minimum coverage area, particularly if the performance of one VOR indication is noticeably different from the other, or if noticeably different from past experience on the same flight path. These tests indicate that airplanes encountering VOR signals that meet (or exceed) ICAO guaranteed minimum signal levels will be unlikely to experience EMI effects from UWB PED emission levels equivalent to FCC 15.209 limits.

- Path Loss data compared to UWB test results: When compared to Path Loss data, the UWB signal levels for operational failure at 1-meter versus inside the airplane matched within about $12 \mathrm{~dB}$ for the Airplane \#3 and \#4 tests. Comparison data was not obtained for Airplane \#2.

- Aircraft System Interdependencies: If the presence of EMI reduces the availability of distant VOR ground transmitters, the overall accuracy of the calculated aircraft position (pilot display or FMS derived) may be reduced.

\subsection{LOC (Instrument Landing System Localizer)}

The Instrument Landing System (ILS) LOC provides a reference signal aligned with the runway centerline and deviation signals when the airplane is displaced left or right of the extended runway centerline. The linear coverage area for this signal is approximately 3 degrees either side of the extended runway centerline from a point emanating at the far end of the runway. The LOC data are displayed on the Attitude Director Indicator (ADI) and Horizontal Situation Indicator (HSI) on standard airplanes. These indicators may be integrated into Primary Flight Displays (PFDs), MultiFunction Displays (MFDs) and Navigation Displays (NDs) on "glass cockpit" airplanes.

\subsubsection{EMI Criteria Derivation}

Observable EMI effects: A \pm 1-to-2 dot side-to-side oscillation of the LOC pointer on the PFD (or ADI), and/or the LOC bar on the ND (or MFD, or HSI). If the LOC Morse code identifier audio was monitored during testing, UWB EMI caused audible tones on the channel with varying levels of annoyance.

Operational EMI Failure: Blanking of the LOC pointer on the PFD (or ADI), and/or the LOC bar on the ND (or MFD, or HSI). Operational EMI failure of the LOC pointer or bar may or may not have been indicated by a failure flag, and may have appeared as though the reference signal was too weak to be received (ie. out of range). From the users perspective, the instrument would be unusable 
and unreliable for any significant LOC variations, but blanking of the LOC pointer or bar was considered the most consistent operational EMI failure criteria between different types of airplanes. HSI.

System EMI Failure: Indicated by a LOC failure flag appearing on the PFD, ND, MFD, ADI or

\subsubsection{Key Observations- LOC:}

- Interference from inside the airplane: LOC could be disrupted on Airplane \#2 when transmitting UWB signals from inside the passenger cabin at levels of $30 \mathrm{~dB}$ below FCC 15.209 limits at the L1 doorway, or at levels 8dB below FCC 15.209 limits from the R1 doorway. On Airplane \#4, LOC could be disrupted when transmitting UWB signals at levels of only $2 \mathrm{~dB}$ or more above FCC 15.209 limits, from the L1 doorway inside the passenger cabin.

- Failure onset times and first-effects levels: Regardless of the UWB PRF used and the particular aircraft, operational failure was always characterized by blanking of the LOC Bar. On Airplane \#4, the audible Morse code identifier tone was monitored, and found to be affected by the UWB signals, but still intelligible at UWB levels causing operational failure. $\Delta \mathrm{F} / \mathrm{NF}$ was only obtained for Airplane \#3. The delays of effects onset were less than one second.

- Effect of different UWB PRFs and Modulations: Operational failure effects and levels were generally not dependent upon UWB PRF, except in the case of Airplane \#2, where the aircraft radio was highly sensitive to one particular UWB PRF. (UWB PRF caused system failure at lower peak amplitudes than other UWB PRFs.) All airplanes were tested at the same LOC tuned frequency. Additional laboratory testing should be performed to better understand the effect of UWB modulation on LOC, and such tests should include aeronautical equipment from different manufacturers.

- Reference Signal Levels: For LOC tests described herein, reference signal levels were between $6 \mathrm{~dB}$ above and $7 \mathrm{~dB}$ below ICAO guaranteed minimum signal levels. Typical LOC manufacturer specifications include assumptions about performance in the presence of noise, but have sensitivities nearly equivalent to ICAO requirements. These tests indicate that airplanes encountering LOC signal levels meeting ICAO guaranteed minimum levels would be at risk for experiencing EMI effects from UWB PED emission levels equivalent to FCC 15.209 limits.

- Path Loss data compared to UWB test results: When compared to Path Loss data, the UWB signal levels for operational failure at 1-meter versus inside the airplane matched within about $11 \mathrm{~dB}$ for the airplane tests. UWB operational failure comparison data was not obtained 1 meter for Airplane \#4.

- $\quad$ Aircraft System Interdependencies: LOC data is used by the flight director displays and autopilot to guide the aircraft on final approach. When used for autoland operations, LOC signals autonomously control the flight path of the airplane. EMI induced dithering of LOC position data during autoland operations could cause erratic aircraft motion, possibly injuring passengers. EMI induced denial of LOC data during autoland would necessitate pilot intervention and could compromise flight safety, particularly during adverse weather conditions.

\subsection{GS (Instrument Landing System Glideslope)}

The ILS GS provides a vertical flight path (nominally 3 degree descent angle) to a point in the landing zone of the runway. The vertical coverage is approximately 0.7 degrees on either side of the 
vertical reference path. The GS data are displayed on the PFD and ND in Airplanes \#1 and \#2, on the ADI and HSI in Airplane \#4, and on the PFD and MFD on Airplane \#3. The position up/down is shown as a diamond-shaped pointer along the right hand side of these displays.

\subsubsection{EMI Criteria Derivation}

Observable EMI effects: A \pm 1-to-2 dot up and down oscillation of the GS pointer on the PFD (or ADI) and the ND (or MFD, or HSI).

Operational EMI Failure: Blanking of the GS pointer on the PFD (or ADI) and the ND (or MFD, or HSI). Operational EMI failure of the GS pointer or bar may or may not have been indicated by a failure flag, and may have appeared as though the reference signal was too weak to be received (ie. out of range). From the users perspective, the instrument would be unusable and unreliable for any significant GS variations, but blanking of the GS pointer or bar was considered the most consistent operational EMI failure criteria between different types of airplanes. HSI.

System EMI Failure: Indicated by a GS failure flag appearing on the PFD, ND, MFD, ADI or

\subsubsection{Key Observations- GS:}

- Interference from inside the airplane: GS could be disrupted on the Airplane \#1 when transmitting UWB signals at levels of $12 \mathrm{~dB}$ or more below FCC 15.209 limits. Negative margins were also found for Airplane \#2. Greatly increased GS susceptibility to random dithering may make interference possible below FCC 15.209 limits on Airplanes \#3 and \#4.

- Failure onset times and first-effects levels: Regardless of the UWB PRF used and the particular aircraft, operational failure was always characterized by blanking of the GS pointer. Failure - recovery - failure sequences occurred within a 1 to $2 \mathrm{~dB}$ signal level change and normally showed no time delay on all airplanes. Flickering, intermittent, and dithering display information were encountered 1 to $2 \mathrm{~dB}$ prior to failure on Airplane \#1. One case of failure time delay was noted on Airplane \#3.

- Effect of different UWB PRFs and Modulations: Operational failure effects and levels were very similar for UWB PRFs greater than $10 \mathrm{MHz}$. All airplanes were tested at the same GS frequency. Random Dithering UWB modulations progressively increased the susceptibility of the GS systems as the Dithering percentage was increased. One random dithering setting caused the GS system to fail at peak UWB power levels up to $25 \mathrm{~dB}$ below unmodulated UWB levels. This alarming effect was consistent among the three airplanes evaluated.

- Reference Signal Levels: For GS tests described herein, reference signal levels were between 5 and $16 \mathrm{~dB}$ below ICAO guaranteed minimum signal levels. Typical GS receivers are between 0 and $13 \mathrm{~dB}$ more sensitive than required by ICAO in order to provide adequate performance margin, and include assumptions about performance in the presence of noise. Pilots typically expect this extra performance margin and will often report GS problems they observe outside the ICAO guaranteed minimum coverage area. This is particularly true when the performance of one GS indicator is noticeably different from the other, or if noticeably different from past experience on the same flight path. These tests indicate that airplanes encountering GS signal levels meeting ICAO guaranteed minimum levels may experience EMI effects from UWB PED emission levels equivalent to FCC 15.209 limits.

- Path Loss data compared to UWB test results: When compared to Path Loss data, the UWB signal levels for operational failure at 1-meter versus inside the airplane matched within 
about $5 \mathrm{~dB}$ for the airplane tests, except for Airplane \#2. This discrepancy should be reevaluated upon acquisition of additional Airplane \#2 path loss data.

- Aircraft System Interdependencies: GS data is used by the flight director displays and autopilot to guide the aircraft on final approach. When used for autoland operations, GS signals autonomously control the flight path of the airplane. EMI induced dithering of GS position data during autoland operations could cause erratic aircraft motion, possibly injuring passengers. EMI induced denial of GS data during autoland would necessitate pilot intervention and could compromise flight safety, particularly during adverse weather conditions.

\subsection{DME (Distance Measuring Equipment)}

The DME system uses the travel time of radio pulses between an aircraft and ground radio reply stations to measure their separation distance. Since DME was originally designed to provide distance to touchdown for instrument approaches, its L-Band frequency is paired with co-located VHF VOR stations or ILS localizer transmitters. The DME systems on all aircraft function in a similar manner using two independent antenna/receiver channels (left and right). The DME-derived data are displayed on the pilots' flight instruments. The specific location of the distance information on the instruments varies among different aircraft. Today DME is also used by the FMC (Flight Management Computer) for general navigation by using multiple DME distance arcs or in combination with VOR bearings to update the aircraft location. DME operates in the band of $960 \mathrm{MHz}$ to $1215 \mathrm{MHz}$

\subsubsection{EMI Criteria Derivation}

Observable EMI effects: Erroneous DME distance data on the ND, MFD, or HSI displays and intermittent to full blanking of the DME ID tone, but NOT blanking of the DME distance data on the ND, MFD, or HSI displays.

Operational EMI Failure: Intermittent to full blanking of numerical DME distance data on the $\mathrm{ND}, \mathrm{MFD}$, or HSI displays. (In practice, an error of 0.5 miles or $3 \%$ of the distance to the facility, whichever is greater, on the cockpit indicator would constitute an operational failure.) Blanking of the numerical DME distance data may appear as though the reference signal is too weak to be received (ie. out of range).

System EMI Failure: No specific failure flags, indications or audible/visual warnings occurred during UWB EMI testing for DME, other than the loss of DME data as defined under the Operational Failure criteria.

\subsubsection{Key Observations- DME:}

- Interference from inside the airplane: DME could be disrupted from within the passenger cabin on all airplanes except Airplane \#1, but only at UWB power levels greater than $16 \mathrm{~dB}$ above FCC 15.209 limits. Considering that the applicable FCC 15.519 UWB limits are 30$34 \mathrm{~dB}$ lower than the FCC15.209 limits (depending upon measurement variations), it is unlikely that handheld UWB products meeting existing FCC rules will pose a threat to aircraft DME systems.

- Failure onset times and first-effects levels: Regardless of the UWB PRF used and the particular aircraft, operational failure was always characterized by blanking of the DME data on ND, MFD, or HSI displays and intermittent to full blanking of the DME ID tone. No time delays in failure or recovery were seen. Occasional DME distance readout variations occurred 
at UWB levels a few $\mathrm{dB}$ below failure threshold. Recovery levels after failure were not well defined in these tests because $10 \mathrm{~dB}$ attenuator steps were used after each failure to allow system recovery.

- Effect of different UWB PRFs and Modulations: Operational failure levels varied by less than 9dB for all UWB PRFs. The UWB PRF causing the most severe interference varied between airplanes, and appeared most related to the degree of overlap (in tuned frequency) between the UWB spectral line and the active DME channel. UWB modulations generally improved the EMI situation by a few $\mathrm{dB}$, but in some cases increased the potential for interference by a few $\mathrm{dB}$. Additional laboratory testing may help to better understand the effect of UWB modulation on DME, but given the relative immunity of DME to FCCapproved UWB levels, this testing is not a likely priority.

- Reference Signal Levels: DME signal levels calculated from ramp test set manufacturer specifications were nearly equivalent to ICAO levels, but DME signal levels measured from the ramp test sets were 10 to $14 \mathrm{~dB}$ higher than applicable ICAO minimum guaranteed levels. It is suspected that that this difference was primarily due to non-consideration of pulse desensitization and other measurement factors. Manufacturer specifications for the DME receivers evaluated were between 0 and $5 \mathrm{~dB}$ more sensitive than required by ICAO. These tests indicate that airplanes encountering DME signal levels meeting ICAO guaranteed minimum levels are not likely to experience EMI effects from UWB PED emission levels equivalent to FCC 15.209 or FCC 15.519 limits.

- Path Loss data compared to UWB test results: When compared to Path Loss data, the UWB signal levels for operational failure at 1-meter versus inside the airplane matched within about $3 \mathrm{~dB}$ for Airplanes \#2 and \#3. This comparison was greater than $9 \mathrm{~dB}$ for Airplane \#1 and $15 \mathrm{~dB}$ for Airplane \#4. The difference on Airplanes \#1 and \#4 was probably due to not finding the optimal coupling position during UWB susceptibility testing.

- Aircraft System Interdependencies: DME data from multiple ground transponders are used by the flight management system (FMS) to calculate accurate position. If the presence of EMI reduces the availability of distant DME ground transponders, the overall accuracy of the calculated aircraft position may be reduced.

\subsection{ATC (Air Traffic Control Radio Beacon System)}

The ATC system consists of airborne transponders and ground-based interrogators. Interrogators send interrogation pulse-groups which trigger each airborne transponder located in the coverage of the antenna main beam. Upon reception of such a pulse group a reply pulse-group is transmitted by a transponder. These replies are received by the interrogator and decoded. The decoded data contained in the messages is forwarded and displayed to the ATC controller. The measurement of the round-trip transit time determines the range to the replying aircraft. The system includes three operating modes; Mode A, Mode C and Mode S. Early ATC systems only included Mode A and Mode C. The pattern of pulses in the multiple-pulse reply provides individual pressure altitude and identity (Mode A) information pertaining to the responding aircraft. Mode $\mathrm{S}$ is a cooperative surveillance and communication system for aircraft and is based on the Mode A and Mode C ATC system.

\subsubsection{EMI Criteria Derivation}

Observable EMI effects: EMI effects, for the most part, were not observable by the crew up to and beyond the point of operational EMI failure. In some cases, a "reply" indication could be monitored to determine when the aircraft stopped replying to interrogations. This would be a negative warning, and not likely to be noticed by the crew. Beginning with Visit \#3, ATC reply efficiency was monitored instead using the analog "XPDR RPLY" indication of the ramp test set. 
Operational EMI Failure was defined as a drop below 90\% in aircraft replies to interrogations. This criteria is set according to ARINC Specification \#718A.

System EMI Failure was defined as an "ATC FAIL" annunciation on the TCAS/ATC console panel. (See Figure 21.) This annunciation was only present on Airplanes \#1 and \#2, and the UWB EMI level required for failure was highly dependent upon whether the airplane was in Flight or Ground mode.

\subsubsection{Key Observations- ATC:}

- Interference from inside the airplane: ATC could be disrupted from within the passenger cabin on all airplanes except Airplane \#1, but only at UWB power levels greater than $5 \mathrm{~dB}$ above FCC 15.209 limits. It should be noted that the ramp test set ATC signal levels were 7 to $16 \mathrm{~dB}$ lower than applicable ICAO levels, so these tests may be considered conservative from a safety point-of-view. Considering that the applicable FCC 15.519 UWB limits are $30-34 \mathrm{~dB}$ lower than the FCC15.209 limits (depending upon measurement variations), it is unlikely that handheld UWB products meeting existing FCC rules will pose a threat to aircraft ATC systems.

- $\quad$ Failure onset times and first-effects levels: Determination of Operational Failure required the use of a ramp test set (otherwise no evidence of operational failure is normally provided to the crew). The first observable effect consisted of a reduction in reply percentage of $10 \%$ or more, which was also considered an operational failure. The onset and recovery of operational failure was instantaneous, and generally occurred with UWB attenuator adjustments of only $2 \mathrm{~dB}$. As UWB power was increased, the aircraft transponder reply percentage would proportionately decrease, with $0 \%$ replies occurring at UWB power levels of 6 to $12 \mathrm{~dB}$ higher than those causing first observable effects. "ATC Fail" annunciation by aircraft caution and warning systems was highly dependent upon whether the system was in Ground or Air mode, and occurred at UWB interference levels much higher than required for operational failure. System failure (activation of the ATC Fail light) typically occurred at UWB levels $20 \mathrm{~dB}$ (Ground Mode) to $65 \mathrm{~dB}$ (Air Mode) higher than required for Operational Failure $(90 \%$ or less replies). The ATC Fail Light was about 40 to $45 \mathrm{~dB}$ more sensitive to EMI in Ground mode than in Air mode. The EMI failure signature of the ATC Fail annunciation warrants further analysis.

- Effect of different UWB PRFs and Modulations: Operational failure levels varied by less than 9dB for all UWB PRFs. Test results indicate that very-low UWB PRFs may have a heightened EMI effect. UWB modulations generally increased the potential for interference by a few $\mathrm{dB}$. Additional laboratory testing may help to better understand the effect of UWB modulation on ATC, but given the relative immunity of ATC to FCC-approved UWB levels, this testing is not a likely priority.

- Reference Signal Levels: ATC test signal levels were 7 to $16 \mathrm{~dB}$ lower than ICAO minimum guaranteed levels. This is particularly interesting because manufacturer specifications for the ATC receivers evaluated were nearly equivalent to ICAO minimum levels. On one particular airplane, 1-meter measurements were performed at two different ramp test set levels $(3 \mathrm{~dB}$ and $10 \mathrm{~dB}$ over threshold). Comparing the two sets of data indicates that the failure threshold of the ATC system is not dependent exclusively on Signal/Interference ratio. Due to it's digital processing, the system may be capable of better performance against noise if it's desired signal level is higher. This behavior should be evaluated in more detail in subsequent testing. These tests indicate that airplanes encountering ATC signal levels meeting ICAO guaranteed minimum levels are not likely to experience EMI effects from UWB PED emission levels equivalent to FCC 15.209 or FCC 15.519 limits. 
- Path Loss data compared to UWB test results: When compared to Path Loss data, the UWB signal levels for operational failure at 1-meter versus inside the airplane matched within $1 \mathrm{~dB}$ for Airplane \#2. This comparison was greater than $10 \mathrm{~dB}$ for Airplane \#3 and $13 \mathrm{~dB}$ for Airplane \#4. The difference on Airplane \#3 and Airplane \#4 was probably due to not finding the optimal coupling position during UWB susceptibility testing. No comparison could be made on Airplane \#1 because insufficient UWB power was available to induce operational failures.

- Aircraft System Interdependencies: On the large transport airplanes, the "ATC Fail" indication was accompanied by the loss of all targets on the TCAS display. This dependency was the same regardless of whether the aircraft was in Ground or Air mode. This dependency was not present on the regional airplanes, as there was no "ATC Fail" indication.

\subsection{TCAS (Traffic Alert and Collision Avoidance System)}

The function of TCAS is to determine the range, altitude and bearing of other aircraft equipped with Mode S/ATCRBS transponders with respect to the location of your own aircraft. The system monitors the trajectory of these aircraft for the purpose of determining if any of them constitute a potential collision hazard. The system is responsible for estimating the separation at closest approach and determining if a potential conflict exists. If so, the system displays an advisory to the pilot. In certain cases, the system also provides guidance for the optimum vertical avoidance maneuver. The correctness of the avoidance maneuver is ensured by coordination of mutual intentions with the other TCAS equipped aircraft through the Mode $\mathrm{S}$ transponder.

\subsubsection{EMI Criteria Derivation}

Observable EMI effects: In some cases, the displayed TCAS airplane range was observed to vary by a small percentage before operational failure (loss of displayed TCAS airplane) occurred.

Operational EMI Failure was defined as the loss of a displayed TCAS airplane due to the presence of EMI. In most cases, the displayed TCAS airplane was verified to reappear upon removal of the EMI source.

System EMI Failure was defined as an "ATC FAIL" annunciation on the TCAS/ATC status panel. This annunciation was only present on the transport category airplanes (\#1 and \#2), and appeared to be more related to EMI to the ATC system, rather than TCAS. However, when the "ATC Fail" annunciation occurred, all displayed TCAS airplanes would disappear. UWB EMI level required for failure was highly dependent upon whether the airplane was in Flight or Ground mode.

\subsubsection{Key Observations- TCAS:}

- Interference from inside the airplane: TCAS could be disrupted from within the passenger cabin on all airplanes except Airplane \#1. All upsets occurred at UWB power levels $7 \mathrm{~dB}$ or more above FCC 15.209 limits. Considering that the applicable FCC 15.519 UWB limits are 30-33dB lower than the FCC15.209 limits (depending upon measurement variations), it is unlikely that handheld UWB products meeting existing FCC rules will pose a threat to aircraft TCAS systems.

- Failure onset times and first-effects levels: Failure occurred with 5 seconds to 1 minute of delay from when the UWB signal is applied, with an average of about 18 seconds. Recovery times and levels were not measured during these tests. In some cases, the displayed TCAS airplane range was observed to vary by a small percentage before operational failure (loss of 
displayed TCAS airplane) occurred. During Test Visit \#1, all aircraft were operated in Ground Mode. However, in subsequent visits, in order for each aircraft to display the TCAS airplane generated by the ramp test set, it was necessary to put each aircraft into air mode. No testing was performed to determine if the failure thresholds would have been different with the aircraft in ground mode versus air mode.

- Effect of different UWB PRFs and Modulations: Operational failure levels varied by less than $6 \mathrm{~dB}$ for all UWB PRFs. If not for an increased susceptibility to the $43.6 \mathrm{MHz}$ PRF on Airplane \#1, the variation would have been less than $4 \mathrm{~dB}$. UWB modulations generally decreased the potential for interference by a few $\mathrm{dB}$.

- $\quad$ Reference Signal Levels: TCAS test signal levels calculated from ramp test set manufacturer specifications were nearly equivalent to ICAO minimum guaranteed levels. Manufacturer specifications for the TCAS receivers evaluated were also nearly equivalent to ICAO minimum levels. These tests indicate that airplanes encountering TCAS signal levels meeting ICAO guaranteed minimum levels are not likely to experience EMI effects from UWB PED emission levels equivalent to FCC 15.209 or FCC 15.519 limits.

- Path Loss data compared to UWB test results: When compared to Path Loss data, the UWB signal levels for operational failure at 1-meter versus inside the airplane matched within $1 \mathrm{~dB}$ for Airplane \#2 (assuming similar path loss to the ATC system). This comparison was $9 \mathrm{~dB}$ for a smaller series of Airplane \#2 and Airplane \#4. Differences are attributed mostly to not finding the optimal coupling position during UWB susceptibility testing. No comparison could be made on Airplane \#1 because insufficient UWB power was available to induce operational failures.

- Aircraft System Interdependencies: On the large transport airplanes, the "ATC Fail" indication was accompanied by the loss of all displayed TCAS airplanes on the TCAS display. This dependency was the same regardless of whether the aircraft was in Ground or Air mode. This dependency was not present on the regional airplanes, as there was no "ATC Fail" indication.

\subsection{GPS (Global Positioning System)}

GPS provides accurate, worldwide navigation capability with a high degree of availability. GPS navigation information is used to supply the aircraft three-dimensional position, velocity, track data, time, and other information to other aircraft subsystems for use in that subsystem's navigation, guidance or performance computations. Altitude, direction and speed information from other aircraft systems enables the aircraft FMS to operate through satellite geometry outages and masked satellite coverage.

\subsubsection{EMI Criteria Derivation}

Observable EMI effects: While there are parameters for monitoring GPS signal health (ie. Signalto-Noise Ratio:SNR, Figure Of Merit: FOM), these parameters are not consistently defined among equipment manufacturers or readily observable on many airplanes. In order to consistently compare data between different airplanes, it was necessary to use common criteria for observable effects. This criteria was taken to be the UWB power level causing loss of a single satellite. On Airplane \#4, SNR was displayed for each individual satellite, revealing decreased SNR at UWB EMI levels far below point at which system experienced a loss of satellite lock. This data is provided in Appendix E. It is important to recognize that EMI effects to GPS may or may not be evident to the flight crew, depending upon the phase of flight and system interdependencies. 
Operational EMI Failure: No Computed Data. The GPS sensor sets the sign status of the navigation and time output to no computed when the integrity of the system is reduced below system certification requirements due to insufficient information (usually evident by blanking of GPS data on relevant display). Operational Failure may or may not be evident to the flight crew, depending upon the phase of flight and system interdependencies.

System EMI Failure: Fail Warning. The GPS sensor provides the sign status of all navigation and time related outputs to fail warning when the bite function has detected a critical fault, which will adversely affect the information provided to other systems or displays. System Failure may or may not be evident to the flight crew, depending upon the phase of flight and system interdependencies.

\subsubsection{Key Observations- GPS:}

- Interference from inside the airplane: Operational failure, defined as "no computed data", did not occur unless the UWB transmitter level was 5dB or more over the FCC 15.209 limits (44dB over the FCC 15.519 limits, Airplane \#4). SNR degradation was shown to occur on Airplane \#4 at levels up to 40dB below the FCC15.519 limits, with the UWB transmitter inside the passenger cabin. It is not known whether this small level of system impairment could be of any consequence to the performance requirements for various GPS applications.

- Failure onset times and first-effects levels: The parameters for monitoring GPS signal health are not consistently defined among equipment manufacturers or readily observable on many airplanes. EMI effects may or may not be evident to the flight crew, depending upon the phase of flight and system interdependencies. In order to consistently compare data between different airplanes, the "first observable effect" criteria was taken to be the UWB power level causing loss of a single satellite. However, on Airplane \#4, SNR was displayed for each individual satellite, revealing decreased SNR at UWB EMI levels 50 to $60 \mathrm{~dB}$ below the point at which system experienced a loss of satellite lock. As the UWB signal level was increased, each GPS receiver increasingly lost lock of some satellites until an insufficient number were left to support the operational mode. At that point, operational failure and system failure occurred suddenly. This generally occurred within a $1 \mathrm{~dB}$ signal level change. Recovery from failure took from 3 to 21 seconds after UWB was turned off.

- Effect of different UWB PRFs and Modulations: Operational failure levels varied by up to 14dB depending upon UWB PRF. Higher UWB PRFs had increased EMI effect on GPS failure threshold. UWB modulations generally decreased the potential for interference by a few $\mathrm{dB}$, except in a few specific cases.

- Reference Signal Levels: GPS test signal levels were dependent upon the GPS constellation view and local weather conditions. Test location coordinates, test time and weather conditions were recorded to allow subsequent analysis of signal levels, however such an analysis was not performed for this report.

- Path Loss data compared to UWB test results: When compared to Path Loss data, the UWB signal levels for operational failure at 1-meter versus inside the airplane matched within $2 \mathrm{~dB}$ for Airplane \#3, and within 5dB for Airplane \#2. No comparison could be made on Airplane \#4 because no UWB EMI testing was performed from inside the airplane.

- Aircraft System Interdependencies: GPS data continues to be increasingly incorporated into numerous aircraft systems. GPS data may be used in flight entertainment, enhanced ground proximity warning, to autoland functions. To assess the safety impact of GPS system failure or impairment due to EMI, it is necessary to consider the criticality of GPS data integrity as applicable to particular flight operations. 


\subsection{SATCOM (Satellite Com.- INMARSAT Aeronautical Mobile Sat. Sys.)}

SATCOM is an aircraft voice and data communications system employing several INMARSAT-II satellites to provide substantially global communications to and from aircraft. United Airlines operates SATCOM systems on several wide-body transport category airplanes. The pilot's cockpit SATCOM instrumentation consists of system status pages that are displayed on the center console aft CDU (Control Display Unit). The pilot can exercise a limited number of control functions in the use of this system.

\subsubsection{EMI Criteria Derivation}

Observable EMI effects: Substantial increase in SYSTEM BIT ERRORS on the SATCOM LOG display. During normal operations (no interfering signal), the SYSTEM BIT ERRORS would remain below 20, the SIGNAL LEVEL would be between 30 and 32, and the STATUS would be "Logged On". Upon introduction of the UWB signal, System BIT Errors would begin to increase, and the signal level would decrease to about 23, but the STATUS would remain "Logged On".

Operational EMI Failure: Loss of satellite lock. The STATUS display on the SATCOM LOG page would change from "Logged On" to "Tuning to Sat". This would generally occur at UWB signal levels causing the System Bit Errors increase towards a displayed value of 200. At this time the SATCOM system would tune to different satellite channels, request logon, wait for acknowledgement, and eventually display "Logged On" on the STATUS display.

System EMI Failure: No specific failure flags, indications or audible/visual warnings occurred during UWB EMI testing for SATCOM, other than the loss of SATCOM data as defined under the Operational Failure criteria.

Note: Only the P-channel (pilot channel) was evaluated, and it is unclear whether loss of the Pchannel will result in the loss of the data and voice channels (e.g., R, T, and C channels).

\subsubsection{Key Observations- SATCOM:}

- Interference from inside the airplane: Operational failure, defined as "loss of satellite lock", did not occur unless the UWB transmitter level was 8dB or more over the FCC 15.209 limits (41dB over the FCC 15.519 limits), with the UWB transmitter inside the passenger cabin at the L1 and R1 doorways. Because BER degradation was shown to occur with UWB power levels about 4 to $10 \mathrm{~dB}$ below those required for operational failure, it is not known whether this small level of system impairment could be of any consequence to the performance requirements for SATCOM. This testing tends to indicate that it is unlikely that handheld UWB products meeting existing FCC rules will pose a threat to aircraft SATCOM systems, however more testing on additional types of SATCOM equipment should be performed with various UWB modulations and PRFs.

- Failure onset times and first-effects levels: Failure onset time was instantaneous. BER degradation was shown to occur with UWB power levels about 4 to $10 \mathrm{~dB}$ below those required for operational failure. EMI effects would not likely be evident to the crew, unless they are actively attempting to use the system. The loss of lock/reacquisition process would automatically take about 15 seconds, once the interfering source was removed.

- Effect of different UWB PRFs and Modulations: UWB PRFs were not varied, and no UTMs were tested, due to lack of available airplane test time. 
- Reference Signal Levels: SATCOM test signal levels were dependent upon the INMARSAT-II constellation view and local weather conditions. Test location coordinates, test time and weather conditions were recorded to allow subsequent analysis of signal levels, however such an analysis was not performed for this report.

- Path Loss data compared to UWB test results: It was not possible to effectively compare path loss data to the UWB test results because a UWB EMI threshold level was not obtained inside the airplane.

- Aircraft System Interdependencies: Commercial air carriers primarily use SATCOM for transoceanic air traffic control voice communications, and some limited voice and data services for passengers. The role of SATCOM is likely to be expanded by commercial air carriers interested in providing weather information to enroute flights, and for providing maintenance and security/emergency-related radio services to their fleets. Additional SATCOM voice and data radio services are often used by business jets and the military.

\subsection{Aircraft System Interdependencies}

Table 5 shows the typical level of integration between systems on various types of air transport aircraft. The systems listed across the top of the table are the systems that were tested in this study. The systems listed down the side are systems that are dependent on the tested systems in some way. For these systems to operate properly they may require some input form the systems listed above. The table shows where direct interdependencies between these two systems occur for a range of air transport type aircraft. An N denotes interdependencies between systems on a Non-Integrated legacy aircraft. This can be categorized as an aircraft without an FMS. An F shows interdependencies on an FMS equipped aircraft. However, this aircraft does not have higher-level system integration such as GPS and SATCOM. Finally, an H denotes a highly integrated modern air transport aircraft.

Clearly, the more sophisticated the level of integration, the more system interdependencies that occur. It follows that with higher levels of integration, the chance that multiple systems can be affected by interference (should it occur) increases. Further, if interference directly degrades multiple systems, the interdependencies can cause an even greater threat to safety. 
Table 5: Aircraft System Interdependencies

\begin{tabular}{|c|c|c|c|c|c|c|c|c|c|}
\hline $\begin{array}{l}\text { Tested } \\
\text { Systems } \\
\text { Dependent } \\
\text { Systems }\end{array}$ & 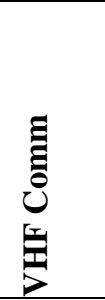 & 遏 & 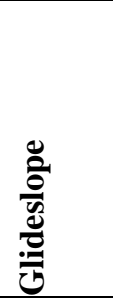 & $\stackrel{x}{3}$ & $\sum_{\text {I }}^{\mathrm{I}}$ & 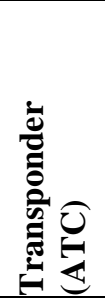 & 帒 & $\sum_{H}^{\infty}$ & $\begin{array}{l}\sum_{0} \\
\text { 足 } \\
\text { W }\end{array}$ \\
\hline FMS & & & & $\mathrm{F} / \mathrm{H}$ & $\mathrm{F} / \mathrm{H}$ & & $\mathrm{H}$ & & $\mathrm{H}$ \\
\hline INS & & & & & & & $\mathrm{H}$ & & \\
\hline $\begin{array}{l}\text { Autopilot/ } \\
\text { Flight Director }\end{array}$ & & $\mathrm{N} / \mathrm{F} / \mathrm{H}$ & $\mathrm{N} / \mathrm{F} / \mathrm{H}$ & $\mathrm{N} / \mathrm{F} / \mathrm{H}$ & & & & & \\
\hline $\begin{array}{l}\text { ACARS } \\
\text { (VHF Data Link) }\end{array}$ & $\mathrm{N} / \mathrm{F} / \mathrm{H}$ & & & & & & $\mathrm{H}$ & & \\
\hline $\begin{array}{l}\text { Air Data } \\
\text { Computer (ADC) }\end{array}$ & & & & & & $\mathrm{N} / \mathrm{F} / \mathrm{H}$ & & $\mathrm{N} / \mathrm{F} / \mathrm{H}$ & $\mathrm{H}$ \\
\hline SATCOM & & & & & & & $\mathrm{H}$ & & $\mathrm{XXX}$ \\
\hline EGPWS & & & & & & & $\mathrm{N} / \mathrm{F} / \mathrm{H}$ & & \\
\hline TCAS & & & & & & $\mathrm{N} / \mathrm{F} / \mathrm{H}$ & & XXX & \\
\hline
\end{tabular}

Key: $\quad \mathrm{N}=$ Non Integrated (Legacy) Aircraft or Pre-FMS Equipped Aircraft

F=FMS Equipped Aircraft

$\mathrm{H}=$ Highly Integrated Aircraft

\subsection{Summary For Aircraft Systems Operating Below $960 \mathrm{MHz}$}

\subsubsection{Interference from inside the airplane:}

Operational failure could be induced on all four aeronautical radio systems evaluated, when transmitting UWB signals at or below FCC 15.209 limit levels from locations inside one or more of the airplanes tested. VHF COM could be disrupted throughout the passenger cabin of every airplane type at UWB signal levels below FCC 15.209 limits. FCC 15.209 limits apply to spurious emissions radiated from handheld UWB systems below 960MHz. In Figure 8, marks in the shaded region indicate the potential for FCC-compliant PEDs to cause operational failure to aeronautical radio systems, when operated inside the airplane passenger cabin. The down-arrows $(\downarrow \downarrow)$ for the Airplane 2 \& 4 VHF COM data indicate that UWB levels during the tests were not the minimum required to cause operational failure. If UWB modulation had been used when transmitting UWB signals (at FCC 15.209 limit levels) from inside the airplanes, test results indicate that EMI effects would have occurred at lower UWB signal levels (up to $25 \mathrm{~dB}$ lower for GS).

The test results shown in Figure 8 are particularly significant when considering policies for the use of PEDs, in-general, on board airplanes. These results represent experimental validation of the fact that PEDs meeting FCC 15.209 and FCC 15.109 limits (such as laptop computers, CD players, DVD players, etc.) can cause EMI effects to aeronautical radios systems if the PED radiated emissions overlap required aircraft radio channels. 


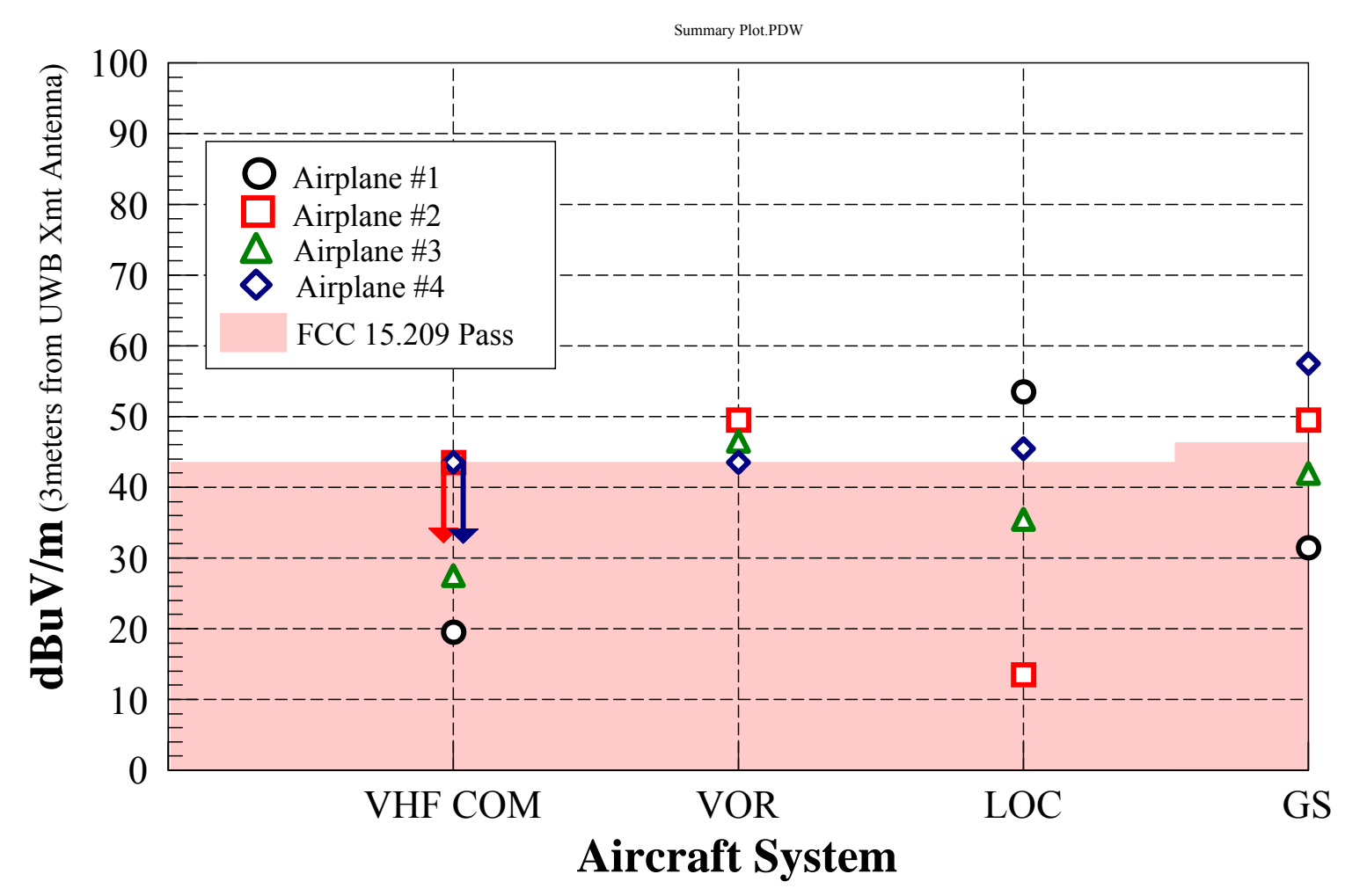

Figure 8: UWB-induced Operational Failure of Aeronautical radio systems operating Below $960 \mathrm{MHz}$. Minimum UWB levels to cause operational failure for each airplane-type are compared to FCC15.209 pass levels. (Marks in the shaded region indicate the potential for FCC-compliant PEDs to cause operational failure to aeronautical radio systems.)

\subsubsection{Failure onset times and first-effects levels:}

Failure onset and recovery times were, for the most part, instantaneous for all four aeronautical radio systems tested (below $960 \mathrm{MHz}$ ). Generally, the UWB signal level required for failure versus recovery was only 1 or $2 \mathrm{~dB}$. The navigation systems generally exhibited indicator deviations (first effects) at UWB signal levels 1 to $2 \mathrm{~dB}$ below failure threshold.

\subsubsection{Effect of different UWB PRFs and Modulations:}

For VHF COM, observable effects and failure levels were highly dependent upon UWB PRF. Depending upon the UWB PRF used and the particular aircraft, failure was characterized by either by a sudden loss of desired signal or by audible interference effects (such as whistles, whines, and tones) that increased in intensity with increasing UWB power level, such that the failure level had to be a subjective decision by the pilot. When audible interference effects occurred, they first appeared at extremely low UWB power levels. There were no time delays in the onset of effects or failures.

For the navigation radios (VOR, LOC, GS), tuning to the audible portion of the signal often revealed audible tones in the victim receiver. For VOR and LOC, observable effects and failure levels were not particularly dependent upon UWB PRF. For GS, the lowest UWB PRF generally reduced the susceptibility of all GS systems by 10 to $20 \mathrm{~dB}$, and random dithering progressively and dramatically increased the susceptibility of GS systems (up to $25 \mathrm{~dB}$ ) as the dithering percentage was increased. 
Each UTM level was calibrated to FCC 15.209 limits according to the FCC-defined measurement process for spurious radiated emissions, which negates the reduction of on-channel power caused by modulation.

\subsection{Summary For Aircraft Systems Operating Above $960 \mathrm{MHz}$}

\subsubsection{Interference from inside the airplane:}

UWB signal power levels in excess of $35 \mathrm{~dB}$ above FCC 15.519 limits were required to cause operational failure on any of the aeronautical radio systems operating above $960 \mathrm{MHz}$. FCC 15.519 limits apply to spurious emissions radiated from handheld UWB systems above $960 \mathrm{MHz}$. Figure 9 shows the minimum UWB signal levels required to induce operational failure for each airplane type, as compared to the FCC 15.519 limits. Marks in the shaded region indicate the potential for FCCcompliant devices to cause operational failure to aeronautical radio systems, when operated inside the airplane passenger cabin. Up-arrows $(\mathbf{\Delta})$ indicate that operational failure could NOT be induced, even at the UWB level shown. Down-arrows $(\nabla \nabla \nabla)$ indicate that UWB levels during the tests were not the minimum required to cause operational failure. These results show that it is unlikely that handheld UWB products meeting existing FCC rules will pose a threat to these aircraft systems.

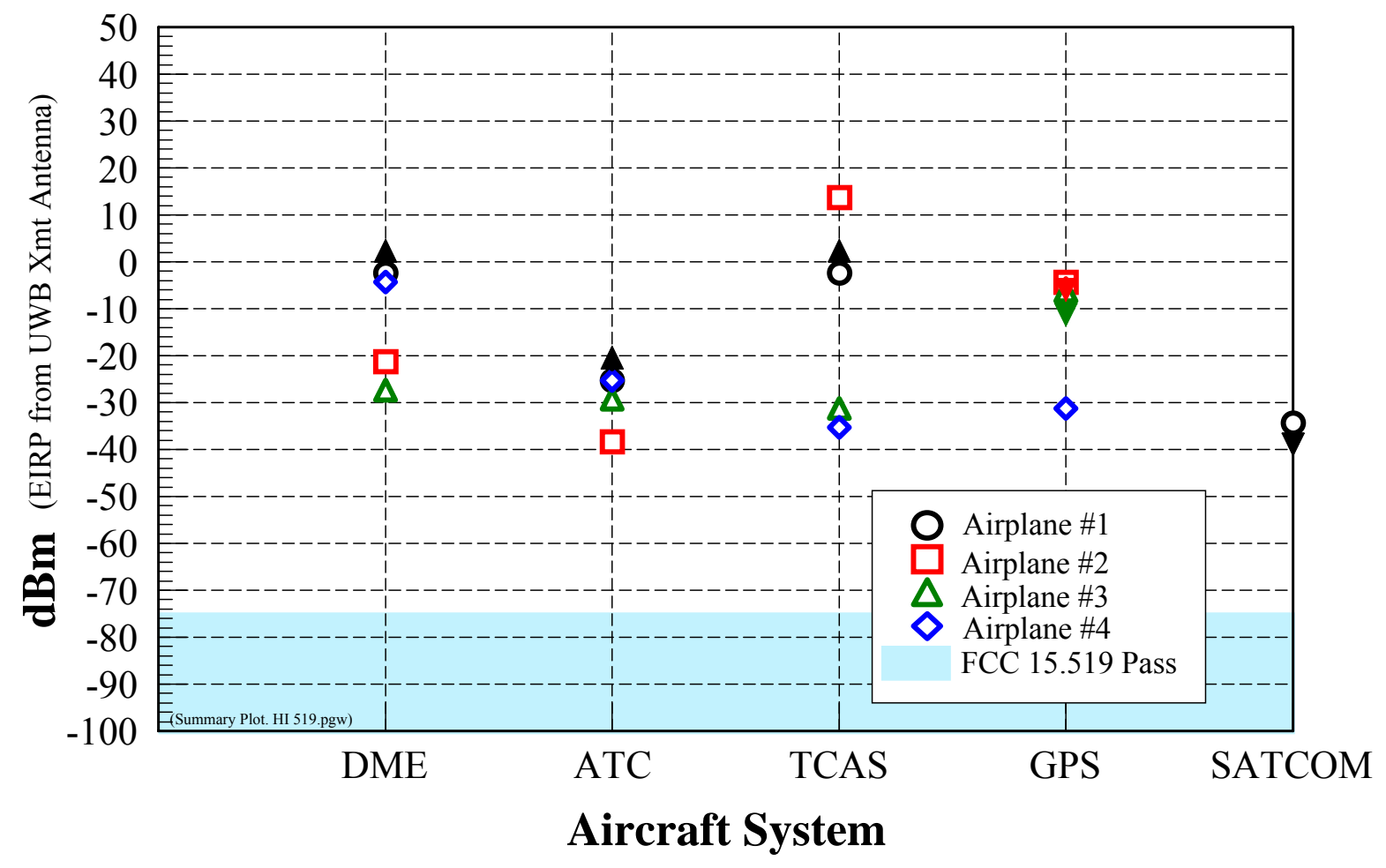

Figure 9: UWB-induced Operational Failure of Aeronautical radio systems operating Above $960 \mathrm{MHz}$. Minimum UWB levels to cause operational failure for each airplane-type are compared to FCC15.519 pass levels. (Marks in the shaded region indicate the potential for FCC-compliant PEDs to cause operational failure to aeronautical radio systems.)

Figure 10 shows the minimum UWB signal levels required to induce operational failure for each airplane type, as compared to the FCC 15.209 limits. Failure levels in the shaded region represent the potential for FCC 15.209-compliant devices to disrupt aeronautical communication and navigation. If 
UWB spurious radiated emission limits were raised to the FCC 15.209 limits, interference margins would be significantly reduced. It is important to note that the levels shown in Figures $9 \& 10$ are operational failure levels. For GPS, operational failure was defined as the loss of a single satellite. However, on Airplane \#4, decreased SNR was shown to occur at UWB EMI levels 50 to $60 \mathrm{~dB}$ below the point at which system experienced a loss of a satellite lock. As the UWB signal level was increased, each GPS receiver increasingly lost lock of some satellites until an insufficient number were left to support the operational mode. At that point, operational failure and system failure occurred suddenly. To assess the safety impact of GPS system failure or impairment due to EMI, it is necessary to consider the criticality of GPS data integrity as applicable to particular flight operations. It is not known whether this small level of system impairment could be of any consequence to the performance requirements for various GPS applications. It would not be appropriate to increase allowable UWB limits on the basis of this data without additional analysis, testing and operational safety assessment.

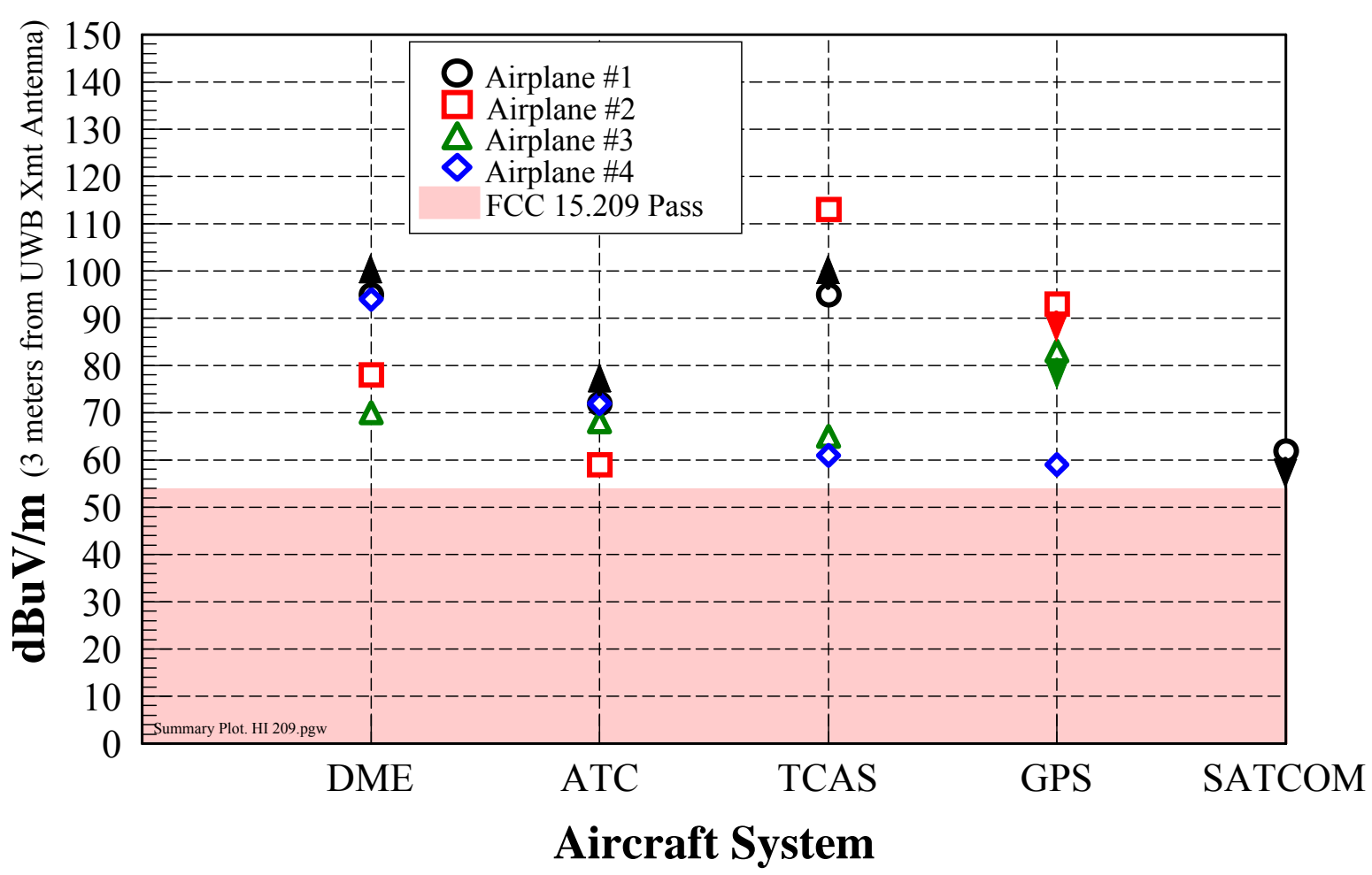

Figure 10: UWB-induced Operational Failure of Aeronautical radio systems operating Above $960 \mathrm{MHz}$. Minimum UWB levels to cause operational failure for each airplane-type are compared to $\underline{\text { FCC15.209 }}$ pass levels (Marks in the shaded region indicate the potential for FCC-compliant PEDs to cause operational failure to aeronautical radio systems. Up-arrows ( $\mathbf{\Lambda}$ ) indicate that operational failure could NOT be induced, even at the UWB level shown. Down-arrows $(\boldsymbol{\nabla} \nabla \boldsymbol{\nabla})$ indicate that UWB levels during the tests were not the minimum required to cause operational failure.)

\subsubsection{Failure onset times and first-effects levels:}

For DME, ATC and TCAS, the onset and recovery of operational failure was instantaneous, and generally occurred with UWB attenuator adjustments of only $2 \mathrm{~dB}$. No time delays in failure or 
recovery were seen. Occasional DME distance readout variations occurred at UWB levels a few $\mathrm{dB}$ below failure threshold. "ATC Fail" annunciation by aircraft caution and warning systems was highly dependent upon whether the system was in Ground or Air mode, and occurred at UWB interference levels much higher than required for operational failure. System failure (activation of the ATC Fail light) typically occurred at UWB levels $20 \mathrm{~dB}$ (Ground Mode) to $65 \mathrm{~dB}$ (Air Mode) higher than required for Operational Failure (90\% or less replies). The ATC Fail Light was about 40 to $45 \mathrm{~dB}$ more sensitive to EMI in Ground mode than in Air mode. On the large transport airplanes, ATC system failure would cause all displayed TCAS airplanes to disappear. In some cases, the displayed TCAS airplane range was observed to vary by a small percentage before operational failure (loss of displayed TCAS airplane) occurred.

For GPS, the parameters for monitoring GPS signal health are not consistently defined among equipment manufacturers or readily observable on many airplanes. EMI effects may or may not be evident to the flight crew, depending upon the phase of flight and system interdependencies. In order to consistently compare data between different airplanes, the "first observable effect" criteria was taken to be the UWB power level causing loss of a single satellite. However, on Airplane \#4, SNR was displayed for each individual satellite, revealing decreased SNR at UWB EMI levels 50 to $60 \mathrm{~dB}$ below the point at which system experienced a loss of satellite lock. As the UWB signal level was increased, each GPS receiver increasingly lost lock of some satellites until an insufficient number were left to support the operational mode. At that point, operational failure and system failure occurred suddenly. This generally occurred within a $1 \mathrm{~dB}$ signal level change. Recovery from failure took from 3 to 21 seconds after UWB was turned off.

For SATCOM, failure onset time was instantaneous. BER degradation was shown to occur with UWB power levels about 4 to $10 \mathrm{~dB}$ below those required for operational failure. EMI effects would not likely be evident to the crew, unless they are actively attempting to use the system. The loss of lock/reacquisition process would automatically take about 15 seconds, once the interfering source was removed.

\subsubsection{Effect of different UWB PRFs and Modulations:}

DME and TCAS failure levels were not susceptible to any particular PRF. ATC tended to be more sensitive (failure at lower UWB levels) to one of the lower PRFs tested. GPS tended to be more sensitive to the higher UWB PRFs that were tested.

Modulation did influence the UWB signal levels required to cause operational failure, but this effect was not consistent among system or airplane types. It is important to note that the internal modulation generator in the UWB source was not particularly stable. This shortcoming would manifest itself in the frequency domain as a random spreading of spectral lines, similar to random dithering, even with no UWB modulation applied. This deficiency likely causes an underestimation of the impact of modulation to UWB EMI susceptibility for aeronautical radios tested above $1 \mathrm{GHz}$. 
(This page was left intentionally blank) 


\section{$5 \quad$ Conclusions and Additional Issues}

\subsection{Conclusions}

1. Aeronautical radio systems operating below $960 \mathrm{MHz}$ are at risk to EMI from handheld UWB consumer products meeting existing FCC requirements. Aircraft testing confirms that passengers may compromise the performance of VHF COM, VOR, LOC and GS aeronautical radios by operating UWB devices within the airplane passenger cabin and outside the airplane, even if their UWB devices radiate at and below applicable FCC spurious emission limits (47CFR15.209). EMI induced dithering of ILS position data during autoland operations could cause erratic aircraft motion. EMI induced denial of ILS data during autoland would necessitate pilot intervention and could compromise flight safety, particularly during adverse weather conditions. In some cases, UWB EMI caused silence on an active and tuned VHF Com channel with no indication to the crew. Such a failure mode could prevent air traffic controller contact with the flight crew without their knowledge. Considering these risks, a ban on the operation of UWB PEDs (as well as other PEDs) during takeoff and landing operations should be maintained.

2. Aeronautical radio systems operating above $960 \mathrm{MHz}$ were not affected by UWB emissions at levels meeting FCC UWB limits (15.519, handheld systems), when emitting from within airplane passenger cabins. Some aircraft receiver systems had modest interference margins that would be adversely affected if FCC UWB limits are increased by any amount. Applicable UWB limits are not adequate to protect aircraft radios from handheld UWB devices operated one meter from aircraft antenna, but appear adequate to protect aircraft radios from handheld UWB devices operated in the passenger cabin (based upon these limited tests). It would not be appropriate to increase allowable FCC limits for UWB on the basis of this data.

3. UWB modulation cannot be assumed to reduce the likelihood of harmful interference. If modulation is present upon UWB device spurious radiated emissions when the devices are tested according to FCC 15.209 limits, no further reduction of on-channel power caused by modulation can be assumed. In fact, the presence of modulation on UWB spurious radiated emissions may contribute to channel overlap within aeronautical radio frequency bands.

4. Numerous UWB PRF selections were shown to be effective at interfering with aircraft radios. EMI effect is usually dependent upon peak UWB signal amplitude in aircraft channel passband. Lower PRFs produce more spectral lines with higher probability of overlap with aircraft frequency channels, and are allowed higher peak spurious radiated power levels than higher PRFs (over $1 \mathrm{MHz}$ ) under current FCC rules.

5. UWB product effects upon onboard wireless systems remain unknown. (Such onboard systems would include cargo smoke detection, cabin communications and surveillance systems.)

\subsection{Important EMI Issues Beyond UWB Focus of This Study}

1. Simultaneous EMI to multiple radio systems: COM/NAV system redundancy is most often achieved by using independent parallel receiving systems from antenna to receiver output. Thus, EMI from a single PED can interfere with all parallel redundant aeronautical radio systems if they are tuned to the same radio channel. In addition, wide bandwidth EMI signals may cause interference to several different COM/NAV systems, operating on different channels, simultaneously. Thus, the redundancy designed to protect against component failure may not be effective in protecting against EMI. 
2. Hidden performance impairment due to EMI: COM/NAV system performance degradation effects can occur up to and including system failure on some aircraft systems without the flags, annunciations, or system status displays changing to indicate system failure of loss of capability. By using ATC ramp test sets during interference testing, some system performance degradation could be detected at EMI levels far below when any flight instrumentation or warning system indication occurred. Some systems (especially satellite systems: GPS and SATCOM) have their function status virtually transparent to the crew on most airplanes. A wide variability of status information and detailed data available to the crew exists among the aircraft tested. In some cases, less information is provided to the crew in flight than when using special display modes that are available to maintenance personnel only during ground testing.

3. Interdependencies of aircraft communication, navigation \& surveillance (CNS) Systems: Some systems were observed to have their performance degraded by interference effects propagating from other systems.

4. Non-standardized displays of navigation and flight information make it impossible to describe the airline-wide effects of EMI expected on particular COM/NAV systems from one aircraft type to another. The number, placement, size, and information content of COM/NAV system status and data displays are highly variable. Even the names of the primary displays and controls are not standardized among aircraft manufacturers or between aircraft types from some individual manufacturers.

5. No crew procedure exists to identify, report, and resolve COM/NAV system EMI events that may be due to spurious (aeronautical radio frequency band) radiation from PEDs.

6. The present aircraft certification process does not address vulnerability to EMI from PEDs. Past and present aeronautical radio systems have been developed, certified and operated on the assumption that the aeronautical mobile bands are protected from EMI that can degrade or fail the system operational performance. T-PED radio technologies that may have high spectral content (like UWB), operating within FCC limits from locations within commercial aircraft, may invalidate these assumptions without warning or remedy.

7. No specific detection devices are in place to alert the crew to the presence of EMI or degradation that may be occurring. Current COM/NAV system status and warning indicators are based on signal availability or equipment failure, and not on loss of capability due to outside EMI presence. Current COM/NAV systems are designed to reduce crew workload and information overload by minimizing the amount of system operation information provided to the crew. The information and format provided to pilots is highly variable between aircraft types and manufacturers. Avionics test equipment used during ground operational checks allows measurement of this degradation well before system failure warnings occur on the flight deck. If similar functions were to be integrated into crew status displays, crew awareness would be improved.

8. The correlation between available test data (ground tests only) to actual flight conditions is under study, but not yet understood. All tests described herein were performed with the test aircraft parked on the ground, with all passenger exits closed, the landing gear deployed, and no cabin pressurization differential from the surrounding environment. PED EMI coupling variation due to cabin pressurization, landing gear position and other factors have subsequently been studied, with results to be published at a later date. 


\section{Recommended Actions}

\subsection{Reducing Aircraft System Susceptibility to PED EMI}

1. Wireless Product Standards bodies (IEEE 802.11, IEEE 802.15, WiMedia Alliance, etc.) should consider requiring lower radiated emission limits than the FCC requires for frequency bands below $960 \mathrm{MHz}$. Some UWB developers have embraced the concept of a common signaling protocol (CSP) or mode (CSM) that enables interoperability between various handheld UWB product standards, and includes the provision for disabling the UWB transmitter via the radio link. The transmit-disable provision will allow simple and automatic control of UWB transmitters in hospitals, secure locations and on board airplanes. For commercial air travelers, this provision may allow greater level of control of UWB transmitters than exists with any other T-PED technology, particularly during the safetycritical takeoff and landing phases of flight, and could be a significant factor in promoting the acceptance of UWB radio technologies. The authors of this report highly recommend that a transmit-disable provision be widely adopted by UWB product manufacturers, and preferably be mandated by the FCC.

2. The FCC should introduce UWB radiated emission limits protecting aeronautical radio frequency bands below $960 \mathrm{MHz}$, and preserve the existing UWB radiated emission limits above $960 \mathrm{MHz}$. The FCC should consider requiring the ability for the radio link to disable the transmitter in all unlicensed T-PEDs. The FCC should consider UWB PRF and modulation requirements that limit the potential for radiated emissions to appear in aeronautical radio frequency bands. The FCC should consider modifying existing UWB rules to explicitly state that PRF and modulation options be selected to maximize spurious radiated emission levels during product testing in order to enable worst-case safety assessment.

3. The FAA, in conjunction with NASA, airlines and avionics manufacturers should initiate a program to quantify the immunity of aeronautical radio systems to PED EMI signals inside and outside their designated operational radio frequency bands. The definition of "typical PED EMI signals" is rapidly changing due to the evolving worldwide spectrum policy environment. Software defined radio (SDR) and "cognitive" radio technologies will inevitably be introduced into mass marketed consumer products. Spurious emissions from newly allocated services will likely affect the noise floor environment in aeronautical radio frequency bands. This program should include the evaluation of legacy as well as emerging aeronautical radio systems. Failure and recovery processes for aeronautical radio systems due to EMI induced effects need to be evaluated in laboratory tests for existing and emerging CNS technologies. EMI effects should be considered in the integration of all COM/NAV systems during development and certification. Most importantly, improved electromagnetic shielding of fuselage apertures (doors, windows, hatches, non-conductive panels, etc.) should be evaluated for merit in mitigating PED coupling to aircraft systems.

4. RTCA SC-202 should be provided with test results from this test effort. Phase 2 of the SC202 terms of reference specifically calls for evaluation of UWB and other emerging PED technologies. Data from this study validates previous RTCA analytical studies predicting that FCC spurious radiated emission limits for PEDs are not adequate to protect aeronautical radio systems. The RTCA should consider changing the SC-202 to a standing committee in order to maintain expertise on continually emerging PED and aeronautical radio compatibility issues. For example, a RTCA-designated representative could be tasked to monitor developments in international spectrum allocations that may increase the potential for the intrusion of PED EMI into present and future aeronautical radio frequency bands. Another RTCA-designee could 
regularly participate in PED industry committees (IEEE, CEA, CTIA, RFID, etc.) identifying new wireless technologies that may adversely affect aeronautical radio services, and also identifying user interfaces that may help mitigate the potential for interference. Yet another RTCA-designee could act as a point-of-contact within the aviation community to facilitate standardized certification processes for new aviation wireless services, and apprise the aviation community of potential problems.

\subsection{Managing PED EMI Effects in the Cockpit}

1. Airplane and Avionics Manufacturers, in conjunction with NASA, the FAA and Airlines, should support development of integrated EMI mitigation functions for aeronautical COM/NAV systems. More pilot input should be introduced for standardizing COM/NAV system concept, design, implementation, certification and operation in today's evloving EMI environment.

2. Airlines should provide flight crew awareness training to identify and respond to EMI interference. New approaches should be initiated for pilot/engineering interaction to improve the ability to react to negative effects of EMI on COM/NAV system operations. Flight simulator testing should be performed to measure pilot reaction to EMI-like effects. Event awareness assessment and learning curve assessment studies should be undertaken to determine how pilots should react to these disturbances and to determine what training should be provided to all airline pilots. Certain PED formats such as UWB were capable of affecting multiple COM/NAV systems simultaneously as well as multiple redundant receiver systems of the same system, and or multiple frequency channels of the same system. The simulations must include simultaneous system disturbances or failures. The pilot reaction study and subsequent appropriate reaction development approach should allow the pilots to "get ahead of the threat", thereby improving the safety of flight. 


\section{$7 \quad$ References}

${ }^{1}$ NASA TM-2002-211949, J. J. Ely, T. W. Shaver, G. L. Fuller, "UWB EMI to Aircraft Radios, Results of Limited Functional Testing With United Airlines and Eagles Wings Inc., in Victorville, CA", October, 2002.

${ }^{2}$ NTIA Report 01-383, “The Temporal and Spectral Characteristics of Ultrawideband Signals”, William Kissick, Editor, January 2001

3 NTIA Report 01-384, "Measurements to Determine Potential Interference to GPS Receivers from Ultrawideband Transmission Systems", J. R. Hoffman, M. G. Cotton, R. J. Achatz, R. N. Statz, R. A. Dalke, February 2001

${ }^{4}$ NTIA Special Publication 01-43, “Assessment of Compatibility Between Ultrawideband Devices and Selected Federal Systems”, L. K. Brunson, J. P. Camacho, W. M. Doolan, R. L. Hinkle, G. F. Hurt, M. J. Murray, R. A. Najmy, P. C. Roosa Jr., R. L. Sole, January 2001.

${ }^{5}$ NTIA Special Publication 01-45, “Assessment of Compatibility Between Ultrawideband (UWB) Systems and Global Positioning System (GPS) Receivers", February, 2001.

6 "Final Rule", Federal Register / Vol. 67, No. 95 / Thursday, 5/16/02, "Ultra-Wideband Transmission Systems", ET Docket No. 98-153, 17 FCC Rcd. 7435 (2002)

${ }^{7}$ IEEE Website: http://www.ieee802.org/15/pub/TG3.html

8 WiMedia website: http://www.wimedia.org; Also see: http://www.uwbinsider.com, http://www.multibandofdm.org, http://www.intel.com/technology/ultrawideband/downloads/wirelessUSB.pdf , http://www.intel.com/technology/ultrawideband/downloads/Ultra-Wideband.pdf

${ }^{9}$ CFR Title 47, Part 15.109 (FCC Rules)

${ }^{10}$ CFR Title 47, Part 15.519 (FCC Rules)

${ }^{11}$ CFR Title 47, Part 15.521 (FCC Rules)

${ }^{12}$ First Report and Order "Revision of Part 15 of the Rules Regarding Ultra-Wideband Transmission Systems, Federal Communication, Washington D.C., ET Docket 98-153, Adopted 14 February 2002, Released 22 April 2002.

${ }^{13}$ Memorandum Opinion and Order and Further Notice of Proposed Rulemaking, "Revision of Part 15 of the Commission's Rules Regarding Ultra-Wideband Transmission Systems", Federal Communication, Washington D.C., ET Docket 98-153, Adopted 13 February 2003, Released 12 March 2003.

${ }^{14}$ Memorandum of Opinion and Order and Further Notice of Proposed Rulemaking, Federal Communications Commission, Adopted 13 February 2003, Released 12 March 2003, ET Docket 98-153. FCC granted petition from: Time Domain Inc. to operate through-wall imaging systems at lower frequencies with increased power.

15 Memorandum of Opinion and Order and Further Notice of Proposed Rulemaking, Federal Communications Commission, Adopted 13 February 2003, Released 12 March 2003, ET Docket 98-153. FCC granted separate petitions from: AGA, APGA, and GPRIC to amend regulations permitting: ground penetrating radars to be operated by personnel other than law enforcement, fire and emergency rescue organizations, scientific research institutes, commercial mining companies, and construction companies; operation of large units without a "dead-man's" switch; operation at any frequency below $10.6 \mathrm{GHz}$, provided the systems comply with applicable emission limits; and to permit "regional", rather than local coordination of each application.

${ }^{16}$ Memorandum of Opinion and Order and Further Notice of Proposed Rulemaking, Federal Communications Commission, Adopted 13 February 2003, Released 12 March 2003, ET Docket 98-153. FCC rejected request from USGPSIC to deny petitions by AGA, APGA, and GPRIC on the grounds that the number of GPR operators would proliferate and cause interference to GPS.

${ }^{17}$ Memorandum of Opinion and Order and Further Notice of Proposed Rulemaking, Federal Communications Commission, Adopted 13 February 2003, Released 12 March 2003, ET Docket 98-153. FCC denied MSSI's petition to permit "any type of UWB device, e.g., a vehicle radar system, to operate in the 3.1-10.6 GHz band, provided it employs a low PRF"; "to prohibit devices from operating under the UWB regulations if they achieve their wide bandwidths due to high data rates".

${ }^{18}$ Memorandum of Opinion and Order and Further Notice of Proposed Rulemaking, Federal Communications Commission, Adopted 13 February 2003, Released 12 March 2003, ET Docket 98-153. FCC declined to act 
on Siemens VDO's petition to permit “pulsed frequency hopping vehicle radars to be included under the definition of a UWB device by permitting such transmitters to occupy the minimum required bandwidth within any 10 millisecond period ...."; stating that "the type of modulation being addressed by Siemens VDO was not considered in the notice and comments leading to the adoption of the UWB regulations. The Commission did agree to consider Siemens request for a waiver as well as for further rulemaking.

${ }^{19}$ Memorandum of Opinion and Order and Further Notice of Proposed Rulemaking, Federal Communications Commission, Adopted 13 February 2003, Released 12 March 2003, ET Docket 98-153. FCC denied Kohler's petition for partial reconsideration requesting an "increase the emission limit for indoor UWB devices from the current $-75.3 \mathrm{dBm}$ to a level of $-53.3 \mathrm{dBm}$ within the $960-1610$ band" on the grounds that ". . . measurements are impractical at the present low limit ...." The FCC noted that one needs to place a low noise preamplifier before the spectrum analyzer and, in any event, Kohler is currently operating under a waiver to the FCC's Regulations which remains in-force for one year beyond the regulations effective date.

${ }^{20}$ Memorandum of Opinion and Order and Further Notice of Proposed Rulemaking, Federal Communications Commission, Adopted 13 February 2003, Released 12 March 2003, ET Docket 98-153. FCC denied separate petitions from Cingular, Qualcomm, and Sprint "each express strong objections to the UWB technical standards adopted in the R\&O". Cingular maintained that ". . . the cellular and PCS spectrum are exclusive bands ...." and that ". . . the decision should be reconsidered because it was not based on adequate analysis of the interference that would be posed to cellular and PCS." Qualcomm argued that "... the emissions limits for UWB systems be revised to require that allowable emissions in the PCS band be that same as those permitted in the GPS band ....' Sprint requested a stay in the effective date maintaining ". .. the R\&O is fraught with so many errors, legal an factual ...."

${ }^{21}$ Memorandum of Opinion and Order and Further Notice of Proposed Rulemaking, Federal Communications Commission, Adopted 13 February 2003, Released 12 March 2003, ET Docket 98-153. FCC disagreed with a joint petition for Sirius and XM radio services that “. . . the Commission disregarded evidence that highly sensitive satellite radio receivers will operate in close proximity to UWB communications and surveillance devices." and ". . . that the $-51.3 \mathrm{dBm}$ limit adopted . . from indoor UWB devices is too great . ..." and that “. . . the rules adopted for handheld UWB devices will permit dense, temporary, semi-permanent or mobile communications networks and that the aggregate emissions from these networks will cause serious interference to SDARS reception."

${ }^{22}$ Memorandum of Opinion and Order and Further Notice of Proposed Rulemaking, Federal Communications Commission, Adopted 13 February 2003, Released 12 March 2003, ET Docket 98-153. FCC rejected SIA's petition stating “... stating that the Commission's analysis in the R\&O of the interference potential to FSS in the 3.7-4.2 GHz band is inconsistent because it develops a protection criteria based on indoor UWB operation but also permits those devices to operate outdoors." and ". . . it requests that the emissions from outdoor UWB devices be reduced in the FSS band ....' because "Based on all these factors, we are not convinced by SIA's latest submission that UWB devices will cause harmful interference to FSS reception ...."

${ }^{23}$ Memorandum of Opinion and Order and Further Notice of Proposed Rulemaking, Federal Communications Commission, Adopted 13 February 2003, Released 12 March 2003, ET Docket 98-153. FCC denied a joint ARINC ATA petition “. . . requesting that all UWB operations, except for coordinated terrestrial imaging systems, be located above $5.5 \mathrm{GHz}$ and that the average power limits between 3.1-5.5 GHz be reduced to -51.3 $\mathrm{dBm}$ for all outdoor UWB devices and to $-61.3 \mathrm{dBm}$ for handheld UWB devices." on the grounds that "ARINC and ATA provide no technical support for their claims that the operation of UWB devices under the adopted standards will result in harmful interference.

${ }^{24}$ Memorandum of Opinion and Order and Further Notice of Proposed Rulemaking, Federal Communications Commission, Adopted 13 February 2003, Released 12 March 2003, ET Docket 98-153. FCC found that WCA's support of the Sprint petition for reconsideration on the basis that UWB emission limits in the 21502162 and 2500-2690 MHz band, where MDS and ITFS services are assigned, are too high and that throughwall imaging systems and surveillance systems should be precluded from operating in these bands was without merit since ". . . WCA has not provided any justification to support its argument that MDS/ITFS stations need additional interference protection from UWB operations ...."

${ }^{25}$ Memorandum of Opinion and Order and Further Notice of Proposed Rulemaking, Federal Communications Commission, Adopted 13 February 2003, Released 12 March 2003, ET Docket 98-153. FCC denied MSSI's petition for reconsideration requesting "... that peak emission measurements of its pulsed emission system 
operating under the non-UWB Part 15 regulations . . . be perform with a . . . without application of a pulse desensitization correction factor (PDCF)" on the grounds that it was outside the scope of this proceeding.

${ }^{26}$ Spectrum Policy Task Force "Report", Federal Communications Commission, Washington D.C., ET Docket 02-135, November 2002.

${ }^{27}$ Notice of Inquiry and Notice of Proposed Rulemaking "Establishment of an Interference Temperature Metric to Quantify and Manage Interference and to Expand Available Unlicensed Operation in the Fixed, Mobile, and Satellite Frequency Bands, ET Docket 03xx, Adopted, xx July 2003, Released xx July 2003.

${ }^{28}$ Order "Request for Declaratory Ruling Regarding Emissions from Digital Circuitry Used with Ultra-Wideband Transmitters", Federal Communications Commission, Washington D.C., Adopted 2 April 2003, Released 2 April 2003.

${ }^{29}$ ITU Document 1-8/TEMP/19(Rev. 1)-E, “Task Group 1/8 (Working Group 2) Working Document for Chapter 3.5.1 of the TG 1/8 Report on Compatibility Studies Between Ultra-Wideband Devices and Terrestrial Broadcasting Services", Oct. 30, 2003.

30 RTCA/DO-199, "Potential Interference to Aircraft Electronic Equipment from Devices Carried Aboard", Prepared by SC-156, September 16, 1988.

${ }^{31}$ RTCA/DO-233, "Portable Electronic Devices Carried on Board Aircraft", Prepared by SC-177, August 20, 1996.

${ }^{32}$ Veda Inc. Report \#79689-96U/P30041, "CV-580 RF Coupling Validation Experiment Report", 11/15/1996

${ }^{33}$ Gerald Fuller, "747-222 Path Loss Test, Las Vegas, Nevada Fall 1999", Prepared under NASA PO \#L-10005

${ }^{34}$ Delta Airlines Engineering, ENGINEERING REPORT Delta/NASA Cooperative Agreement NCC-1-381

Deliverable Reports, Report No. 10-76052-20, December 8, 2000.

${ }^{35}$ Fuller, G.: B737-200 and B747-400 Path Loss Tests, Victorville, California. Eagles Wings Inc., Prepared for

NASA LaRC under NASA PO\# L-16099, Task 1, 2 and 3, 2002.

${ }^{36}$ NASA/TP-2003-212438, Troung X. Nguyen, Sandra V. Koppen, Jay J. Ely, Reuben A. Williams, Laura J. Smith and Maria Theresa P. Salud, "Portable Wireless LAN Device and Two-Way Radio Threat Assessment for Aircraft Navigation Radios", July 2003. http://techreports.larc.nasa.gov/ltrs/PDF/2003/tp/NASA-2003tp212438.pdf

${ }^{37}$ See the RTCA/SC-202 website: http://www.rtca.org/comm/sc202.asp

${ }^{38}$ NASA/TP-2003-212446, Jay J. Ely, Truong X. Nguyen, Sandra V. Koppen, John H. Beggs and Maria Theresa P. Salud, "Wireless Phone Threat Assessment and New Wireless Technology Concerns for Aircraft Navigation Radios", July 2003. http://techreports.larc.nasa.gov/ltrs/PDF/2003/tp/NASA-2003-tp212446.pdf

${ }^{39}$ NASA/TP-2003-212438, Troung X. Nguyen, Sandra V. Koppen, Jay J. Ely, Reuben A. Williams, Laura J. Smith and Maria Theresa P. Salud, "Portable Wireless LAN Device and Two-Way Radio Threat Assessment for Aircraft Navigation Radios", July 2003. http://techreports.larc.nasa.gov/ltrs/PDF/2003/tp/NASA-2003tp212438.pdf

${ }^{40}$ CFR Title 47, Part 22.925 (FCC Rules)

${ }^{41}$ CFR Title 14, Parts 91.21 and 121.306, "Use of Portable Electronic Devices Aboard Aircraft", (Federal Airworthiness Regulations)

${ }^{42}$ FAA Advisory Circular 91.21-1A: "Use of Portable Electronic Devices Aboard Aircraft"

${ }^{43}$ RTCA Special Committee 202 Presentations from Bill Strauss and Consumer Electronics Association (CEA) survey, October 30, 2003.

${ }^{44}$ John H. Santhoff, “Can't We All Just Get Along?: The Case for a Common Signaling Protocol”, UWB Insider Website, February 24, 2004, http://www.uwbinsider.com/viewpoints/print/1_7_common_signaling_protocol.html

${ }^{45}$ John Santhoff, Yasaman Bahreini and Kazimierz (Kai) Siwiak, "Common signaling mode needed" EE Times Website, May 21, 2004 http://www.eetimes.com/article/showArticle.jhtml?articleId=20300703

${ }^{46}$ UWB Ground Penetrating Radar EMI Demonstration and Briefings, "GPR Effects on ATC SystemsOperational Tests", "GPR Emission Measurements- Tests Using the Measurement Procedures of "First Report and Order' FCC 02-48 Appendix F”, FAA Hughes Technical Center, Electronic copies, 4/16/03 
${ }^{47}$ FAA Doc. 33234, "UWB EMI Test Plan for the GLU-920/GNLU-930 Commercial Aviation Navigation Receiver", 5/28/2003, Federal Register/Vol. 68, No. 111/Tuesday, June 10, 2003/ Notices, page 34695, [Docket No. FAA-2003-15361]

48 FAA Doc. 33235, "UWB EMI Test Plan for the VHF-920 Commercial Aviation Communications Transceiver", 5/28/2003, Federal Register/Vol. 68, No. 111/Tuesday, June 10, 2003/ Notices, page 34695, [Docket No. FAA-2003-15361]

${ }^{49}$ FAA Doc. 33236, "UWB RFI Test Plan for the GNLU-930 Commercial Aviation Multimode GPS Receiver", 5/28/2003, Federal Register/Vol. 68, No. 111/Tuesday, June 10, 2003/ Notices, page 34695, [Docket No. FAA-2003-15361]

${ }^{50}$ NTIA Report 01-383, "The Temporal and Spectral Characteristics of Ultrawideband Signals", William Kissick, Editor, January 2001.

${ }^{51}$ NTIA Special Publication 01-43, "Assessment of Compatibility Between Ultrawideband Devices and Selected Federal Systems”, L. K. Brunson, J. P. Camacho, W. M. Doolan, R. L. Hinkle, G. F. Hurt, M. J. Murray, R. A. Najmy, P. C. Roosa Jr., R. L. Sole, January 2001.

${ }^{52}$ NTIA Special Publication 01-45, "Assessment of Compatibility Between Ultrawideband (UWB) Systems and Global Positioning System (GPS) Receivers", February, 2001

53 NTIA Report 01-384, "Measurements to Determine Potential Interference to GPS Receivers from Ultrawideband Transmission Systems", J. R. Hoffman, M. G. Cotton, R. J. Achatz, R. N. Statz, R. A. Dalke, February 2001

${ }^{54}$ NTIA IRAC Study, "Assessment of Compatiblity Between Ultrawideband Devices Operating at the Levels Permitted by the First Report and Order and Aeronautical Radionavigation Systems Operating Below $1 \mathrm{GHz",}$ E. F. Drocella, D. S. Anderson, DRAFT 2/2003 (Pre-decisional IRAC document)

${ }^{55}$ NETEX AN/ARN-147 Study, "Ultra Wideband Electromagnetic Interference Test Report", Defense Advanced Research Projects Agency (DARPA) Networking in Extreme Environments (NETEX) Program, AN/ARN147 Commercial Instrument Landing System, 2/18/2003.

${ }^{56}$ NETEX AN/ARC-210 Study, "Ultra Wideband Electromagnetic Interference Test Report", Defense Advanced Research Projects Agency (DARPA) Networking in Extreme Environments (NETEX) Program, AN/ARC-210 VHF/UHF Communications System, 2/19/2003.

${ }^{57}$ NETEX Final Report, "UWB Parameters for EMC Coexistence with Legacy Systems”, Defense Advanced Research Projects Agency (DARPA) Networking in Extreme Environments (NETEX) Program, Final Report, 31 June 2003.

${ }^{58}$ NASA TM-2002-211949, J. J. Ely, T. W. Shaver, G. L. Fuller, "UWB EMI to Aircraft Radios, Results of Limited Functional Testing With United Airlines and Eagles Wings Inc., in Victorville, CA", October, 2002. 


\section{Appendix A: Team Biographies}

Comprised of eight persons, the UWB Aircraft Direct Effects Measurement Team possesses many years experience in the fields of EMI, HIRF, RFI, and RF Spectrum Management. Individual members have spent years measuring the effects of Radio Frequency Interference (RFI) to aircraft communications and navigation systems as well as to aircraft wiring. Arranged in alphabetical order below is a synopsis of each Team member's career.

\section{Jay Ely}

Jay Ely is a research engineer for the High Intensity Radiated Field laboratory in the Electromagnetic Research Branch, at NASA's Langley Research Center, in Hampton, Virginia. Since 1996, he has contributed to numerous research projects involving commercial airplanes and laboratory electromagnetic measurement instrumentation and facilities. His current research focuses upon assessing and mitigating electromagnetic interference to aircraft systems from existing and emerging wireless technologies such as IEEE 802.1x, Bluetooth, Citizen's Band, and Ultra Wideband. Mr. Ely has coordinated research projects between NASA's Aviation Safety and Security Program, the FAA, the NTSB, Boeing, Delta Air Lines, United Airlines, universities, avionics manufacturers, and others. $\mathrm{He}$ is interested in expanding research of terrorist EMI threats and emerging wireless technologies that may impact evolving aircraft, spacecraft and UAV communication, navigation and surveillance technologies. From 1987 to 1996, Mr. Ely was a member of the Space Shuttle launch team at the Kennedy Space Center, performing preflight checkout, troubleshooting, and validation of the navigation, communication, rendezvous RADAR, cockpit displays and remote manipulator Shuttle Orbiter systems. He holds a BSEE degree from the University of South Florida and a MSEE degree from the University of Central Florida. Jay Ely enjoys the company of his wife and three children in southeastern Virginia.

\section{Gerald Fuller}

Gerald Fuller is the owner and President of Eagles Wings Incorporated (EWI), an organization established in 1993 to provide engineering support on EMI problems such as EMC, HIRF, Lightning, and PEDs to the commercial aviation community. He has conducted research, analysis, and seminars for and with Delta Air Lines, United Airlines, NASA, and the FAA in the capacity of principal investigator. Mr. Fuller has authored numerous reports and papers on these subjects and provided tutorial seminars at the Digital Avionics Systems Conference (DASC) for over ten years.

Between 1989 and 1998, while working for or under contract to VEDA/Veridan Corporation, Galaxy Scientific, and CKC Laboratories, Gerald Fuller was the principal investigator for the HIRF and electronic terrorism studies between 1989 and 1998, for which he developed and conducted seminars. The FAA Tech Center, Air 100 and the Security Research and Development Division of FAA Headquarters, as well as the NASA Langley Research Center, sponsored this work. He served for seven years on the SAE-AE4R committee. He has taught over 100 seminars to US and foreign government and contractor audiences and is the author of the textbook "Understanding HIRF".

Mr. Fuller holds a BS and MS in electrical engineering form the University of Maryland in 1959 and 1961 respectively. He completed all the coursework and exams for a $\mathrm{PhD}$ in $\mathrm{EE}$, with a minor in physics at the University of Maryland in 1964 prior to going on active duty. As an Air Force officer, Mr. Fuller served in the USAF for six years and received the Air Force commendation medal for his work in nuclear intelligence. Following that he worked at the NSA for seven years in both signal and 
electronic intelligence and communications security. As a GS-15 he received the meritorious civil service award. He then worked for eight years at ESL in Sunnyvale, California in support of DOD National Security Programs in communications command and control, counter measures and electronic warfare.

\section{Rob Fuschino}

Captain Fuschino pilots an Airbus A320 for United Airlines. He also serves as a Flight Technical Manager in their Flight Standards and Technology division where he manages future Flight Operations Communications Technologies.

Previous to his present position, Captain Fuschino served as an Engineering Test Pilot at the United Airlines Training Center where he also served as a Pilot Instructor in the 737 and 727 . Captain Fuschino was chosen to represent United Airlines on the FAA-Industry Next Generation Communication (NEXCOM) Aviation Rule Making Committee. The committee was charged with determining the proper technology and operational capabilities of the next generation ATC communications infrastructure.

Previous to his career with United, he served as an F-16 Experimental Test Pilot for the U.S. Air Force. Captain Fuschino holds a BS in Electrical Engineering and Mathematics from the Air Force Academy and an MS in Electrical Engineering from the University of South Florida. He was a Distinguished Graduate from the U.S. Air Force Test Pilot School and is a member of the Institute of Electrical and Electronics Engineers (IEEE) and the Society of Experimental Test Pilots.

\section{Brian Haynes}

Mr. Haynes manages the Flight Operations Technical group at United Airlines, encompassing strategic technology research, planning and implementation across United's fleet of over 500 aircraft. As the technology arm of United Flight Standards and Technology, responsibilities range from avionics and communication systems strategy to security and safety enhancement technologies. He has represented United on various industry technical committees, including RTCA SC181, SC195, and SC202, and the ATA Digital Displays Working Group. In addition to leading United's work with NASA, Mr. Haynes also leads United's AIR_NET initiative for comprehensive information delivery and management to aircraft, and the United/Department of Homeland Security Counter-MANPADS research program.

Prior to joining United, Mr. Haynes led airborne datalink research and applications development efforts at Honeywell's Bendix/King division, including various aviation research programs in conjunction with NASA's AGATE and Aviation Safety programs. Major accomplishments included development of the first General Aviation VDL Mode 2 datalink system, and creation of the industry's first FAA-selected Flight Information Services Datalink (FISDL) program. Mr. Haynes also served as President of Pan Am Weather Systems, a division of Pan American Airlines, leading development and implementation of satellite communications data systems, weather radar data networks, and related ground-based computer systems.

\section{William (Bill) Larsen}

Mr. Larsen flew in the Air Force as a maintenance test pilot. After leaving the Air Force he joined the Boeing Airplane Company as a manufacturing Engineer working to establish the processes and 
tooling for production of the B-707, B-720, and KC-135. He later transferred to the Boeing Space Division and worked on flight controls for the Saturn booster, Minuteman ICBM, Dynasoar Spacecraft, and with two others demonstrated the feasibility of docking two vehicles in space and landing a space vehicle on the surface of the moon. This concept was later taken to NASA and became the Apollo Space Craft and Lunar Excursion Module.

Mr. Larsen then joined NASA to work in the field of simulation. He later developed a flight experiment which was scheduled to fly on Apollo 18. Mr. Larsen left NASA to become one of the founders and Director of Engineering for a startup computer company. He next joined the FAA to work in the area of Simulation, flight controls, and Avionics systems development.

Recently he assisted the FAA certification (for the first time ever) of DOD facilities and processes of an air logistic center as a commercial repair station for aircraft above 75,000 lbs. Gross. This releases to the airline industry intact aircraft non-destructive testing technology of structure using the technologies of real-time X-ray radiography, neutron radiography, and laser-ultrasonics. Mr. Larsen is an AIAA Associate Fellow and holds BSME, BSEE, and MSME degrees.

\section{Warren Martin}

Warren Martin is a Program Manager at the Jet Propulsion Laboratory (JPL) in Pasadena, California. Currently, he is attached to NASA Headquarters' Office of Space Flight where he serves as Program Manager for the NASA Noise Floor Study. The study includes this investigation of potential harmful interference to aircraft communications and navigation systems posed by Ultra Wide Band (UWB) systems, as well as, measurements of the existing noise levels in several frequency bands of critical importance to NASA. Mr. Martin concurrently serves as Manager of the Future Missions

Planning Office within JPL's Interplanetary Network Directorate, where he has been involved in spectrum management matters since the 1970s.

Previously, he was a co-investigator for celestial mechanics, relativity, and auroral discharge investigations on a multiplicity of NASA space missions. He served as Chairman of the Consultative Committee for Space Data Systems (CCSDS) RF and Modulation Subpanel from 1982 until 1997. The CCSDS is a consortium of international civilian space agencies established to develop international standards for space missions. He served as the CCSDS representative to the Space Frequency Coordination Group (SFCG) from 1985 until 2002.

Mr. Martin began his JPL career in 1962 working in the Communications Research Section where he specialized in developing systems for deep space communications, particularly those concerned with precise time synchronization and the precise measurement of distance between a deep space probe and an earth station.

Warren Martin holds several patents, has written numerous articles, and is the recipient of both the NASA Superior Scientific Achievement and the NASA Exceptional Service Medals. He holds BS and MS degrees from UCLA, BSL and JD degrees from Glendale College of Law. He is currently a member of the California Bar on inactive status.

\section{Timothy (Tim) Shaver}

Tim Shaver is a Transportation Industry Analyst for the Federal Aviation Administration in Washington DC. Currently, he is assigned to the AIR-130 Aircraft Avionics Certification Branch and 
is responsible for Flight Data Recorder Systems. Due to his previous history with portable electronic device (PED) interference testing, he actively works on the RTCA SC202 PED committee as well as participating in this testing activity.

Before joining the FAA, Tim worked for United Airlines in San Francisco CA. He held several positions at United including, Radio/Electrical Mechanic, 747 Fleet Avionics Engineer, Liaison Engineer, 767/757 Fleet Avionics Engineer, 757/767 Lead Avionics Engineer and lastly, Manager of Flight Avionics Engineering. In this last position, he became involved with testing aircraft avionics for susceptibility to interference from PED EMI to ensure United's compliance with 14CFR requirements. He has worked in this area with NASA and Eagles Wings for the past several years.

Before joining United, Tim spent eight years active duty in the Air Force as a Guidance and Control Technician at Offutt AFB, NE. He was responsible for maintaining auto-pilot, instrument and inertial navigation systems on $\mathrm{E} 4(\mathrm{~B} 747-200)$ and $\mathrm{EC} / \mathrm{RC} / \mathrm{VC} / \mathrm{KC}-135$ aircraft. He received the bulk of his technical education from the military.

\section{John Zimmerman}

John Zimmerman is a senior United Airlines Boeing 767 Captain. He began his aviation career in civilian aviation and then served in the Air Force during the Vietnam era as a KC-135 (Boeing 707) Instructor Pilot. He has served as an aircrew member on Douglas DC-6, -7, -8, Lockheed Constellation, Boeing $-707,-720,-727,-737,-757,-767$ aircraft. He was designated by the FAA as a Line Check Airman on the B-737.

Captain Zimmerman has long been involved in RFI issues, and is Project Manager of the Air Line Pilots Association (ALPA) ATC RFI Working Group, as well as a member of the ALPA Air Safety Aircraft Design/Operations (ADO) Group. He has spoken at meetings of the CGSIC, IEEE PLANS, ARINC AFC, IATA SPSG, and to FAA Spectrum Management field engineers on the subject of radio interference from an airline pilot's perspective. He hosts a website, aeroRFI.org, which provides an interface between FAA Spectrum Management engineers and the airline pilot community, as well as an extensive audio reference file. He has been formally recognized by the FAA Administrator for his contributions. For 10 years he has taught Crew Resource Management (CRM) courses to new captains, first officers and flight attendants.

Captain Zimmerman holds an MS in Aeronautical Science from Embry-Riddle University, FAA Airframe and Powerplant Aviation Mechanic licenses, and also FCC Amateur Extra, Commercial Radiotelegraph and Radiotelephone licenses with Radar endorsements. 


\section{Appendix B: $\quad$ Glossary \& Terms}

\section{Glossary}

\begin{tabular}{|c|c|}
\hline ABPSK & Aviation BPSK \\
\hline ACARS & Aircraft Communications Addressing and Reporting System \\
\hline ACI & Administratively Controlled Information \\
\hline $\mathrm{ACU}$ & Antenna Control Unit \\
\hline ADI & Attitude Director Indicator \\
\hline AES & Aircraft Earth Station \\
\hline AQPSK & Aviation QPSK [a version of offset QPSK] \\
\hline ARINC & $\begin{array}{l}\text { Aeronautical Radio Inc. - a non-profit, airline owned communications \& systems } \\
\text { engineering company. }\end{array}$ \\
\hline AM & Amplitude Modulation \\
\hline ANSI & American National Standards Institute \\
\hline $\mathrm{ARC}$ & Ames Research Center \\
\hline ASA & Atlantic Southeast Airlines \\
\hline ARC & Ames Research Center (NASA) \\
\hline ATC & Air Traffic Control Transponder (Radar Beacon) \\
\hline ATCRBS & Air Traffic Control Radio Beacon System \\
\hline AWGN & Additive White Gaussian Noise \\
\hline BER & Bit Error Rate \\
\hline BITE & Built-in-Test Equipment \\
\hline Bps or $\mathrm{b} / \mathrm{s}$ & Bits per Second \\
\hline BPSK & Binary Phase Shift Keying \\
\hline BSU & Beam Steering Unit \\
\hline $\mathrm{C}$ & Celsius [temperature] \\
\hline $\mathrm{CA}$ & California [postal abbreviation] \\
\hline C/A Code & GPS Course Acquisition Code \\
\hline CDI & Course Deviation Indicator \\
\hline CDU & Control and Display Unit \\
\hline CFR & Code of Federal Regulations \\
\hline CISPR & International Special Committee on Radio Interference (IEC) \\
\hline $\mathrm{COM}$ & Communications \\
\hline $\mathrm{COM} / \mathrm{NAV}$ & Communications and Navigation equipment \\
\hline $\mathrm{C} / \mathrm{N}_{\mathrm{o}}$ & Ratio of Carrier Signal Power to Noise Spectral Density \\
\hline CNS & Communications Navigation and Surveillance \\
\hline CRC & Cyclic Redundancy Code \\
\hline $\mathrm{C}_{\mathrm{R}}$ & Channel Number (SATCOM) \\
\hline CRT & Cathode Ray Tube \\
\hline $\mathrm{CW}$ & Continuous Wave \\
\hline DARPA & Defense Advanced Research Projects Agency \\
\hline $\mathrm{dB}$ & Decibels (10 log [Power-1 / Power-2]) \\
\hline $\mathrm{dBi}$ & dB Relative to an Isotropically Radiating (point source) Antenna \\
\hline $\mathrm{dBm}$ & $\mathrm{dB}$ relative to 1 -milliwatt of power [10 log Power-1 / 1-Milliwatt]) \\
\hline dBW & $\mathrm{dB}$ relative to $1-$ Watt of power $[10 \log$ Power-1 / 1 -Watt]) \\
\hline DME & Distance Measuring Equipment \\
\hline DPSK & Differential Phase Shift Keying [modulation] \\
\hline DOD & Department of Defense \\
\hline
\end{tabular}




\begin{tabular}{|c|c|}
\hline DOT & Department of Transportation \\
\hline DSB & Double Sideband (ie. suppressed carrier AM) \\
\hline DU & Diplexer Unit \\
\hline EIRP & Effective Isotropically Radiated Power \\
\hline EMC & Electromagnetic Compatibility \\
\hline EMI & Electro-Magnetic Interference \\
\hline EUROCAE & European Organisation for Civil Aviation Equipment (the " $\mathrm{s}$ " is intentional) \\
\hline EWI & Eagles Wings Incorporated \\
\hline FAA & Federal Aviation Administration \\
\hline FAR & Federal Aviation Regulations \\
\hline FAT & Fresno International Airport, California \\
\hline $\mathrm{FCC}$ & Federal Communications Commission \\
\hline FM & Frequency Modulation \\
\hline FMC & Flight Management Computer \\
\hline FOM & Figure of Merit \\
\hline FRS & Family Radio Service \\
\hline $\mathrm{Ft}$ & Feet \\
\hline Gen. & Generator \\
\hline GES & Ground Earth Station \\
\hline $\mathrm{GHz}$ & Gigahertz \\
\hline GMRS & General Mobile Radio Service \\
\hline GPR & Ground Penetrating Radar \\
\hline GPRIC & Ground Penetrating Radar Industry Coalition \\
\hline GPS & Global Positioning Satellite \\
\hline GPSSU & Global Positioning System Sensor Unit \\
\hline GPWS & Ground Proximity Warning System \\
\hline GS & Glideslope \\
\hline $\mathrm{C} / \mathrm{T}$ & Gain divided by System Noise Temperature [a receiver figure of merit] \\
\hline $\mathrm{HF}$ & High Frequency $(3-30 \mathrm{MHz})$ \\
\hline HGA & High Gain Antenna (SATCOM) \\
\hline HIRF & High Intensity Radiated Field. \\
\hline HPA & High Power Amplifier \\
\hline HPR & High Power Relay \\
\hline HSI & Horizontal Situation Indicator \\
\hline $\mathrm{Hz}$ & Hertz (formerly cycles per second) \\
\hline ICAO & International Civil Aviation Organization \\
\hline I.D. & Identification \\
\hline IEEE & Institute of Electrical and Electronic Engineers \\
\hline IF & Intermediate Frequency \\
\hline IFR & Instrument Flight Rules \\
\hline ILS & Instrument Landing System \\
\hline Incr. & Increase \\
\hline INMASAT & International Marine Satellite \\
\hline IRAC & Interdepartmental Radio Advisory Committee (NTIA) \\
\hline IPL & Interference Path Loss \\
\hline IRS & Inertial Reference System \\
\hline ISO & International Standards Organization \\
\hline JPL & Jet Propulsion Laboratory (NASA) \\
\hline $\mathrm{Kbps}$ or $\mathrm{Kb} / \mathrm{s}$ & Kilo Bits per Second \\
\hline
\end{tabular}




\begin{tabular}{|c|c|}
\hline $\mathrm{kHz}$ & Kilohertz \\
\hline L-Band & $1-2 \mathrm{GHz}$ \\
\hline $\mathrm{L} 1, \mathrm{~L} 2, \ldots \mathrm{Ln}$ & Left side aircraft access doors, numbered front to back \\
\hline LAAS & Local Area Augmentation System \\
\hline LaRC & Langley Research Center (NASA) \\
\hline LAT & Latitude \\
\hline LGA & Low Gain Antenna (SATCOM) \\
\hline LNA & Low Noise Amplifier \\
\hline LOC & Localizer \\
\hline LONG & Longitude \\
\hline LRN & Long Range Navigation \\
\hline LRU & Line-Replaceable Unit \\
\hline MEAS & Measurement \\
\hline MFD & Multifunction Flight Display \\
\hline $\mathrm{MHz}$ & Mega Hertz \\
\hline Mkr. & Marker \\
\hline MLS & Microwave Landing System \\
\hline MPL & Minimum Path Loss \\
\hline Mod. & Modulation \\
\hline MOPS & Minimum Operation and Performance Standards \\
\hline $\mathrm{MO} \& \mathrm{O}$ & Memorandum Opinion and Order \\
\hline MPL & Minimum Path Loss \\
\hline MSI & Multispectral Solutions Incorporated \\
\hline MTL & Minimum Triggering Level \\
\hline MU & Management Unit \\
\hline NASA & National Aeronautics and Space Administration \\
\hline NAV & Navigation \\
\hline ND & Navigational Display \\
\hline NETEX & Networking in Extreme Environments (A DOD Project) \\
\hline NM (nm) & Nautical Mile \\
\hline NPRM & Notice of Proposed Rulemaking \\
\hline NTIA & National Telecommunications and Information Administration \\
\hline OAK & Oakland [a California city] \\
\hline OOK & On Off Keying \\
\hline QPSK & Quaternary Phase Shift Keying \\
\hline PAM & Pulse Amplitude Modulation \\
\hline $\mathrm{P} 1, \mathrm{P} 2, \ldots \mathrm{Pn}$ & Port (left) side aircraft windows, numbered front to back \\
\hline PCS & Personal Communications Service \\
\hline PDA & Portable Digital Assistant \\
\hline PED & Portable Electronic Device \\
\hline PFD & Primary Flight Display \\
\hline $\mathrm{PN}$ & Pseudo Noise \\
\hline PRF & Pulse Repetition Frequency \\
\hline QPSK & Quadrature Phase Shift Keying \\
\hline $\mathrm{R} 1, \mathrm{R} 2, \ldots \mathrm{Rn}$ & Right side aircraft access doors, numbered front to back \\
\hline RA & Resolution Advisories \\
\hline RAIM & Receiver Autonomous Integrity Monitoring \\
\hline RBW & Resolution Band Width \\
\hline Rev. & Receive \\
\hline
\end{tabular}




$\begin{array}{ll}\text { RCVR } & \text { Receiver } \\ \text { RF } & \text { Radio Frequency } \\ \text { RFU } & \text { Radio Frequency Unit } \\ \text { RLS } & \text { Reliable Link Service } \\ \text { RMS } & \text { Root Mean Square } \\ \text { RTCA } & \text { Radio Technical Committee on Aeronautics } \\ \text { S1, S2, ..Sn } & \text { Starboard (right) side aircraft windows, numbered front to back } \\ \text { SATCOM } & \text { Satellite Communications [equip. using INMARSAT for data and voice] } \\ \text { SC 202 } & \text { RTCA Special Committee on PEDs } \\ \text { SDU } & \text { Satellite Data Unit } \\ \text { SFO } & \text { San Francisco International Airport, California } \\ \text { SPD } & \text { Speed } \\ \text { S/N, SNR } & \text { Signal-to-Noise Ratio } \\ \text { SW } & \text { Sky West - a commuter airline headquartered in St. Georges, UT } \\ \text { TA } & \text { Traffic Advisory } \\ \text { TCAS } & \text { Traffic Alert and Collision Avoidance System } \\ \text { TDM } & \text { Time Division Multiplexing } \\ \text { TDMA } & \text { Time Division Multiple Access } \\ \text { TIC } & \text { Avionics test set manufactured by Tel-Instrument Electronics Corp. } \\ \text { TRK } & \text { Track } \\ \text { TSA } & \text { Transportation Security Agency } \\ \text { TTFF } & \text { Time-to-First-Fix [GPS acquisition time from cold start] } \\ \text { UAL } & \text { United Air Lines } \\ \text { UAT } & \text { Universal Access Transceiver } \\ \text { UHF } & \text { Ultra High Frequency (300 MHz to 3 GHz) } \\ \text { U.S. } & \text { United States } \\ \text { USGIC } & \text { United States GPS Industry Council } \\ \text { UTM } & \text { UWB Threat Modulation } \\ \text { UWB } & \text { Ultra Wide Band } \\ \text { VAC } & \text { Volts Alternating Current } \\ \text { VDB } & \text { VHF Data Broadcast } \\ \text { VHF } & \text { Very High Frequency (30 - 300 MHz) } \\ \text { VOR } & \text { VHF Omnidirectional Range } \\ \text { W } & \text { Watt [a unit of power] } \\ \text { WCA } & \text { Wireless Communications Association, Intl. - trade organization } \\ & \end{array}$




\section{Terms}

FCC Part 15 Rules: A set of rules, adopted by the Federal Communications Commission regulating the use of unlicensed devices.

P-Channel Pilot Channel (SATCOM)

Reference Signal: Generated by an RF source, usually with an adjustable level, used by the investigators to simulate that signal which the specific instrument under test was designed to receive.

UWB Test Signal: That signal generated by the UWB simulator which may pose a treat to the specific aircraft instrument under test.

UWB Treat Signal: A UWB emission causing a threat of interference to another aircraft communication or navigation system. 
(This page was left intentionally blank) 
The public reporting burden for this collection of information is estimated to average 1 hour per response, including the time for reviewing instructions, searching existing

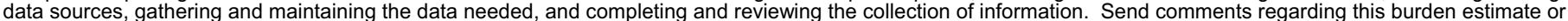

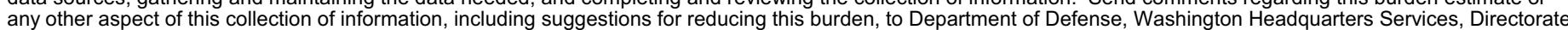
for Information Operations and Reports (0704-0188), 1215 Jefferson Davis Highway, Suite 1204, Arlington, VA 22202-4302. Respondents should be aware that notwithstanding any other provision of law, no person shall be subject to any penalty for failing to comply with a collection of information if it does not display a currently valid OMB control number.

PLEASE DO NOT RETURN YOUR FORM TO THE ABOVE ADDRESS
1. REPORT DATE (DD-MM-YYYY)
2. REPORT TYPE
3. DATES COVERED (From - To)
01-01-2005

\section{TITLE AND SUBTITLE}

UWB EMI to Aircraft Radios: Field Evaluation on Operational Commercial Transport Airplanes

NCC3-1043 \& NCC3-1078
5C. PROGRAM ELEMENT NUMBER

\section{6. $\operatorname{AUTHOR(S)}$}

5d. PROJECT NUMBER

Ely, J., Martin W., Shaver T., Fuller G., Zimmerman J., Fuschino R., Larsen, W.

\section{5e. TASK NUMBER}

5f. WORK UNIT NUMBER

\section{PERFORMING ORGANIZATION NAME(S) AND ADDRESS(ES)}

NASA Langley Research Center, Hampton, Virginia; NASA Jet Propulsion Laboratory, Pasadena, California; Federal Aviation Administration, Washington, DC; Eagle Wings Incorporated, Mariposa, California; United Airlines, Denver, Colorado; Federal Aviation Administration, Moffet Federal Airfield,California.

\section{SPONSORING/MONITORING AGENCY NAME(S) AND ADDRESS(ES)}

10. SPONSORING/MONITOR'S ACRONYM(S)

National Aeronautics and Space Administration

Washington, DC 20546-0001

NASA

11. SPONSORING/MONITORING REPORT NUMBER

TP-2005-213606 (Vol 1)

\section{DISTRIBUTION/AVAILABILITY STATEMENT}

Unclassified, Unlimited

Subject Category 04

Availability: NASA CASI(301) 621-0390

\section{SUPPLEMENTARY NOTES}

This report was edited by A. J. Oria of Overlook Systems Technologies, Inc.

\section{ABSTRACT}

Ultrawideband (UWB) transmitters may soon be integrated into a wide variety of portable electronic devices (PEDs) that passengers routinely carry on board commercial airplanes. Airlines and the FAA will have difficulty controlling passenger use of UWB transmitters during flights with current airline policies and existing wireless product standards. The aeronautical community is concerned as to whether evolving FCC UWB rules are adequate to protect legacy and emerging aeronautical radio systems from electromagnetic interference (EMI) from emerging UWB products. To address these concerns, the NASA Office of Space Communications and Chief Spectrum Managers assembled a multidisciplinary team from NASA LaRC, NASA JPL, NASA ARC, FAA, United Airlines, Sky West Airlines, and Eagles Wings Inc. to carry out a comprehensive series of tests aimed at determining the nature and extent of any EMI to aeronautical communication and navigation systems from UWB devices meeting FCCapproved and proposed levels for unlicensed handheld transmitters.

\section{SUBJECT TERMS}

electromagnetic interference, aircraft, communications, navigation, ultrawideband

16. SECURITY CLASSIFICATION OF:

\begin{tabular}{|l|l|l|l|} 
a. REPORT & b. ABSTRACT & c. THIS PAGE & ABSTRACT \\
$\mathrm{U}$ & $\mathrm{U}$ & $\mathrm{U}$ & $\mathrm{UU}$ \\
\end{tabular}

\begin{tabular}{|c|l|}
$\begin{array}{c}\text { 18. NUMBER } \\
\text { OF } \\
\text { PAGES }\end{array}$ & $\begin{array}{l}\text { 19a. NAME OF RESPONSIBLE PERSON } \\
\text { STI Help Desk (email:help@ @ sti.nasa.gov) }\end{array}$ \\
\cline { 2 - 2 } 68 & $\begin{array}{l}\text { 19b. TELEPHONE NUMBER (Include area code) } \\
\text { (301) } 621-0390\end{array}$ \\
\hline
\end{tabular}

